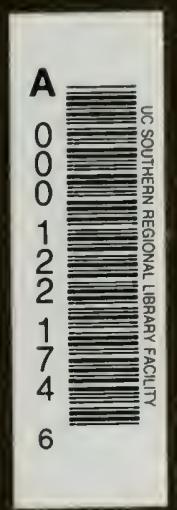





\section{Abhandlungen zur Geschichte der Medicin.}

Herausgegeben von

Professor Dr. Hugo Magnus, Docent Dr. Max Neuburger und Sanitätsrat Dr. Karl Sudhoff.

\section{Heft IX.}

\section{Die}

Anfänge der Anatomie

bei den

\section{alten Kulturvölkern.}

Von

Dr. Ludwig Hopf.

Breslau 190.1

J. U. Kern's Verlag

(Max Müller). 


\section{ind 사}

11

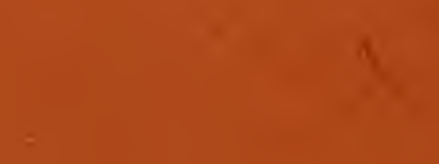





\section{Abhandlungen zur Geschichte der Medicin.}

Herausgegeben von

Professor Dr. Hugo Magnus, Docent Dr. Max Neuburger und Sanitätsrat Dr. Karl Sudhoff.

Hef't IX.

\section{Die Anfänge der Anatomie}

bei den

alten Kulturvölkern.

Von

Dr. Ludwig Hopf.

Breslau 1904.

J. U. Kern's Verlag (Max Müller). 


\section{Die Anfänge der Anatomie}

bei den

\section{alten Kulturvölkern.}

Ein Beitrag zur Geschichte der Anatomie

von

Dr. Ludwig Hopf.

Anatome non a diis neque a Heroibus, sed tanquam scientia homini proxima

ab ipsis hominibus originem habet.

j. Hyril.

\section{Breslau 1904.}

J. U. Kern's Verlag (Max Müller). 



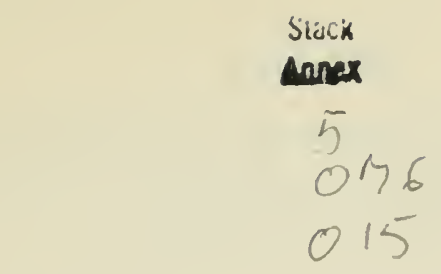

\section{Inha1ts.Übersicht.}

Einleitung. Altere Schritten über den Ursprung der Anatomie. Jos. Hyrtls „Antiquitates anatomicae rariores." Ritter v. Töplys „Geschichte der

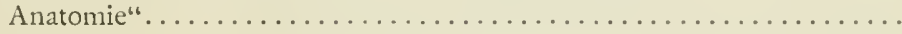

I. Primitive Laien-Anatomie....................... 3

1. Alteste Benennungen der Körperteile............. 4

Die Benennungen erfolgen schon bei den Kindern aller Völker. - Babylonisch-Assyrische Benennungen. - Benennungen bei den Hebräern. - Altägyptische Benennungen. - Indogermanische Benennungen.

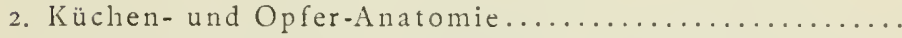

Primitive Wege zur Kenntnisnahme ron inneren Körperteilen. Zufälliges Auffinden von Leichen oder Leichenteilen. Auswaiden von Jagdtieren. - Z ubereitung der Fleischspeisen.

Tierische Opfer. Unterscheidung bestimmter Teile des Opfertieres. Opferdienst in Babylonien und Assyrien. In Ägypten. In Palästina. Bei den Indogermanen: Altindischer Opferritus. Griechischer Opferritus. Etruskisch-römischer Opferritus. - Keltische Opfer. - Germanische Opfer.

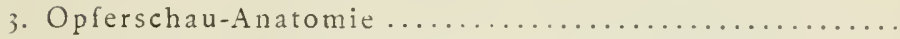

Opferschau gelıt bis in die ältesten Zeiten der Kulturvölker zurück.

Babylonisch-assyrische Opferschau. - Ägyptische Opferschau. - Griechische Opferschau. - Etruskische Opferschau. - Römische Opferschau. - Keliische Opferschau. -- Germanische Opferschau. - Opferschau-Anatomie der Hebräer abweichend.

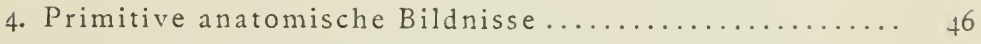

a. Körperteile in der Bilderschrift.............. 46 Sumerer. - Ägypter.

b. Bildliche Darstellungen aus der Opfer-Anatomie. Alte bildliche Darstellungen aus Ägypten. 
c. Bildliche Darstellungen aus der Opferschau-Anatomie.

Die etruskische Bronzeleber von Piacenza.

Die Alabasterleber von Volterra.

Die babylonische Terracottaleber.

d. Bilder von menschlichen Körperteilen als Weih-

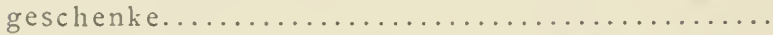

Babylonisch-assyrischer Penis nit Weihinschrift.

Altägyptische Weihgeschenke: Oliren, Vorderarm.

Altphönizische Weihgeschenke: Goldene Bubonen.

Altgriechische W'eihgeschenke: Alle Körperteile.

Etruskisch-römische Weihgeschenke: Alle Körperteile.

Germanische Weihgeschenke. Fortdauer dieser alten

Sitte in einzelnen katholischen Ländern Deutschlands und Österreichs.

II. Anfänge einer wissenschaftlichen Anatomie. ............

1. Altertum.

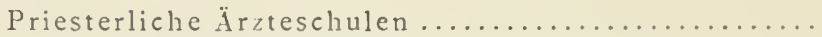

Sumerer. Alteste Anatomie der arischen lnder. Altägyptische Anatonie. Einbalsamierungsverfahren. Altägyptische Gefäßlehre. Altgriechische Anatomie: Naturphilosophen. Asklepiadenschulen von Knidos und Kos. - Hippokralische Anatomie. - Unmittelbare Nachfolger des Hippokrates. Anatomisches Wissen des Plato und Aristoteles. - Anatomie der nachhippokratischen Empiriker. - Anatomische Schule von Alexandria. - Anatomie der griechischen Ärzte in Rom. Dogmatiker, Methodiker, Pneumatiker, Eklektiker. Galenos v. Pergamon, der bedeutendste Anatom unter den griech. Ärzten in Rom. - Altrömische Anatomie. Der Römer Celsus der einzige römische Anatom. - Anatomie des Talmud.

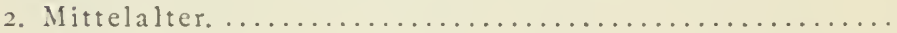

Griechische Ärzte der letzten Jahrhunderte des römischen Kaiserreiclis.

Kirchenväter und ihre somatisch-anthropologischen Schriften. Anatomen der byzantinischen Periode der Medizin.

Anatomie der Araber.

Anatomie der indisclien Ärzte Caraka, Susruta und Vaghbata. Chinesische Anatomie.

Anatomie im mittelalterlichen Japan.

Tibetanische Anatomie.

Germanische Anatomie des frühen Mittelalters.

Mönchische Medizin und Anatomie: Isidorv. Sevilla, Beda

Venerabilis, Hrabanus Maurus.

An a tomie der Salemitaner: Alphanus I., Konstantinus Africanus,

Copho junior; Anatomie in "Regimen sanitatis." 
Anatomie der scholastischen Naturforscher: Albertus Magnus, Bartholomaeus Anglicus, Thomas Cantimpratensis, Vincentius liellovacensis, Konrad v. Megenberg.

Anatomie in Montpellier und auf den italienischen Universitäten.

Mondino de Liucci seziert zum erstenmale wieder menschliche Leichname.

Nachfolger des Mondino.

Vesal. 



\section{E in le it ung.}

Die Uranfänge der Anatomie zu erforschen, sind schon im 18. Jahrhundert die verschiedensten Anläufe mit mehr oder minder Glück unternommen worden. Im Jahre i 725 ließ J. Franc. Lempoël sein ,Specimen inaugur. exhibens anatomiae originem, Lugd. Batav." erscheinen. Ihm folgte Barch. Sam. Sellius ,de anatomiae historiae scriptoribus, Kiel I730." Dann erschienen die fleißigen, hochgelehrten Untersuchungen von Goelicke „Introduct. in hist. liter. anatomes, Francof ad Viadr. I738." In der 1752 in Erfurt gedruckten Abhandlung von Andr. Nunn „De dignitate anatomes ad chirurgiam" ist der Einfluß der Anatomie auf die Chirurgie von den ältesten Zeiten an geschichtlich nachgewiesen. Ganz besonders aber hervorzuheben sind die von Kurella gesammelten und 1754 in Berlin herausgegebenen Dissertationen, die unter dem Präsidium des weiland Anatomie-Professors Phil. Jac. Hartmann (I648-I707) in den Jahren 1683-1693 in Königsberg entstanden und 1693 als Sammelband unter dem Titel „Disquisitiones historicae de re anatomica Veterum a $\mathrm{Ph}$. Jac. Hartmann summo studio institutae" erschienen sind. Besonders wichtig sind die Dissertationen „De originibus anatomes" und "De peritia Veterum anat. in genere". - Das oben angeführte Sammelwerk von Kurella enthält auch zwei Dissertationen aus dem Gebiete der Geschichte der Anatomie, beide in Altdorf, unter dem Professor der Medizin und Anatomie Joh. Heinr. Schulze herausgegeben und zwar ,Historiae anatomiae specimen primum, Altdorf I $72 \mathrm{I}^{\text {" }}$ und „Specimen secundum, Altdorf 1723". - Den Schluß der im 18. Jahrhundert erschienenen anatomisch-historischen Arbeiten bilden Ch. Gotfr. Grimers „Analecta ad Antiquitate med., quibus Anatome Aegyptiorum et Hippocratis etc. explorantur, Vratislav. I774" und die historisch-kritische, von Crevelt (Bonn I787) aus dem Französischen übersetzte $\mathrm{Ab}$ handlung über „Die von den Alten sowohl als von den Neueren in der Anatomie gemachten Entdeckungen". 
Was alles über den Ursprung und die allmähliche Entwicklung der Anatomie gedacht und geschrieben worden war, hat der geniale Jos. Hyrtl, mein einstiger hochverehrter Lehrer, zusammengefaßt in seiner Inauguraldissertation ,Antiquitates anatomicae rariores, quibus origo, incrementa et status anatomes apud antiquissimae memoriae gentes historica fide illustrantur, Vindobonae I 835." Wie seine Vorgänger auf diesem Gebiete, ist Hyrtl bei dem Forschen nach dem Ursprung der Anatomie auf die frühesten gesellschaftlichen Zustände der Menschheit zurückgegangen und hat alle möglichen Falitoren in Erwägung gezogen, die dem Menschen zur Kenntnis seiner körperlichen Verhältnisse verhelfen konnten.

Unter diesen Faktoren spielt der Zufall, das Auffinden von Leichnamen, an denen der Naturmensch seine Neugierde befriedigen konnte, eine der ersten Rollen. „Lubenter fateor, mentis aciem in promovendis rerum anatomicarum administrationibus parvum, manuum dexteritatem multum, plurimum autem casum fortuitum contulisse."*)

In allerjüngster Zeit ist mir die 6. Lieferung des Handbuchs der Geschichte der Medizin (Jena, Gust. Fischer 1903) mit der Abhandlung von Robert Ritter v. Töply (Wien) „Geschichte der Anatomie" zu Händen gekommen.

*) J. Hyrtl a. a, O. S, г 7 . 
I.

\section{Primitive Laien-Anatomie.}

\section{I. Älteste Benennungen der Körperteile.}

Daß die Kenntnis der anatomischen Körperverhältnisse des Menschen ureigenstes Verdienst ist, hat Hyrtl in den Worten ausgedrückt, welche als Motto auf dem Titelblatt gegenwärtiger Abhandlung stehen: „Anatome non a diis reque a Heroibus, sed tanquam scientia homini proxima ab ipsis hominibus originem habet". Es ist nur zu verwundern, daß ein so scharfsinniger Geist die Wahrheit dieser Worte nicht im eigentlichen Sinn derselben weiter $\mathrm{zu}$ begründen versucht hat. Denn wenn er selber zugeben muß „forsan non tanta erat hominis feri et silvestris discendi cupido, ut fratris aut socii defuncti corpus sacrilega manu violaret et ignotorum ibidem apocalypsim quaerat", so gab es etwas zu erforschen, was noch viel näher lag, nämlich seinen eigenen Körper und die Körper seiner nächsten Angehörigen im lebenden Zustande. Daß diese Forschungen am eigenen Körper schon in frühester Kindheit beginnen, hat ja der Physiologe Preyer in seinem klassischen Werke über die psychologische Entwicklung des Kindes bewiesen. Das Experimentieren, worunter solche Bewegungen $\mathrm{zu}$ verstehen sind, wodurch das allmähliche Bekanntwerden mit dem eigenen Körper und die Herrschaft über denselben erworben wird, ist ja nicht nur den jungen Tieren, sondern auch dem menschlichen Säugling eigen. Die einzelnen Gliedmaßen sind es, an denen die menschlichen Säuglinge ihre ersten Experimente machen, ehe ihnen die Bedeutung derselben als Teile ihres eigenen Körpers zum Bewußtsein gelangt. Dasselbe Ausstrecken und Anziehen der Gliedmaßen, dasselbe Tasten und Greifen bei jungen Tieren und Menschen. Die bei den ersten geglückten Greifversuchen eintretende Tastempfindung muß dem Säugling augenscheinlich sehr interessant sein. Noch in der 23. Woche betrachtete das Kind Preyers seine Hände sehr aufmerksam, wenn zufällig beim Umhergreifen die eine Hand die andere erfaßt hatte. Noch in der 
32. Woche wurde es beobachtet, wie es auf dem Rücken liegend, seine vertikal emporgestreckten Beine lange ansah, dann mit seinen Händen nach den Füßen griff und die Zehen in den Mund führte. Erst durch diese Spiele, welche die Vorstellung von den Gliedern des eigenen Körpers erwecken, entsteht allmählich das Ichgefühl, wenn dasselbe auch im I5. Monat so wenig entwickelt ist, daß sich das Kind in den eigenen Finger beißt und noch im 23. Monat so unklar, daß es, auf dem Boden sitzend, seinem eigenen Fuße einen Zwieback anbietet.

Ist das Kind aber einmal zur Klarheit über die einzelnen Teile seines Körpers, zum primitiven Verständnis der gesprochenen Worte und zu den ersten Anfängen des' eigenen Sprechens gelangt, so macht es ihm das größte Vergnügen, die Frage: „Wo ist dein Kopf? Wo ist deine Hand? Wo ist dein Fuß?" mit lautem „da, da, da" zu beantworten. Diese Bezeichnungen der äußeren, sicht- und fühlbaren Körperteile mit besonderen, jedem Volke eigenen Namen sind für unsere Betrachtung außerordentlich wichtig, denn sie bilden in Wirklichkeit die Uranfänge der Anatomie. Wir finden dieselben bei allen Völkern der Erde; sie alle aufzuzählen, würde allein den Umfang des allergrößten Buches erfordern. Es dürfte genügen, den Wortschatz der alten Kulturvölter heranzuziehen, wenn sich auch leider unsere Kenntnis noch vielfach mangelhaft erweist und die Quellen vielmals verschlossen bleiben.

Was die alten Kulturvölker in Babylon und Assyrien betrifft, so hatten schon ihre Vorläufer, die ins 4.-5. Jahrtausend v. Chr. zurüchreichenden Sumerer eine Bilderschrift, welche reichlich Bilder von Körperteilen aufweist. Diese Bilderschrift wurde später keilförmig, doch muß der Ersatz der Bilder durch die Keilschriftzeichen für den Nichtphilologen unverstanden bleiben, so wenn nach v. Oefele*) die mamma $\square$ in alter Schrift TIT, in späterer Schrift $=[\| \equiv$ geschrieben wird. (Die Milchdrüsen, die außer dem Menschen nur bei den Affen und Fledermäusen an der Brust sitzen, wurden keilschriftlich aus Analogie mit den Haustieren gleichlautend auch auf die menschlichen Weichen übertragen)**). Leider harrt das Meiste, was von Tafelresten der

*) Handbuch der Gesch. der Medizin, Jena, Gust. Fischer I9or, Bd. I, S. $; 8$.

**) v. Oefele, Keilschriftmedizin in Parallelen, S. I6. 
Bibliothek des Assurbanipal (Sardanapal 668-626 v. Ch.) in Ninive ausgegraben wurde, noch der Entzifferung, doch konnte ich schon in den 3 ersten mir zugänglichen Bänden der von Eberh. Schrader herausgegebenen „Keilinschriftlichen Bibliothek" (Berlin, Reutter 1889-1891) die Worte für „Kopf, Auge, Wange, Kiefer, Lippen, Zunge, Fuß, Arm, Hoden und männliches Glied vielfach finden. Weiteres ist von fortgesetzter Entzifferung der Theetafeln und Tafelreste zu erwarten.

v. Töply (Geschichte der Anatomie, im Handb. d. Gesch. der Medizin, 6. Lieferung, S. I 58) teilt noch weitere Benennungen aus den von Küchler veröffentlichten Texten mit.

libbu $=$ das ganze Leibesinnere, muh $=$ das Schädeldach, lítá $=$ Beine mit Hinterbacken, rabiti $=$ großer Finger, Daumen, $\mathrm{Ku}=$ Unterleib, Eingeweide, sak. Šà $=$ epigastrium, $\mathrm{Au}=$ Magen, $\sin ^{\frac{1}{1}}=$ Fleischteile, Muskeln (?), im = After, napša $=$ Kehle, maška $=$ Zitzen (?), Kabittu = Leber.

Einmal komme eine Reihefolge von Körperteilen vor, nämlich Scheitel, Nacken, Hände, Brust und libbi, naglabi und Beine.

Die Sprache der Hebräer enthält ebenfalls reichlich Bezeichnungen für alle äußeren, sicht- und fühlbaren Körperteile, z. B. von Skeletteilen: Schädel, Halswirbel, Rippe, Hand, Fuß, Oberschenkel; ferner als greifbare Bestandteile: Haut, Fleisch, Fett. Von den Bezeichnungen für innere Organe, welche, wie bei anderen Völkern, auf dem Wege der Opfer-Anatomie gefunden wurden, soll weiter unten die Rede sein.

Was die Körperteile, ihre Bedeutung und Benennung im Altägyptischen betrifft, so hat darüber G. Ebers eingehende Untersuchungen angestellt, deren Ergebnisse in den Abhandlungen der kgl. bayr. Akademie der Wissenschaften (historisch-philologische Klasse) Bd. XXI, S. $87 \mathrm{ff}$. veröffentlicht worden sind. Ebers fand, daß schon in den allerältesten Texten den Gliedmaßen besondere Aufmerksamkeit geschenkt wurde, weil man schon in ältester Zeit dem Körper liebevolle Beobachtung schenkte. Bilder von Körperteilen spielen in dem phonetischen Teile der Hieroglyphenschrift und zwar in den alphabetischen, den Silben- und WVortzeichen, eine Rolle. Von alphabetischen Zeichen z. B. finden sich Bilder des Armes, der Hand, des Knies, des Beines, des 
Mundes sehr häufig. Noch viel häufiger stößt man auf Bilder von Körperteilen in den zahlreichen Silben- und Wortzeichen. „Die zu dem ideographischen Element der Hieroglyphen gehörenden Determinativa (sowohl spezielle als generelle), welche man zur Erklärung der lautlich geschriebenen Worte hinter diese zu setzen pflegte, sind für uns besonders wichtig, weil man durch sie die in der Schrift erwähnten Körperteile schon auf den ersten Blick erkennen kann. Ein Beinpaar $\triangle \wedge$ z. B. deutet schon in den alten Pyramidentexten eine Fortbewegung an." Unter den Determinativen sind es überhaupt mehr als ein halbes Hundert, die auf Körperteile hinweisen. Vielfach unterscheiden sie sich nur durch die Stellung oder durch die Gegenstände, mit denen sie verbunden sind.

Wie in der Schrift, so haben die Körperteile auch in der Sprache eine hervorragende Bedeutung, weil der Ägypter gewöhnt war, auch das abstrakte durch sinnliche Wahrnehmung (anthropomorph oder theromorph) sich näher zu bringen. So müssen z. B. Gesicht, Ohr, Auge, Nase, Mund, Lippe, Rücken, Hand etc. zur Verbildlichung von Abstraktem in der Sprache dienen.

Die auch anderen Völkern geläufige Bestimmung der Maße nach Körperteilen ist bei den Ägyptern auf das Genaueste durchgeführt. Für die Elle galt der Unterarm nebst Hand mit nach unten gekrümmten Fingern. Auf die Elle kamen 28 Fingerbreiten $=7$ Handbreiten. Die Hand ohne Daumen wurde $z \mathrm{u} 4$, die Hand mit Daumen zu 5 Fingerbreiten, die Faust zu 6 Fingern berechnet.

Das ganze Land Ägypten wurde eingeteilt in 14 Bezirke mit je einem Mausoleum, in welchem ein besonderer Körperteil des Osiris bestattet gedacht wurde, so das linke Bein im ersten Bezirk, der Leib im zweiten, die Kinnladen im dritten, das rechte Bein im vierten, der Phallus im fünften, das Haupt im sechsten, der Hals im zwölften, der Rückgrat im dreizehnten, Arm und Hände im vierzehnten. (In den Bezirken 7-II sollten die inneren Organe, Magen und große Eingeweide, kleine. Eingeweide, Lunge, Leber mit Gallenblase, Herz bestattet sein.)

Auch am Himmel mußten die Körperteile zur Erklärung siderischer Erscheinungen, besonders des Lichtes, dienen, in erster Linie das Auge. In den ältesten Zeiten ist es die Himmelsgöttin 
Nut, in deren Antlitz man sich Sonne und Mond als Augen dachte. Später trat an ihre Stelle der Gott Horus, dessen Augen die erwärmende und erleuchtende Kraft der Himmelslichter zugeschrieben wurde. Seine Nase wurde gedacht als Rast für den Wind, die Lippen als Türfügel des Himmels, die Zunge als Wiederholerin und Erneuerin des Lebens, der Gaumen als Abschätzer des Richtigen, der Wahrheit, die Kiefer mit den glänzend sich aneinanderreihenden Zähnen als Mitglieder des Zyklus der glänzenden Lichtgötter.

Der ganze Himmel wurde anthropomorph dargestellt als ein Weib, das in langem, mit Sternen geschmücktem Gewande sich über die Erde neigt, indem es sich mit Händen und Füßen aufstützt. Einzelne Sterne, die zusammen ein Sternbild ausmachen, trugen den Namen von Körperteilen der Gesamtfigur, z. B. dem Sternbild des Orion gehörten außer dem Orion selbst noch vier Sterne an, die als Körperteile von ihm betrachtet wurden, und zwar der Oberarm, der Vorderarm, die Hand und das Ohr. Ferner gab es ein Schenkelgestirn (der große Bär), ein Beingestirn und ein Sternbild "der Riese" mit dessen Haupt, Hals, Nacken, Brust, Knie, Fuß und Fußsohle.

v. Töply (Gesch. der Anat., a. a. O. S. 760) gibt in Nachfolgendem ein Verzeichnis der ägyptischen Körperteile-Benennungen nach dem hieroglyphischen Alphabet:

$3 \mathrm{~m}=$ die Faust, $3 \mathrm{gb}=$ das Knie, $3 \mathrm{t}=$ der Rücken, 'iwf = Fleisch, 'ib = Herz, Magen, 'im-h-t = Baucheingeweide, Rückgrat, Rückenwirbelsäule, 'imt $=$ Eingeweide, 'imt-phwi = der Hintere, 'irt = das Auge, 'ihtï $=$ Kehle, Luftröhre; $w^{\prime}=$ Fleisch, Blut, wrrf $=$ das Bein, wpm $=$ die Zunge; babaw shf $\mathrm{m}$ dada $=$ die 7 Höhlen im Kopfe, b'ab = Vorhaut (?), bgst $=$ Kehle, phwi $=$ Hinterteil, pst $=$ Rückgrat, $p d=F u ß$; fnd $=\mathrm{Nase}$, tpnfnd $=\mathrm{Nasen-}$ spitze; $m_{3 t}=$ Auge, mndt $=$ Brust, Zitze, mb: $=$ Elle, m $^{\prime}$ hyk $=$ der Hals, msht $=$ der Schenkel,

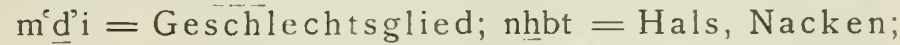
${ }^{\prime} \mathrm{nh}=\mathrm{Ohr}, \mathrm{ns}=\mathrm{Zunge}$; $\mathrm{r} 3=$ Mund, $\mathrm{r}_{3}$ '-ib $=$ der Magen, $r \underline{h^{c}} \underline{t}=$ Kardia, rma-hrw $=$ Oberarm, $\mathrm{rmn} \underline{\mathrm{hr}}=$ Unterarm, 'rti = Kinnladen, $r d=F u ß$, $\mathrm{rd}-\mathrm{ib}=$ linkes Bein, rd wam = rechtes Bein;

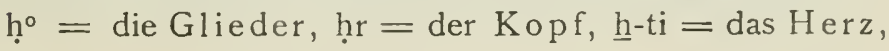


litt $=$ Kehle, Luftröhre; habwt $=$ Nacken, hpd $\stackrel{=}{=}$ eibl. Scham, hpdw $=$ Nieren, hft $=$ Antlitz, hntt $=$ Nase, hrivi $=$ Hoden, hrhpt $=$ Geschlechtsteil, Blase, h-t $=$ Bauch, Magen; $3=$ der Rücken, sbk $=$ Fußsohle, spt = Lippe, $\operatorname{sdb}=$ Schienbein; $\breve{s n}=$ Haar, $\breve{s p}=$ palmus, $s, 3 \mathrm{~h}=$ die Zehen, śśt = Knöchel; k. hii = Arm, Vorderarm, Hand, 'twt' $=$ Mandeln, tp $=\mathrm{Kopf}$; d-t = die Hand; tbt $=\mathrm{Fußsohle;}$ d’b $=$ Finger, $\underline{\mathrm{d} d t}=$ Rückgrat.

Wenden wir uns wieder zu dem alten Kulturerdteil Asien zurück, so wäre es gewiß von höchstem Interesse, die ältesten Benennungen anzuführen, welche die Chinesen den einzelnen Körperteilen gegeben haben. Leider aber muß ich vorerst auf solche Angaben verzichten, da die großen mir zugänglichen Bibliotheken nicht im Besitze von chinesisch-deutschen Wörterbüchern sind, die eine etymologische Erklärung der verwendeten Benennungen gegeben hätten. Unter diesen Umständen habe ich auch keinen Versuch gemacht, einen Einblick in die frühesten Benennungen der Körperteile bei den Japanern zu gewinnen, da meine Erwartungen wohl ebenso vergebliche gewesen wären.

Um so befriedigender ist das Resultat der Untersuchung, wenn wir uns zu der Völkergruppe der Indogermanen wenden und hier wieder ein geschlossenes Ganzes mit ursprünglich gleichlautender Benennung der äußerlich sicht- und fühlbaren Körperteile vorfinden. Wir kennen für eine ganze Reihe von Körperteilen die alt-indogermanischen Wurzelausdrücke aus der uralten Zeit, als die Indogermanen noch vereint eine gemeinsame Sprache redeten, und können von da an die Wandlungen verfolgen, welche diese Wurzelausdrücke im Laufe der Zeit nach Trennung der einzelnen Völkerfamilien erfahren haben. Fragen wir einen Laien, woraus der menschliche Körper bestehe, so wird er uns sagen: Aus Haut, Fleisch und Knochen. Wurzelausdrücke für diese drei Elemente des Körpers*) sind schon in dem alt-indogermanischen Sprachstamm enthalten und zwar:

$$
\begin{aligned}
& \text { für Haut pal-va, } \\
& =\text { Fleisch mams-a, } \\
& =\text { Knochen ast-a. }
\end{aligned}
$$

") Dr. Pauli „Über die Benennung der Körperteile bei den Indogermanen“. Stettin 1867 . 
Aber auch für eine ganze Reihe einzelner Körperteile sind die Wurzelausdrücke gefunden worden, wie sich dies bei der Einzelaufführung in Nachfolgendem ergeben wird.

Kopf. Es bestanden mehrere Namen. Der verbreitetste ist Kar mit verschiedenen Ableitungsendigungen: sanskr. ciras, baktr. caro, Ableitungen: lat. cerebrum $=$ das im Kopf Getragene, griech. xpaviov, goth. hvacrnei $=$ Hirnschädel, althochdtsch. hirni $=$ Gehirn.

Eine andere indogermanische Bezeichnung für Kopf ist Kap, sanskr. Kapalas = Hirnschädel und -Schale, lat. caput, goth. haubith. Als Vorgänger des neuhochdeutschen Wortes "Schädel" figuriert das mittelhochdeutsche schedel, während im Althochdeutschen dafür Gëbal eintritt.

Hinterhaupt. Ein indogermanisches Wort dafür ist nicht zu finden. Die indogermanischen Völker scheinen es nicht vom übrigen Kopf getrennt zu haben. Althochd. ankia = Genick, Nacken.

Stirn. Ein gemeinsamer indogermanischer Name dafür bestand nicht. Althochd. stirna $=$ Ausbreitung, Fläche, cf. latein. sterno $=$ ausbreiten.

Nicht zu erklären sind: lithauisch Kakta, slavisch c'elo.

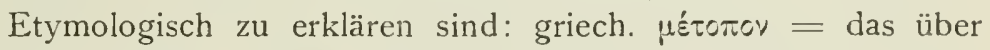
den Augen, lat. frons $=$ das mit Augenbrauen Versehene.

Schläfe. Auch hierfür bestand kein gemeinsamer Name.

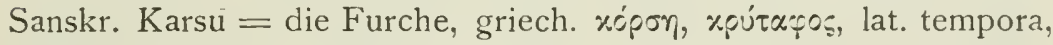
althochd. slâf, slav. skranye.

Antlitz. Weil überall bei der Benennung zuerst das Einzelne bevorzugt wird, bestand kein gemein-indogermanischer Name. Sanskr. anikam, baktr. ainiko $=$ das dem Auge Zugewandte, griech. ipóswiov, lat. facies, goth. andaugi, althochd. andi.

Anderen Ursprungs ist: lith. veidas (cf. lat. video) $=$ der das Sehorgan enthaltende Körperteil.

A uge. Ursilbe ak mit verschiedenen Endigungen. Sanskr.

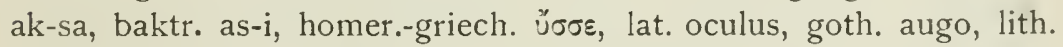
akis, slav. oko.

A ugenbraue. Altind. bhrū, sanskr. bhrūs, baktr. bvrat, griech. ¿’̧púr, nord. brun, lith. brunas, slav. bru'vi.

Ohr. Altindogerm. aus, griech. ¿̃us, lat. auris, goth. auso, lith. ausis, slav. ucho. Davon weichen ab die Benennungen der asiat.-Indogerm. Inder: karnas, Baktrer: kareno. 
Nase. Altindogerman. nas, sanskr. nas, nasa, nasja, baktr. naonha, altpers. naha, lat. nasus, althochd. nasa, lith. nosis, slav. nosu. Welche Grundform dem griech. pis fív vorangegangen ist, läßt sich nicht ermitteln.

Wange. Kein indogerman. Name festzustellen. Sanskr. paras-ja $=$ neben dem Munde, griech. $\pi x p \varepsilon t \dot{x}$, lat. gena, althochdtsch. wangâ (wang $=$ Fläche).

Mund. Altindogerm. as, sanskr. as, lat. os. Abweichend:

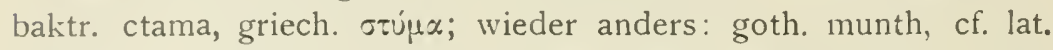
mentum v. mino hervorragen, vulgär deutsch maul, althochdeutsch mul, goth. mul, cf. althochd. muljan, lat. molo, lith. malu, slav. melja $=$ zermalmen, mahlen.

Lippe. Altindogerm. aus-ta, sanskr. os'thas, slav. aus-ta, usta, $=$ Mund, cf. sanskr. os-ami, lat. uro $=$ glühen, rot sein. Abweichend: lat. labium, althochd. lefs (mittelhochd. leffo, schlürfen).

Kinn. Altindogerm. gap, griech. үદ́veเov, goth. kinus.

Kinnladen, Ki fer. Sanskr. hanus, griech. yévus, yux́vos, lith. kandas.

Zahn. Altindogerman. dantas, sanskr. dantas, griech. ¿̇õoús, lat. dēns, goth. túnthus, althochd. zand, lith. dantis, ebenfalls altindogerman. gambh-a, sanskr. gambhas, griech. Yaupós, slav. zahn.

Zunge. Keine indogerm. Wurzelbezeichnung. Indisch g'ihva, baktr. hizva $=$ die rufende, griech. $\gamma \lambda \dot{\omega} \sigma \sigma \alpha=$ die spitzige, lat. lingna (älter dingua), goth. tuggo, lith. lezuvis = die leckende, unklar slav. jezyka.

Hals. Indogerm. darsa, griech. ঠ̇єьp' = Nacken, Hals, lat. dorsum, anders altindogerm. grivā, sanskr. griva, baktr. griva $=$ Hals, Nacken, sanskr. grivina $=$ Halswirbel, abweichend: lat. collum, deutsch hals, lith. kaklas, altindogerm. die Urform targh, lat.

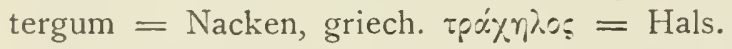

Innere Halsteile. Noch keine altindogerm. Bezeichnungen vorhanden. Erst später wurden Kehllkopf, Luftröhre, Speiseröhre unterschieden. Für das ganze Gebiet gemeinsam ist die indogerm. Urform gar, sanskr. galass, baktr. garo, lat. gula, althochd. kēlā, russisch gorlo. Vom indogerm. gar stammen auch ab: lith. gerkla, althochd. querca, nordisch kverk.

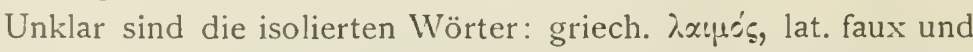
guttur. Das althochdeutsche gurgula gilt, vom Tier übertragen, für 
Schlund, Schlundkopf, Luftröhre, Kehle, Speiseröhre, Kehldeckel und Zäpfchen.

Rücken. Wahrscheinlich altindogerm. plak-ta, plak-ti, sanskr. prs'tham, baktr. parstis, slav. ples'ti Schulterblätter, plesta Schulter, Rücken, cf. unser: flach.

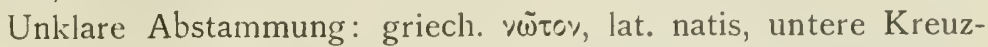
gegend, slav. chribitu, lith. nugara, nord. hryggr, althochd. hrucki, abweichend: lat. spina, russ. spina von den spitzen Dornfortsätzen.

Schulter. Altindogerm. am-sa.

Schulterblatt. Altindogerm pat.

Achsel. Altindogerm. akslâ, althochd. ahsala.

Brust. Keine altindogerm. Wurzelbezeichnung. Sanskr. uras, baktr. uro, cf. griech. $\varepsilon \dot{u p o s}=$ Breite, griech. otépvov $=$ Ausgebreitetes.

Unklar und alleinstehend: griech. $\sigma \tau \tilde{\eta} \vartheta \circ:$, lat. pectus, goth. brusts, lith. krutine, slav. grudi.

Rippe. Grundform park-i, sanskr. parkus (Sichel), slav. pri'si (Plural), anders slav. rebro (Sing.), althochd. ripi, cf. indogerm. rebb $=$ Umschlingung; vereinzelt: griech. $\pi \grave{i}$ supai, lat. costa, slav. kosti (Knochen).

Körperseite. Keine altindogerman. Bezeichnung. Sanskr. parcvam (v. parcus) $=$ das mit Rippen Versehene, die Seite, griech. $\pi \lambda$ sup $x$, lat. latus (das Substantiv zu latus, breit), althochd. sita, vielleicht verwandt mit sanskr. sita $=$ Furche, unklar: slavisch boku.

Weiche. Keine altindogerm. Bezeichnung. Althochd. weih $=$ debilis, infirmus $=$ die weichen Bauchseiten.

Bauch. Kein gemeinsamer altindogerm. Ausdruck vorhanden. Sanskr. udaram, baktr. udaro; isoliert: griech. viōús (Grundbedeutung das Erquickende), lat. venter, althochd. wanast, cf. sanskr. wanati $=$ spenden, goth. vamba, wahrscheinlich Zusammenhang mit lith. bamba $=$ Nabel.

Le nde. Altindogerm. klau-ni, gemein-german. lend, althochdeutsch lent $\mathrm{i}=$ die linde, fettreiche Gegend, wo die Nieren sitzen.

Becken. Kein altindogerm. Ausdruck dafür. Althochdeutsch beckin, lat. pelvis.

Rumpf. (Der ganze Leib ohne Gliedmaßen.) Altindogerm. karp, baktr. keress = Körper, lat. corpus, althochd. href (Leib), 
außerdem: sanskr. tanus, baktr. tanus $=$ der Leib, das Ausgedehnte, althochd. $\overline{\mathrm{i} b}=$ Leib, Leben.

Genitalien (Schamteile). Indogerm. kam $=$ sich bedecken (mit dem Hemd), germ. skaman = sich bedecken (aus Schande), ferner: gemein-germ. lithu = Glied (männl. und weibl.), von lîfu, altgerm. lith $=$ gehen.

Hodensack. Althochd. pûtil (Beutel).

Gliedmaßen. Kein gemeinsamer Name bei den alten Indogermanen, da zuerst das Einzelne bezeichnet wurde und erst später Sammelworte an die Reihe kamen.

A rm. Altindogerm. bhagh-u.

Oberarm. Altindogerm. ar-ma, sanskr. irmas, goth. arms, althochd. aram.

Ellbogen. Altindogerm. al, lat. cubitus $=$ Beugung, Krümmung.

Elle. Altindogerm. al, lat. ulna.

Speiche. Kein altindogerm. Wurzelausdruck.

Hand. Altindogerm. ghast-a, ghar, ma-chan-ar, lat. manus, anders: griech. $\chi \varepsilon i \rho$.

Innere Handfläche. Altindogerm. pal-ma.

Finger. Lat. digitus, griech. óx́xuios.

Daumen. Lat. pollux.

Nagel. Altindogerm. nagh-a, griech. Čnğ, lat. unquis.

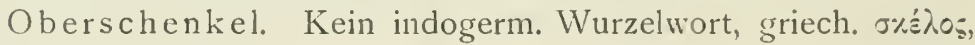
lat. femur.

Knie. Altindogerm. gan-u, griech. róvu, lat. genu.

Unterschenkel. Kein altindogerm. Wurzelwort. Schienbein: lat. tibia, Wadenbein: lat. fibula, griech. $\pi \varepsilon p c ́ v \eta$.

Fuß. Altindogerm. pad, griech. $\pi \sigma_{\overline{5}}$, lat. pes.

Ferse: Altindogerm. prars-na.

\section{Küchen- und Opfer-Anatomie.}

Alle Schriftsteller, welche die Wege besprechen, auf welchen der Mensch zur Kenntnis der inneren Körperteile gelangt sei, sprechen dem Zufall eine große Bedeutung zu. Auch der vorsichtige Hyrtl läßt in seiner oben angeführten Dissertation*) bei

*) J. Hyrtl a. a. O., S. 36 tf. 
der Entwicklung der Anatomie den Zufall dieselbe Rolle spielen, wie bei vielen anderen Erfindungen und Entdeckungen des Menschen. Als Hauptgewährsmann führt er den alten Galen an (Admin. anat., lib. I, cp. 2), der die verschiedenen Möglichkeiten des Bekanntwerdens mit inneren Körperteilen aufzählt. Durch Austreten von Flüssen können Knochen aus Gräbern herausgeschwemmt werden; gar nicht selten finde man das von Geiern abgefleischte Gebein eines Räubers; eine gute Gelegenheit, anatomische Studien zu machen, finde man an Hingerichteten oder an solchen, welche den wilden Tieren vorgeworfen worden waren. Weitere Gelegenheit, die Weichteile zu sehen, bieten schwere Verwundungen, weshalb Galen seine Schüler anwies, mit dem Heere des M. Antonius nach Germanien zu ziehen. Was die Muskeln betreffe, so lassen sich in den Fechtschulen und in der Armee wertvolle Beobachtungen machen. Immerhin habe der Zufall die größte Rolle gespielt in der Geschichte der Osteologie, weil Knochen so ungemein häufig entweder einzeln oder als ganzes Skelett gefunden werden.

Aber dieses zufällige Auffinden von Verwundeten oder Toten, von einzelnen Knochen oder ganzen Skeletten genügte Hyrtl nicht als Mittel, um die Erwerbung primitiver anatomischer Kenntnisse zu erklären. Sein scharfer Verstand und seine Vertrautheit mit der Geschichte der Menschheit ließ ihn noch einen anderen Weg erkennen, auf welchem sich die Anatomie entwickeln mußte, nämlich die Erfahrung bei den Verrichtungen des täglichen Lebens. Mit Recht weist er als einen Irrtum die Annahme Hallers zurück, die Anatomie müsse schon deshalb jünger sein, als die Botanik, weil der Mensch sich anfangs nur von Pflanzenstoffen und erst später nach eingetretenem Kampf mit der Tierwelt von Fleisch ernährt habe. Dieser Annahme hält Hyrtl die Tatsache entgegen, daß alle Naturvölker vorzugsweise von dem Ertrage der Jagd (und des Fischfangs) leben, und zieht daraus den weiteren Schluß, daß dies schon in der frühesten Periode der Menschheit der Fall gewesen sein müsse, ein Schluß, der durch die späteren prähistorischen Forschungen vollauf bestätigt wurde. Dieselben haben ja ergeben, daß im Leben des paläolithischen Menschen nur diejenigen Vegetabilien zur Verwendung liamen, welche er, wie z. B. Früchte und Beeren, auf seinen Streifzügen gefunden hatte, während im übrigen die Ansprüche des Lebens durch das Fleisch des erlegten wilden Getiers gedeckt wurden. „His intentus laboribus nec philosophiae, nec medicinae neque minus anatomes necessitatem vidit 
(homo ferus atque silvestris). Nihilo minus aliquam fuisse internae corporum animatorum structurae notitiam, caeda et rapina partam, contendere andeo. - Sub ipsa coena cruenta partium differentiam animadvertit, duras, molles, succulentas, rigidas, sapidas, insipidas aliasque..., similiaque in suo corpore esse simpliciter conclusit. - Ingravidatam feminam simili utero foetum gestare, quem sub animalium praegnantium caede totius invenerat."*)

So bildete denn die Jagd eine ausgiebige Quelle, aus welcher der Naturmensch die Kenntnis von der Beschaffenheit der inneren Teile des tierischen Körpers schöpfen und sekundär auf seinen eigenen Körper anwenden konnte. Noch vicl reichlicher floß die Quelle der Belehrung, als sich der Mensch durch Züchtung von Haustieren, deren Fleisch ihm jederzeit zu Gebot stand, unabhängig von dem Zufall der Jagd gemacht hatte. „Quid, quaeso, anatomes autoritati demet, si in culinis aut a pastoribus aut venatoribus primo excultam fuisse comperiamur? Maximis rebus parva subsunt principia, quid mirum, si ab ove aut foetante hirio aut laceratis ferarum cadaveribus originem traxerit? "**)

Das Auswaiden größerer Tiere geschah wohl in der Regel an Ort und Stelle und gewährte nur dem Jäger selbst einen Einblick auf die inneren Teile. Kleinere Jagdtiere aber wurden ganz mitgenommen und vor der Höhle oder der späteren Hütte resp. Zelt zerlegt, wo auch der nomadisierende oder seßhafte Viehzüchter die Haustiere schlachtete. Immer war es das Familienhaupt, dem das Zerlegen des Tieres zufiel, aber an den Wohnplätzen hatte er bei diesem Geschäfte eifrige Zuschauer an den Weibern und Kindern, die auf diese Art an der Erweiterung der anatomischen Kenntnisse wesentlichen Anteil gewannen.

Auch die $\mathrm{Zubereitung}$ der Fleischspeisen, wobei noch detailliertere anatomische Kenntnisse erworben wurden, war anfänglich immer Sache des Familienvaters. Mit Recht konnte daher Hyrtl sagen,***) die Küche, in welcher die Anatomie ihren ersten Anfang genommen hatte, habe derselben auch weiteres Wachstum gebracht. Sei doch diese Art von Anatomie die allergewöhnlichste gewesen und jedem zur Ausübung offen gestanden, ohne daß er dabei mit Schmutz und Ekel zu kämpfen hatte. Solche, welche

*) J. Hyrtl a. a. O., S. I8.

${ }^{* *}$ ) J. Hyrtl a. a. O., S. I6.

$\left.{ }^{* * *}\right)$ J. Hyrtl a. a. O., S. 22. 
sich besonders gut auf das Zerlegen und Zubereiten des Fleisches verstanden, waren noch in späterer Zeit, als der Mensch die ersten rohen Stufen schon längst überschritten hatte, in hohem Ansehen. Aus der griechischen Heroenzeit hat uns Homer die Namen des Tantaliden Agamemnon und des Thrasymenes (Nestors Sohn), als zweier vorzüglicher Köche hinterlassen.

Allmählich entwickelte sich eine Art Spezialistentum von Köchen, denen nicht blos in der Zubereitung, sondern auch schon in dem Zerlegen der Jagd- und Herdentiere eine besondere Geschicklichkeit zugeschrieben wurde und die deshalb schon A. Haller (Biblioth. anat. p. 3) als Vorläufer der wissenschaftlichen Anatomie betrachtet wissen wollte. Philo stellte die Köche den Ärzten gleich, und Galen, der nicht so weit geht, schreibt ihnen wenigstens eine ausgedehnte praktische Erfahrung in der Anatomie zu, wenn er sagt: „Et qui praeterea est nedum medicus, sed ne coquus, qui nesciat, sanquinem a corde pulmoni peo unicam venam administrari?" und an anderer Stelle: „Medicos romanos anatomen doscendi gratia cum exercitu Germaniam profectos esse et proelio caesorum hostium cadavera post pugnas dissecuisse, non plus vero inde cognitionis hausisse, quam coquos, idque quia rerum anatomicarum ignari huic labori semet accinxerunt". Auch Soranus (lib. de matr.) bestätigte die anatomischen Kenntnisse der Köche, die in Gallien sogar den Schweinen den uterus oder die Eierstöcke ausschneiden, um sie dadurch fetter zu machen.

Bei näherer Untersuchung stellt sich heraus, daß diese anatomisch erfahrenen Köche ursprünglich immer mit dem Opferdienst in Verbindung gestanden haben. Athenaeus versichert, die alten, der Opferbräuche kundigen Köche haben sowohl bei Hochzeiten, wie bei Opfern fungiert und seien häufig die Diener der Opferpriester gewesen. In der frühesten Geschichte der Menschheit freilich waren Mahlzeit und Opfer immer vereinigt, da an keine Mahlzeit, zumal eine festliche, gedacht werden konnte, an welcher die Geister (Götter) nicht teilnahmen.*) Die Zubereitung des Fleisches und des Fleischopfers war ursprünglich immer Sache des Mannes, des Familienvaters. Später fielen Mahlzeit und Opfer auseinander, und mit dieser Zeit begegnen wir dem Auftreten einer eigenen Kaste, welche mit der Gottheit in besonders nahem Verhältnis zu stehen vorgab und die leitende Oberaufsicht über alle

*) Lippert, Kulturgeschichte der Menschheit, Bd. I, S. I 40. 
Opfer beanspruchte. Für die niederen Dienstleistungen bei den Opfern wurden besondere Ministranten beigezogen und nun zog sich durch Jahrtausende hindurch jenes großartige Opferwesen, das schon in kulturgeschichtlicher Beziehung unser volles Interesse beansprucht, noch mehr aber für die Entwicklung der Anatomie von großer Bedeutung war.

Geopfert wurden wilde und Haustiere, geopfert wurden aber auch vom grauesten Altertum bis in geschichtliche Zeiten Menschen und häufig in der Weise, daß ihr geöffneter Leib die inneren Teile erkennen ließ. Bei einzelnen Kulturvölkern (Ägypter, Griechen, Römer) stoßen wir auf Traditionen, daß dieser oder jener Heros oder Fürst die Umwandlung der Menschenopfer in Tieropfer angeordnet habe. In der Tradition der Hebräer ist es Jahveh selbst, der den Patriarchen Abraham den tierischen Ersatz für das geplante und zurückgewiesene Opfer seines Sohnes Isaak finden läßt.

Wenn freilich, wie es von den Babyloniern, Assyrern und Phöniziern überliefert ist, dem Hauptgotte (Bal, Bel) ga n ze Menschen, Kinder und Erwachsene, als Brandopfer dargebracht wurden, konnte dabei kein Gewinn für die Anatomie herauskommen. Es ist aber auch durch Entzifferung der Steininschriften und Tontafeln nachgewiesen, daß daneben unzählige $\mathrm{R}$ inder, Stiere, Schafe und Böcke dem Messer der Priester zum Opfer gefallen sind. Um nur ein Beispiel anzuführen, so enthält eine Inschrift des Nabuabal-iddin (ca. $883-852 \mathrm{v}$. Ch.) folgende Worte*): „Opfer nach Herzenswunsch an fetten Stieren, Schafen, Fettfleisch vom Rind, Fleisch von Böcken. - An den Böcken, den Opfern des Königs für das ganze Jahr: Schenkelfleisch, das halbe Innere des Fleischs, zwei Knöchel, ein Topf mit Fleischbrühe; aus den Opfern an Rindern und Böcken des Opfergottes etc."

Schon in dieser Stelle werden ganz bestimmte Teile des Opfertieres unterschieden, was auf eine exakte Zerlegung derselben schließen läßt. Noch deutlicher wird diese auf anatomischer Basis bestehende Auslese bei den Ägyptern. Was zunächst die Art der Opfertiere betrifft, so erhalten wir darüber Auskunft aus dem großen Papyrus Harris Nr. I, in welchem König Ramses III. die Errichtung des Tempels von Medinet-Abu auf der Westseite Thebens schildert und folgende Worte an seinen Gott richtet**):

*) Keilinschriftl. Biblioth., herausg. v. Eberh. Schrader, Berlin I8yo, Bd. II, S. 26 I.

**) Heinr. Brugsch, Steininschrift und Bibelwort, Berlin I891, S. 28 ;. 
„Ich machte viel des heiligen Eigentums zu Opfergaben für Dich an Brot, Wein, Bier, Geflügel, jungen Stieren, Kälbern und Kühen in großer Menge, an Antilopen und Gazellen, als Opfer in seinem (des Tempels) Schlachthause." Von dem König Picachi, dem äthiopischen Eroberer Ägyptens, wird in einer hieroglyphischen Inschrift erzählt: „Der König begab sich nach der sandigen Höhe in On und er brachte der aufgehenden Sonne gegenüber ein großes Opfer auf der sandigen Höhe von On dar, das aus weißen Kühen, Milch, Balsam etc. bestand."*) - Außer den oben angeführten Tieren wurden auch Gänse und Schweine geopfert. Herodot (II, 47) beschreibt die Opferung eines Schweines an den Mond, wobei das Schwanzende, die Milz und das Netz mit allem Fett, das die Eingeweide überzog, bedeckt und dann verbrannt wurde. - Eingehende Studien über den Opferritus der alten Ägypter hat G. Wilkinson**) angestellt. Nach Abschneiden des Kopfs und Entfernung der Haut wurde das Opfer in einzelne Teile zerlegt, wie sie auf einem Wandgemälde in Theben dargestellt sind.

1. Hinterfuß,

2. Dickbein (Schenkel),

3. Herz,

4. Nieren,

5. Rippenstück,

6. Kreuzbein mit Schwanz,

7. anderes Rippenstück,

8. Leber.

Auf den Altar kamen gewöhnlich der Kopf, der eine Hinterschenkel und ein Rippenstück. - Bei Brandopfern wurde ebenfalls zuerst der Kopf und die Haut entfernt, dann der Magen herausgenommen und nur die Eingeweide und das. Fett zurückgelassen, worauf die Schenkel mit dem Dickfleisch, die Schultern und der Nacken weggenommen wurden. Hierauf wurde der Leib mit wohlriechenden Spezereien gefüllt und verbrannt.

An die Opfergebräuche der Ägypter schließen sich in natürlicher Folge die der Hebräer an, weil nicht ohne triftige Gründe anzunehmen ist, daß sie vieles von den Ägyptern entlehnt haben. Durch die im 2. und 3. Buch Moses enthaltenen rituellen Vorschriften sind wir über die Opfer der Hebräer auf das Genaueste

*) Heinr. Brugsch a. a. O. S. 288.

**) G. Wilkinson, Manners and Customs of the ancient Egyptians, Vol. II, 356 ff. 
unterrichtet. Wir erfahren aus 3. Moses $17,3 \mathrm{ff}$., daß private Schlächtereien im Lager oder außerhalb desselben verboten waren. Nur vor der Wohnung Jahves war das Schlachten von Tieren gestattet und nur durch die Hand des Priesters und seiner Gehilfen, welche die für Jahveh und die Priester bestimmten Teile auszuscheiden hatten. Es kamen zur Opferung Farren, Schafe, Widder, Ziegen, von Armen dargebracht auch Turteltauben und junge Haustauben. Das tägliche gemeinsame Opfer bestand in einem Farren als Sündopfer zur Versöhnung. Außerdem wurden täglich zwei jährige Lämmer, eines morgens und eines abends als Brandopfer geopfert. Nachdem der zum Sündopfer bestimmte Farren herbeigeführt war und Aaron und seine Söhne ihre Hände auf des Farren Haupt gelegt hatten, wurde derselbe vor der Türe der Stiftshütte geschlachtet, das Blut teils an die Hörner des Altars gestrichen, teils auf den Boden am Altar geschüttet. Dann wurde das Fett am Eingeweide, das Netz über der Leber und die zwei Nieren mit dem Fett genommen und auf dem Altar angezündet. Das Netz über der Leber mußte an den Nieren abgerissen werden. Des Farren Fleisch, Fell und Mist wurde außen vor dem Lager mit Feuer verbrannt als Sündopfer. Wollte als Sündopfer von einem Privatmann ein Schaf dargebracht werden, so mußte es weiblichen Geschlechts und „ohne Wandel" sein, ebenso event. eine $\mathrm{Ziegenmutter.}$

Kam ein Widder zur Opferung, so wurde er entweder vollständig verbrannt, nachdem er in Stücke zerlegt und die Eingeweide und Schenkel gewaschen waren, oder die Verbrennung war nur eine teilweise. Das Fett, der Schwanz, das Fett am Eingeweide, das Netz über der Leber und die zwei Nieren mit dem Fett darüber, nebst der rechten Schulter wurden mit einem Brot, einem Ölkuchen, und einem Fladen ungesäuerten Brotes zuerst auf die Hände Aarons und seiner Söhne gelegt und dann auf dem Altar als Brandopfer zum „süßen Geruch vor dem Herrn“ verbrannt. Die Brust und die linke Schulter fielen an Aaron und seine Söhne.

Wurde ein Dankopfer dargebracht, so fiel die Brust und die rechte Schulter an den Priester, das Fett aber mußte auf dem Altar verbrannt werden, denn ,alles Fett war des Herrn," kein Israelite durfte das Fett eines Schlachttieres verzehren; noch viel strenger aber war ihm der Genußs von Blut verboten, denn „,des Leibes Leben ist im Blute". 
So war der tägliche Opferdienst für die Hebräer eine fortdauernde Quelle für Erwerbung anatomischer Kenntnisse, ja Hyrtl*) schreibt ihnen sogar die Kenntnis der Nebennieren zu und beruft sich dabei auf die Stelle im Levit. VII, 3-5, worin es nach der Vulgata heißt: „Et offerent duos renes cum adipe, quo teguntur, ilia et reticulum jecoris cum renunculis". Daß die an den Haustieren gewonnenen anatomischen Kenntnisse auf den Menschen übertragen wurden, ist nur natürlich. Die Sprache der Bibel verfügt über eine sehr reiche Terminologie nicht nur der äußeren Körperteile, wie wir eben gesehen haben, sondern auch der inneren Organe. Das von Luther gebrauchte Wort Ader wurde von den alten Völkern bis auf Herophilos in gleicher Weise für jedes schnurförmige Gebilde des Körpers, also für Sehne, Nerv und Blutgefäß gebraucht. Das Wort Fle isch wurde bald für den ganzen Körper, bald für die Muskulatur zur Unterscheidung von den anderen Weichteilen gebraucht. Die biblische Anatomie erstreckt sich aber noch weiter. Kazenelson**) vermutet sogar, daß mit dem Worte Auchoth (das Verborgene) die Bezeichnung des Gehirns, des Sitzes der höchsten und edelsten Wahrnehmungen des Menschen verbunden sei. Eine andere Vermutung ist, daß mit dem Bibelworte „Anhängsel der Leber" die Bauchspeicheldrüse gemeint sei, er beruft sich dabei auf eine alte Schilderung der Opferritualien, worin von einem hinter der Leber zwischen beiden Nieren gelegenen Leberfinger die Rede sei. Leber und Galle sind genau bestimmte anatomische Bezeichnungen. Die Nieren sind oft erwähnt, aber ohne Hinweis auf ihre physiologische Funktion, sondern als Sitz des Bewußtseins und des Gewissens. Unter Bauch versteht die Bibel nicht nur den äußeren Körperteil, sondern auch die Höhlung, in welcher die Verdauungs- und Zeugungsteile liegen. Mit Eingeweide wird der ganze Darmkanal bezeichnet, doch haben die Hebräer noch ein anderes Wort für Darm, das aber auch zur Bezeichnung für die Körperhöhlen und im übertragenen Sinne als Ausdruck für Gefühlsorgan dient. Das am häufigsten in der Bibel genannte Organ ist das Herz, nicht nur im anatomischen Sinn, sondern auch zur Bezeichnung eines Organs für die Gesamtheit der geistigen Kräfte des Menschen. Weitere

*) J. Hyrtl, a. a. O., S. 29.

*) Dr. L. Kazenelson, d. normale u. pathol. Anatomie des Talmud, übers. von N. Hirschberg, Halle 1896 , u. Koberts histor. Studien Bd. V, S. 178f. 
mehrfach genannte Organe sind der Kehlkopf, zuweilen einfach „Hals", der Schlund als Schluckwerkzeug, die Zunge als Sprachorgan und der Gaumen als Geschmacksorgan im physiologischen und psychologischen Sinn. Was aber sehr auffallen muß, ist das, daß im Brustkorb die Lunge und im Unterleib die Milz und die Harnblase in der Bibel mit keinem Worte erwähnt sind, obwohl doch die Opferanatomie täglich mit Notwendigkeit auf die Kenntnis von diesen Organen führen mußte.

Ebenso ausgebildet wie bei den Ägyptern und den semitischen Völkern Asiens war die Opferanatomie bei den Indogermanen, und auch hier wieder gelangen wir durch altindogermanische Wurzelausdrücke für innere Organe in jene fernentlegenen Zeiten, in denen die einzelnen Glieder der großen Völkerfamilie noch ungetrennt neben einander wohnten und aus dem Leibesinhalt ihrer Opfertiere die gemeinsamen Bezeichnungen für ihre eigenen inneren Organe entnahmen. Solche altindogermanische Wurzelausdrücke sind:

für (rohes) Fleisch: Kruv,

= Mark: mazg-a, margh,

= Sehne, Nerv: san, snur-va,

$=$ Muskel: mus,

= Schale: skel,

= Lunge: plauman,

cf. sanskr. plavate $=$ schwimmen und lith. plankin $=$ schwimmen, lith. planki, slav. plusta $=$ Lunge; andere altindogerm. Bezeichnung

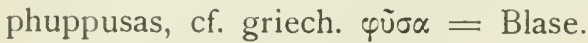

Für Herz existiert kein gemein-indogerm. Wort. Sanskr. hrt, baktr. zaredhujem, goth. havrsto, lith. szirdis, slav. sru'dice, $=$ das Zitternde, Schwingende.

Für Leber jak, mit verschied. Ableitungsendigungen, sanskr. jakrt, abweichend: slav. jetra, lith. kēpene, cf. képalas, Brotlaib.

Für Galle gha, mit verschied. Ableitungsendigungen. Slav. zluci, cf. althochd. gelo gelb, lat. fulvus, lith. zalas, slav. zeleni=grün.

Für Milz splagh (unklare Bedeutung). Sanskr. plihan, lith. bluznis.

Für die Nieren und die Eingeweide ist kein gemeinsames indogerm. Wurzelwort vorhanden. Bezeichnungen für diese Teile treten erst in der altindischen Opferanatomie und in derjenigen der nach erfolgter Trennung ausgeschiedenen anderen indogermanischen Völker auf. 
Über den altindischen Opferritus haben wir durch die Untersuchungen von Dr. Jul. Schwab*) gründlichen Aufschluß erhalten. Wir wissen, daß der Brauch, in Verbindung mit Früchteopfern auch Tiere zu opfern, in sehr frühe Zeit zurückgeht. Fleischnahrung war ja in vedischer Zeit allgemein gebräuchlich, weshalb auch das Opfer mit Ausnahme der für die Gottheit dargebrachten Stücke verzehrt wurde. Auch das erfahren wir, daß in den frühesten, rohesten Zeiten Menschenopfer gebracht wurden. Es wird damit die Angabe des Solinus Polyhistor. (de moribus Indorum c. 52) bestätigt, daß die alten Inder ihre nächsten Anverwandten, sogar die Eltern, wenn sie von Altersschwäche befallen wurden, geopfert und ihr Fleisch nebst Eingeweiden verzehrt haben. Später betraf die Opferung nur Feinde oder Verbrecher. Dafür traten die verschiedensten Tiere, wilde und zahme, männliche und weibliche, an die Stelle, wenn auch letztere, namentlich die Kuh, geschont wurden. Bei der Auswahl wurde auf die angenommene Vorliebe des Gottes für dieses oder jenes Tier, oder auf die scheinbare Übereinstimmung äußerer Merkmale mit gewissen Eigenschaften der Gottheit Rücksicht genommen. Man opferte Pferde, Rinder, Schafe und $\mathrm{Ziegen;} \mathrm{das} \mathrm{gewöhnlichste} \mathrm{Opfertier} \mathrm{war} \mathrm{der} \mathrm{Ziegenbock,} \mathrm{der}$ eine von zwei Zwillingen; der andere und die gleichalterigen Herdgenossen mußten noch leben. Das Tier mußte in jeder Beziehung fehler- und tadellos sein; auf Fettreichtum wurde wegen Darbringung des Fettes, namentlich der Nieren, besonders gesehen.

Nachdem der bestimmte Tag, gewöhnlich ein Neumond- oder Vollmondtag, gekommen war, wurde das Tier zur Opferstätte gebracht, wo 6 Priester nach bestimmtem vedischen Ritus fungierten, unter Oberaufsicht eines das Ganze überwachenden Brahmanen. Getötet mußte das Tier werden durch Ersticken bei Zuhalten des Mundes oder durch Erwürgen mittelst der Schlinge, wobei es aber keinen Ton von sich geben durfte. Dann mußte die $\mathrm{Haut}$ in einem Stück abgetrennt und bevor der $\mathrm{Nabel}$ aufgeschlitzt war, das $\mathrm{Net} z$ herausgenommen werden. Hierauf erteilte der Oberpriester folgenden Befehl an die Schlächter**): „Seiner Brust gebt die Gestalt eines Adlers, den Oberschenkeln der Vorderfüße die von Beilen, den Unterschenkeln derselben die von spitzen Pföcken, den beiden Schulterblättern die von Schildkröten!

*) Dr. Jul. Schwab, Das altindische Tieropfer, Erlangen I 886.

**) J. Schwab a. a. O., S. Ios. 
An einem Stücke lasset den $\mathrm{R} u ̈ c k e n$, die Oberschenkel der Hinterfüße machet gleich zwei Türflügeln, die beiden Unterschenkel derselben gleich zwei Oleanderblättern. Der Reihe nach löset seine $26 \mathrm{R}$ ippen aus; jedes einzelne Glied lasset unversehrt! Zerschneidet nicht den Dickdarm, ihn für den Mastdarm haltend, noch soll unter euren Kindern und Enkeln ein Zerleger solches tun!“

Besonders umständlich war die Herausnahme und Darbringung des Netzes. Der Schlächter legte das Tier auf den Rücken, bezeichnete durch Auflegen eines geweihten Grashalms eine Stelle rechts vom Nabel und eröffnete mit Durchschneiden dieses Halms, der Haut und der Bauchdecken die Bauchhöhle, um dann nach Erweiterung des Schnittes das Netz herauszuziehen. Dasselbe wurde gereinigt, mit Wasser abgespült und mit dem Messer alles Ungehörige entfernt. Während nun das Netz über dem Feuer gekocht wurde, mußte der Schlächter den Schnitt in den Bauch mit der Hand bedecken. Dann erst wurde das Netz aus dem Kochwasser herausgenommen, an zwei geweihte Bratspieße gesteckt und im Feuer zu Ehren der Gottheit verbrannt.*)

Nun ging es weiter an das Zerlegen des Opfertieres. Als zur Opferspeise geeignet erschienen:

I. das Herz, das in allen Überlieferungen als erstes Stück genannt wird. Seine Gestalt wird verglichen mit dem Kelche der Lotosblume, weniger zutreffend mit der Frucht des Mangobaums;

2. die Zunge;

3. das Bruststück mit dem Knochen;

4. die Leber, deren dunkle Farbe hervorgehoben wird;

5. die Nieren, welche geschildert werden als bohnenförmig und zu beiden Seiten der Wirbelsäule sitzend, in Fett eingehüllt;

6. das Rückenstück, d. h. die Wirbel mit den Querfortsätzen und den daran befindlichen Fleischstücken, die zurückbleiben, wenn die Rippen ausgebrochen werden;

7. der Oberschenkel des linken Vorderfußes mit dem Bein;

8. der rechte Hinterbacken mit oder ohne Bein;

9. der Oberschenkel des rechten Vorderfußes;

IO. der linke Hinterbacken;

II. der Mastdarm. Da bei allen Darbringungen Teile von ihm beigelegt wurden, wurde er zerschnitten;

•) J. Schwab a. a. O., S. II7. 
12. der rechte Lungenflügel;

13. der linke Lungenflügel;

14. die Milz, dic geschildert wird als nur oben mit der Wirbelsäule in Verbindung stehend;

15. das Fett, in der Regel nur das die Nieren und das Herz umhüllende. Im Notfalle bei einem mageren Tiere wurde auch das Fett des Bauchfells und der Eingeweide genommen;

16. der Dickdarm;

17. die kleinen, spiralförmig verlaufenden Gedärme;

18. der Schweif.

Die Fleischstücke wurden gekocht, das Herz am Feucr geröstet; das Blut aber wurde den bösen Geistern geweiht. Die Priester erhielten als Speise Stücke des Herzens, der Zunge, der Brust, der Leber, der beiden Nieren, Fett des Herzens oder anderer Teile, außerdem knochenfreie Fleischstücke z. B. von den Hinterbacken.

Nach der Lehre der Brahmanen wurde angenommen, daß jedes Opfer durch Agni (Feuer), dem es dargebracht wurde, aufs neue geboren werde und so lebendig zu den Göttern gelange.

Wir erkennen in diesem altindischen Opferritus eine bis in das Einzelste peinlich durchgeführte Disziplin bezügl. der Herausnahme und Zerlegung der einzelnen Teile des Tierkörpers. Wenn wir nun weiter die immer wiederkehrende Wiederholung der einzelnen Prozeduren in Erwägung ziehen, so müßten wir es wirklich als ein Wunder betrachten, wenn diese Opferpriester nicht mit der Zeit einen ganz bedeutenden Fond von anatomischen Kenntnissen erworben hätten, allerdings von tierischer Anatomie, aber daß dieselbe damals und auch viel später noch auf den Menschen übertragen wurde, darüber besteht gar kein Zweifel.

Weniger umständlich, aber immerhin ebenfalls mit großer Sorgfalt, wurden die griechischen Opfer ausgeführt. Daß die Griechen auch Menschenopfer gebracht haben, ist nicht nur durch die Traditionen aus der ältesten sogen. Heroenzeit, sondern auch durch geschichtliche Überlieferung, sogar noch aus makedonischer Zeit, nachgewiesen. Später traten an die Stelle der willkürlich geopferten Menschen Verbrecher, in allen Fällen aber fehlen Nachrichten über die Art ihrer Opferung, aus denen man auf etwaigen Gewinn für die Kenntnis menschlicher Anatomie schließen könnte. 
Die gewöhnlichen Opfer bildeten immer Tiere, sowohl wildes Getier, als zahme Haus- und Herdentiere. Rehopfer fanden statt zu Patrai in Achaia zu Ehren der Artemis Laphria (Pausan. VII, I8. 12). Hirsche wurden ebenfalls der Artemis sowohl in Kleinasien, als in Griechenland geopfert (cf. das Hirschopfer als Ersatz für Menschenopfer in der Sage von der Iphigenia). Aus historischer Zeit sind Hirschopfer verbürgt für die Artemis Laphria zu Patrai, für die Isis in Phokis und für die Athene in Laodicea. Von Haus- und Herdentieren fanden Verwendung am häufigsten Rinder, Schafe, $\mathrm{Ziegen}$ und Schweine, seltener Esel (dem Apollo) und Hunde (der Hekate), noch seltener Vögel (Hahn, Gans, Perlhuhn). Die Tiere mußten gesund und unversehrt sein, Gebrauchstiere, z. B. Ochsen wurden gewöhnlich nicht geopfert.*)

Nachdem das bekränzte und sonst geschmückte Opfertier am Altar mit der Keule oder dem Beile niedergeschlagen und ihm mit dem Opfermesser die Kehle durchschnitten war, um das Blut zu gewinnen, ging es an die Abhäutung und Zerlegung, wobei die den Göttern gewidmeten Teile auf die Seite gelegt wurden. Bei Homer sind dies die $\mu \eta_{i}: \alpha$, d. h. die mit mehr oder weniger Fleisch ausgeschnittenen Schenkelknochen, in späterer Zeit der Rückgrat oder der untere Teil desselben mit dem Schwanze. Die Frommen schnitten größere Stücke aus, die Unfrommen möglichst kleine mit möglichst wenig Fleisch. Außerdem erhielten die Götter das Fett und von jedem Gliede etwas; niemals wurde vergessen, den Göttern die Gallenblase und den Schwanz, also für den Menschen wertlose Bestandteile des Opfertieres, darzubringen. Alles den Göttern Dargebrachte, die Gallenblase, der Schwanz und ver-

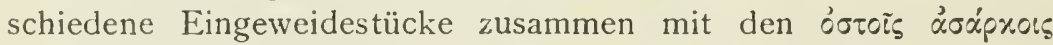
wurden mit der Fetthaut umwunden auf den Altar gelegt und verbrannt. Die Zunge hob man im heroischen Zeitalter auf, um sie später nach beendigter Opfermahlzeit als Götterspeise in das Feuer zu werfen. Später wurde die Zunge häufig dem Hermes dargebracht, wenn sie nicht bei gewissen Staatsopfern ausgeschnitten und den bei den Opfern fungierenden Herolden zugewiesen wurde. Die edleren Eingeweide dagegen ( $\sigma \pi \lambda \dot{\alpha} \gamma y v x)$, wozu das Herz, die Leber und die Lunge gehörten, wurden gewöhnlich beim Opferschmaus zuerst verzehrt. Das Blut wurde als Gabe für die Götter und für die Schatten der Unterwelt in eine Grube gegossen

*) K. F. Hermann, Lehrbuch der griech. Antiquitäten, 2. Bd., $\int 26$ und 27. 


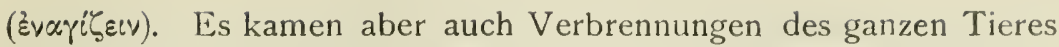

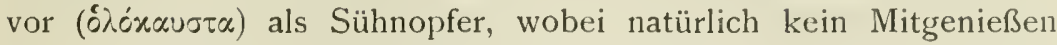
der Menschen, aber auch keine Einsichtnahme von den inneren Teilen des Tieres stattfand.*)

Der anatomische Gewinn, den die Griechen in der frühesten Periode ihrer Geschichte aus dem Zuschauen bei den Tieropfern davontrugen, wird am besten aus den Dichtungen Homers (zirka I000 v. Ch.) kenntlich. Das Leben des Menschen liegt im Hauche, dem Träger der geistigen Tätigkeit, der seinen Sitz im Zwerchfell ( $\left.\rho^{\prime} \varepsilon^{\prime} \varepsilon_{5}\right)$ hat. Im übrigen stehen dem Dichter bei seinen Schilderungen von Kämpfen und Verwundungen so mannigfaltige Bezeichnungen für innere Organe zu Gebot, daß wir uns dazu verstehen müssen, die in den beiden Ärzten Machaon und Podalirios repräsentierten anatomischen Kenntnisse damaliger Zeit als recht ansehnlich zu respektieren. $\mathrm{Ob}$ die Wunden gefährlich sind oder nicht, richtet sich in jedem Fall nach der Bedeutung des betroffenen Körperteils. Il. IV v. 52 I werden einem Helden durch einen Steinwurf über dem Knöchel beide Unterschenkelknochen nebst den Sehnen zertrümmert. Il. IV, 525 läßt eine in den Nabel eingebohrte Lanze alle Gedärme zur Erde herausstürzen. Il. V, $67 \mathrm{f}$. fährt ein Geschoß einem Helden rechts hindurch ins Gesäß, daß ihm die Spitze vorn die Blase durchbohrend am Schambein wieder hervordrang. Il. VIII, $325 \mathrm{f}$, wird Teucros von Hektor mit einem zackigen Feldstein am Schlüsselbein getroffen, „zwischen Hals und Brust, wo am tödlichsten ist die Verletzung". Il. XIV, $465 \mathrm{f}$. fliegt die blinkende Lanze, „wo Haupt und Nacken sich füget, oben am Wirbel hinein" und hat wegen Durchschneidung des verlängerten Marks augenblicklichen Tod des Helden zur Folge. Il. XVII, 297 entspritzt das Gehirn aus der Wunde des Schädels blutig hervor. Il. XX, $478 \mathrm{f}$. wird ein Held unter dem Buge des Armes verletzt, wo der Sehnen (Nerven) Geflecht sich vereinigt, und er harrt, am Arme gelähmet, vor sich schauend den Tod. Il. XX, $469 \mathrm{f}$. haut ein Held dem andern das Schwert in die Leber, daß ihm die Leber entsank und das schwarze Blut aus der Wunde ganz den Busen erfüllte. Il. XXII, 396f. endlich durchbohrt der grimme Achilles dem Hector beiderseits hinten die Sehnen zwischen Knöchel und Ferse, nachdem er ihn durch einen Lanzenstoß in die Kehle, die gefährlichste Stelle des Lebens, getötet hatte.

*) G. F. Schömann, Griechische Altertümer, 4. Aufl., 2. Bd., S. 226, 262. K. F. Hermann a. a. O., $\int 28$. 
Noch andere Stellen aus der Ilias und Odyssee könnte ich anführen, doch sei es an diesen wenigen Proben genug, um den scharfen anatomischen Blick des hochbegabten Griechenvolkes schon in ihrer Heroenzeit zu beweisen.

Die Opfer-Anatomie der Römer fällt größtenteils mit derjenigen der Etrusker zusammen. „Omnem hanc ex Etruria scientiam adhibebant," sagt _Cicero*) und meint damit sicher nicht bloß die römische Opferschau, sondern auch ihre Opfer-Anatomie, wenn auch nicht geleugnet werden kann, daß viele altertümliche lateinische Ausdrücke auf frühe selbständige Anfänge des römischen Opferdienstes hindeuten (s. unten).

Von den Etruskern weiß man, ${ }^{* *}$ ) daß sie alle Opfertiere in zwei Klassen einteilten, nämlich in hostiae animales (Opfertiere) und hostiae consultatoriae (Opferschautiere). Nach Eckermann wurde, wie bei den alten Persern nur das Leben des Tieres dem Gotte geopfert, während die Eingeweide nicht dargebracht und verbrannt wurden. Es sei dies ein Ersatz- und Sühnopfer gewesen zum Loskauf der Seelen von der Unterwelt und zur Verwandlung der Seelen in dii animales. Dahin gehörten nach Eckermann alle Expiations- und Prokurationsopfer. Dieses Umgehen der Eingeweide als Brandopfer aber wäre anderen Völkern gegenüber eine Ausnahme gewesen. In der Tat haben auch die Untersuchungen K. O. Müllers ${ }^{*}$ ) ergeben, daß die Eingeweide, welche wahrscheinlich als verschiedenen Göttern angehörend galten, zuerst gesotten und dann kunstgerecht zugeschnitten den Göttern als Brandopfer dargebracht wurden. Bei der Umständlichkeit, mit welcher die Etrusker alle ihre religiösen Gebräuche betrieben, läßt dieser Opferritus mit seiner kunstgerechten Zerlegung der einzelnen Teile auf eine nicht unbedeutende anatomische Gewandtheit schließen.

Tieropfer werden in der Geschichte der Römer sehr frühe erwähnt, so Ziegenopfer der Luperci (Priester des Pan) unter Romulus (Plut. Rom. 2I) und Hundeopfer (rutilae canes) zu Sühnezwecken alljährlich vor der Porta catularia. Im allgemeinen unterschied $\operatorname{man} \uparrow$ ) hostiae $=$ pecudes, und victimae $=$ armenta

") Cicero, de Divinatione, ed. Moser, lib. I, 2., S. 12.

**) K. Echermann, Lehrb. der Religionsgesch. u. Mythologie d. vorzüglichsten Völker des Altertums, I 845 , Halle, 2. Bd., S. I $83 \mathrm{f}$.

**) K. O. Müller, die Etrusker, II., S. 178.

†) J. Marquardt, Röm. Staatsverwaltung, 3. Bd., S. $169 \mathrm{ff}$. 
(Pfugvieh) und nach dem Alter lactentes und majores. Von den lactentes mußten Schweine 5, Schafe 7, Rinder 30 Tage alt sein. Hatten die Tiere beide Reihen Zähne, so gehörten sie zu den majores. Den Göttinnen wurden weibliche, den Göttern männliche Tiere geopfert; was die Farbe betrifft, so erhielten die Götter der Unterwelt nur schwarze Tiere, Jupiter aber immer ein junges männliches Rind von weißer Farbe oder wenigstens mit einem weißen Flecke (Blässe) auf der Stirn. Die Juno erhielt eine Kuh oder eine porca oder agna; die Minerva eine Kuh oder ein Kuhkalb, die Tellus eine trächtige Kuh, die Ceres eine Sau, die Proserpina eine unfruchtbare Kuh. Dem Janus wurde ein Schafbock dargebracht, dem Neptun ein Stier, dem Mars ein Stier, ein Eber oder ein Schafbock, an den Iden des Oktobers ein Pferd, dem Liber pater und dem Merkur ein Ziegenbock, dem Vulkan ein rotes Kalb und ein Eber, dem Robigus und den Lares praestites ein Hund, dem Silvanus ein Schwein und dem Äskulap ein Hahn oder eine Henne.

Das zu opfernde Tier mußte von untadeliger Beschaffenheit sein, und wurde, wenn so befunden, geschmückt mit Binden und Bändern, oft auch mit vergoldeten Hörnern, an den Altar geführt und wenn es gerne folgte, durch eine immolatio, d. h. durch Aufstreuen von mola salsa (Mehlschrot mit Salz) auf den Kopf ausgezeichnet. Nachdem nun der Opferpriester das Gebet gesprochen hatte, während dessen die Teilnehmer in ehrfurchtsvollem Schweigen umherstanden, wurde das Tier von den ministri (cultrarii, popae, victimarii) geschlachtet, Rinder mit dem Beil (securis, dolubra), Kälber mit dem Hammer, Schweine mit einem Stein, Kleinvieh mit einem Messer (secespita). Auch das Zerlegen besorgten die ministri nach bestimmten Regeln, wonach die viscera (das Fleisch) zum Opferschmaus, die exta (Eingeweide) zu Gaben für die Götter bestimmt wurden. - $\mathrm{Zu}$ den exta zählte man die Leber (jecur), die Galle (fel), die Lunge (pulmo), das Herz (cor) und das Netz (omentum).

Wurden alle diese exta in richtigem Zustand befunden, so bereitete man dieselben kunstgerecht zur Darbringung auf dem Altare vor, indem man sie entweder in Töpfen (ollae) kochte, oder an Spießen briet. Dann wurden sie zerlegt, in einer Schüssel zu einem Gericht (prosecta) hergerichtet und durch besondere Fleischstücke (augmenta) vermehrt. Zur Bereitung dieser augmenta gab es eigene Lokalitäten (magmentaria). Besonders auf den Altar gelegte 
Fleischspeisen, die von den secunda prosecta, den viscera herrührten, hießen magmenta (majora augmenta).*)

Über diese umständlichen Zerlegungsarbeiten, welche einen vollen Einblick in die Opfer-Anatomie der Römer gewähren, sind uns detaillierte Angaben von zwei alten Schriftstellern erhalten.

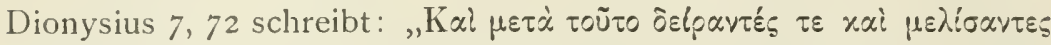

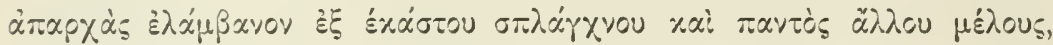

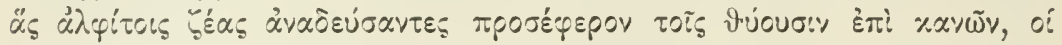

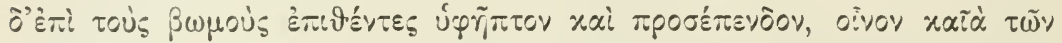

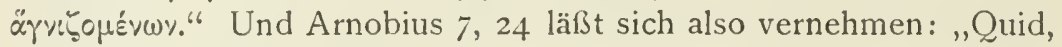
inquam, sibi haec volunt: apexaones, hirciae, silicernia, longavi? quae sunt nomina et farciminum genera, hirquino alia sanguine, comminutis alia inculcata pulmonibus? Quid taedae, quid neniae, quid offae non vulgi, sed quibus est nomen appellatioque penitae?" Wir sehen, daß Arnobius mit diesen veralteten Namen für besondere Fleischstücke und Würste, die in verschiedener Weise mit Fleisch- und Eingeweidestücken gefüllt und augenscheinlich nur bei besonderen Opferfestlichkeiten hergestellt wurden, nichts mehr anzufangen wußte. Es sind dies Ausdrücke, die von den alten pontifices geschaffen, später dem Volke nicht mehr verständlich waren. Nur die Lexikographen Varro und Festus geben sich Mühe, dieselben zu erklären. Was die offae penitae betrifft, so werden wir durch Festus **) belehrt, daß darunter Schwanzstücke zu verstehen sind; ebenso erfahren wir von ihm, daß unter caro strebula ein Hüftstück (unpiov) und unter ruma ein Halsstück zu verstehen ist. Die offae taedae waren wahrscheinlich Hochzeits-Opferstücke, die offae neniae dagegen solche, welche bei Leichenopfern hergestellt wurden.

Die Namen der verschiedenen Würste, welche die Römer bei bestimmten Opferfeierlichkeiten verzehrten, sucht der alte M. Terentius Varro etymologisch, namentlich aus der Art der verwendeten Därme zu erklären. Die oben von Arnobius erwähnte, ,apexao“ genannte Wurst hieß nach Varro $\dagger$ ) deswegen so, „quod in hoc farcimine summo quiddam eminet, ab eo, quod ut in capite apex". Von einer anderen dicken Wurst schreibt er: „Quod fartum intestinum crassundiis, Lucanum dicunt." Eine dritte hieß fundolum

*) Varro, de lingna latina 5, I1 1. 112.

**) Text. Pomp. Festus, ed. Müller 1839, p. 242.

***) Festus a. a. O. p. 3 I 3.

t) Varro a. a. O. V, II. 
„, a fundo, quod non in utraque parte, sed ex una parte, sola aper-

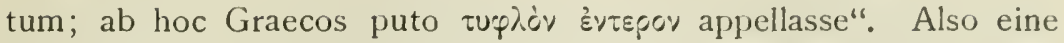
Blinddarmwurst! - Eine andere Art wird beschrieben: „Ab eadem fartura farcimina extis appellata, a quo in eo, quod tenuissimum intestinum fartum, hila dicta ab hilo." (Saitenwürstchen?) Schließlich kommt er auch auf die Erklärung der von Arnobius angeführten longavi. „Tertium fartum est longavo, quod longius quam duo illa (nämlich die hila und die fundola).

Außer den Bitt- und Dankopfern, die mit Zerlegen der Tiere, Opfergaben für den Altar und Opferschmäusen verbunden waren, gab es aber auch Sühnopfer (hostiae animales piaculares, ursprünglich Menschenopfer), bei denen die Opfertiere entweder ganz verbrannt oder den Priestern zur Verwendung überlassen wurden. Nur bei Piacularopfern nach Prodigien und bei den jährlich vorgenommenen Sühnungen wurde eine Ausnahme von dieser Opferung oder Überlassung in toto gemacht, welche, wenn allgemein eingeführt, wenig geeignet gewesen wäre, die anatomischen Kenntnisse der Opferpriester, der ministri und der Teilnehmer zu vermehren.

Daß die alten Kelten reichlich Opfer und zwar nicht bloß Tier-, sondern auch Menschenopfer ihren Göttern dargebracht haben, wird von allen klassischen Schriftstellern, die sich mit diesem Volke beschäftigten, bestätigt. Leider fehlen die näheren Angaben über die verschiedenen Opferarten, welche uns einen Anhalt gegeben hätten, den Einfluß dieser Opfer auf die Entwicklung einer, wenn auch primitiven, Anatomie zu beurteilen.

Um so besser sind wir, dank der eingehenden Arbeiten J. Grimms,*) U. Jahns**) und Dr. M. Höflers***) über die OpferAnatomie der $\mathrm{G}$ erman en unterrichtet. Daß die Germanen Menschenopfer bis in die historische Zeit hinein gebracht haben, ist nicht $\mathrm{zu}$ bestreiten. Ein klassischer Zeuge hierfür ist Tacitus mit den bekannten 2 Stellen über die Opferung der kriegsgefangenen Römer im Teutoburger Wald und über die alljährlichen Menschenopfer der Semnonen an der altheiligen Opferstätte. Selbst unter den christlich gewordenen germanischen Stämmen tauchte in schwerer

") J. Grimm, deutsche Mythologie, 3. Band.

"*) U. Jahn, deutsche Opfergebräuche.

***) Dr. M. Höfler, Opfer-Anatomie. Anthropol. Corr.-Blatt i8g6. Deutsches Krankheitsnamenbuch. 
Not die alte Sitte der Opferung Kriegsgefangener auf. Die ebenfalls geschichtlich bewiesenen Kindesopfer*) mußten schon durch die Gesetze der Westgothen und später durch die Capitularien Karls d. Gr. als Menschenmord verboten werden. Die Gottheit, welcher die Kindesopfer dargebracht wurden, war die BerchtaStampa. Später mußte sie sich mit Tieropfern, ja mit stellvertretenden Puppen, Haaren, ja sogar Gebäcken (Bubenschenkel) begnügen. In welcher Weise aber in heidnischer Zeit die Kindesopfer ausgenutzt wurden, ist daraus zu ersehen, daß nach Wuttke heute noch der Volksaberglaube einem Kindsfinger oder geräuchertem Abschnitt vom Herz, der Lunge, der Leber oder den Nieren eines Kindes die Eigenschaft zuschreibt, den Träger unsichtbar zu machen.

Als Opferzeiten wurden bestimmte heilige Tage (z. B. Donnerstag) festgehalten; als Opferstätten benützte man im Altgermanischen die sogen. Plotzgärten und Plotzhöfe (von dem althochd. blôzan, pluotzan = opfern). Dort stand der Opferpriester, der Gode, der mit der Zeit an Stelle des früheren privaten Opferleiters, des ,guten“ Hausvaters getreten war, und erwartete, umgeben von der andächtig harrenden Gemeinde, die Herbeiführung des mit Blumen bekränzten Opfertieres (Pferd, Rind, Schaf, Schwein, Hirsch etc.). Dasselbe wurde von den Dienern des Gode auf den Opferstein oder auf das „Rehbrett" gelegt, resp. gebunden und von dem Gode, nachdem derselbe zum Schwur seinen Mittelfinger (Metzgerfinger) auf des Opfers Haupt gelegt hatte, durch einen Stich mit dem geraden Schlachtmesser in das Herz oder in die Halsschlagader getötet, eine Praktik, die gelernt sein mußte und in der Regel vom Vater auf den Sohn vererbt wurde.

Aus dem in der Edda (Jordan 34I) erwähnten Ausdruck ,Blutaarschneiden" schließt Höfler, daß der Gode darauf dem Opfer die beiderseitigen Rippenknorpel-Verbindungen durchschnitt und die vorderen Brustrippen flügelförmig umschlug, so daß das blutende Herz frei lag. ,Jede einzelne Erscheinung an dem noch lebenden oder toten Opfer (Nensch oder Tier), die sich nun nach dem Todesstich des Gode vor den Augen der Zuschauer vollzog, hieß „Ferch". Dasselbe bedeutet 1 . das herauszunehmende Herz, das noch pulsierte und klopfte, 2. alles mit dem Herzen Herausgenommene, z. B. das mit dem Herzen verwachsene Zwerchfell, 3. das aus dem angestochenen Herzen im Strahl oder Bogen

*) Lippert, Kulturgeschichte der Menschheit, II., S. 34. 
herausspringende Blut, 4. überhaupt arterielles, fließendes Blut, 5. die Konvulsionen und Zuckungen der Glieder, der Augenlider und Muskeln, wie sie beim Verblutungstod sichtbar sind."

Unter allen Umständen erforderte das Zurückpräparieren der Haut und Brustmuskulatur, das Durchschneiden der Rippenknorpel und das flügelförmige Zurückschlagen der Rippen, um dem Volke das zuckende Herz zu zeigen, eine ganz respektable anatomische Gewandtheit des Gode. Die Notwendigkeit des raschen Handelns war augenscheinlich durch die Wichtigkeit bedingt, welche beim germanischen Opfer dem Blut und den Erscheinungen des Herzens beigelegt wurde. Ist doch durch Kluge nachgewiesen, daß die indogermanischen Sprachen kein gemeinsames Wort für „Blut" und "Herz" haben, sondern daß diese Bezeichnungen den germanischen Stämmen eigentümlich sind. Es ist dies in hohem Grade auffallend, da das Blut und das Herz jedem Volke bei jedem Opfer sichtbar werden und hernach auch benannt werden mußte. In der Tat haben wir bei Schilderung des altindischen Tieropfers gesehen, daß das Herz als erste Opferspeise betrachtet und das Blut den Göttern der Unterwelt dargebracht worden ist. Höfler ist geneigt, für die noch vereinigten alten Indogermanen eine andere Tötungsart (etwa durch den Genickfang) anzunehmen, bei welcher erst nachträglich bei Öffnung des Tierkörpers das Blut und Herz zum Vorschein gekommen sei. Aber gesehen und benannt mußten sie schon in dieser urältesten Zeit worden sein, es ist daher wohl möglich, daß Pauli*) Recht hat, wenn er als indogermanisches Wurzelwort für Blut ,,as“, für Herz ,kard" anführt, möglich ist aber auch, daß später noch richtigere Wurzelausdrücke gefunden werden. Das gemeingermanische Wort „Blut" (althochd. pluot) wäre dann nach Höfler wohl abzuleiten von der "blühend" roten, frischen Farbe desselben.

Im Gegensatz zu dem oben erwähnten altindischen Opferritus, bei welchem das Blut für die Götter der Unterwelt weggeschüttet wurde, galt bei den Germanen das Blut als das geheiligteste Material des Opfertiers. Es wurde sorgfältigst auslaufen gelassen und diente als Brandopfer, nachdem die Umstehenden mittelst Erlenund Wacholderreisern damit besprengt worden waren.

Beim Herausnehmen des Herzens, das bei größeren Tieren durch Schnitte mit dem Opfermesser (in ältester Zeit mit

") Pauli a. a. O., S. 28. 
dem steinernen ostersahs), bei kleineren durch einfaches Herausreißen bewerkstelligt wurde, hatte der Gode das Vorhandensein eines "Vorherzens" (Herzbeutel und Fett vor dem Herzen) und die sogen. „Herzbänder" zu berücksichtigen, mit welchen das Herz und die übrigen Brusteingeweide an der Brustwirbelsäule befestigt sind. Dann wurde das Herz als eine Speise der Götter zu den übrigen "Opfergarben" gelegt.

Hierauf ging es an die Herausnahme der mit dem Rachen (hraho) zusammenhängenden Eingeweide, nämlich der Schlundröhre, der Luftröhre, der Lunge und des unten abschließenden Zwerchfells (Kra- oder Kronfleisch). Dieses gemeingermanische Wort „Kronfleisch" läßt nach Höfler auf die entfernten Zeiten zurückblicken, in welchen aus Mangel an physiologischem Verständnis alles als zu den Kralautorganen gehörend bezeichnet wurde, was bei der Opfertechnik mit letzteren zugleich herausgenommen wurde. Die Lunge, d. h. der leichtere Teil der Kralautorgane (germanisch ling = leicht sein, indogermanisch lengh = leicht) wurde vom Gode ebenfalls zu der Opfergarbe gelegt für das Brandopfer. Daher der Ausdruck "Godes-Lunge".

Herz und Lunge bildet das "Gehäng" des Opfertieres, das rom „Gereb" der Bauchhöhle durch das Zwerchfell (Mittelreff) getrennt ist. Auch das Auslösen der Baucheingeweide geschah bei kleineren Tieren durch einfaches Abreißen, bei größeren durch das Messer des Opferpriesters.

Die Leber wurde vom Gode für das Brandopfer herausgeholt (cf. "Godesleber") und darauf die Gallenblase mit der bitteren, unreinen Galle weggeschnitten.

Aus dem Namen der nun ebenfalls herausgenommenen Milz will Höfler auf eine physiologische Deutung dieses Organs bei den alten Germanen schließen, da das (germanische) Wort "Milz" zu „Malz" etymologische Beziehung habe und wahrscheinlich als ein den Speisebrei mälzendes, schmelzendes und erweichendes Organ betrachtet worden sei.

Ob der Magen (Weidsack) besonders oder gemeinsam mit dem übrigen Verdauungskanal samt dem Gekröse herausgeholt worden ist, läßt sich aus der Höflerschen Schilderung nicht genau ermitteln. Wahrscheinlich ist das letztere. Je nach Größe, Leere oder Fülle, größerem oder geringerem Fettgehalt, Beweglichkeit etc. sprach man von einem Faistdarm oder Großdarm, von Kleindarm und Bodenstück. - Das fettreiche Gekröse hieß "Inschlitt". 
Alle Eingeweide zusammen, wahrscheinlich den Magen eingerechnet, bildeten als zusammenhängende, auf einmal herausgeholte Masse in der Sprache des Opferpriesters, die sich teilweise bis in unsere Tage in der Sprache der Metzger erhalten hat, das „Geschling, Geleer, Gerick, Gepütt, Geling, Geleber, Gerebb, Gekrös, Gemasch, Gelöse etc. - Jeder Darm als hohler Rohrgang hieß "Ader" und wurde durch Loslösen von dem Netz oder Gekröse ausgeädert." (Mit dem Namen „Ader" wurden aber auch die Blutgefäße, die Nerven und Sehnen bezeichnet.) Darauf wurden die Gedärme des ïblen Geruchs wegen mit Spezereien und Harzen (selbst importierter Myrrhe), Wacholderbeeren und Rauchkräutern bestreut und zum Verbrennen beiseite gelegt. Schließlich wurden die Genitalien der männlichen, wie der weiblichen Opfertiere vom Gode mit dem Schrotmesser oder Bräteisen (angels. bretisern) ausgelöst (cf. angels. belisnod $=$ castratus) und die Teilnehmer am Kultopfer mit diesem „Geschret" berührt, worauf dasselbe mit Vorliebe an Bäumen im Kultwalde aufgehängt wurde. Jetzt noch findet man nach Höfler Holzungen, die nach alter Benennung den Namen „Hundsfud, Saufud" tragen.

Nachdem nun die Brust- und Baucheingeweide ,,ausgew a idet" waren, blieb der Rumpf mit den Rippen unter dem Namen „Krippe“ (Gerippe) zurück; nur die Nieren mit dem Lendenfett blieben an ihrem Platze in der Leibeshöhle, um später mit dem Lendenfleisch gebraten $\mathrm{zu}$ werden.

Immer noch war der Körper von der $\mathrm{Haut}$ bedeckt geblieben. Um diese abzuziehen, benützte der Opferpriester das krumme Schabmesser. Die Haut kleinerer Schlachttiere und solcher von Familienopfern wurde als „Büttling“ (Wasserbalg) benutzt. Die Haut größerer Tiere scheint man mit den Knochenabfällen und dem nicht zum Götteropfer bestimmten „Gebütt" (dem Ausgeworfenen) gefüllt und dann verbrannt zu haben, wenn sie nicht dem Gode zufiel, um dann vom "Löher" in Eichenloh gegerbt zu werden. Als letztes inneres Organ kam das Gehirn (brägen) nach Abnahme des Kopfes und Entfernung des Grund- oder Hinterhauptbeins an die Reihe. Wahrscheinlich wurde es beim Opferschmause verzehrt. Der enthirnte Schädel (die Kopfpfanne) wurde zu Trinkgefäßen, in späterer Zeit noch zur Aufnahme für das in dreierlei Art dargebrachte Opferkorn verwendet.

Und nun fiel dem Gode die Aufgabe zu, sowohl der Gottheit, als dem gierig herumstehenden Volke durch Austeilen des Fleisches 
(brat) gerecht zu werden. Zu der für die Gottheit bestimmten Opfer garbe, d. h. dem vollständig gar gemachten Opfer (garva = fertig gemacht) gehörten außer dem oben erwähnten Herz verschiedene Fleischstücke und als bestes derselben die Garbschale am heiligen oder Kreutzbein, weil sie das fettreiche, bratige Fleisch an der Beckenschal e enthielt (Garbbraten). (DieserGarbbraten, der später als tributa an den Zellenmönch oder an die Widdumsinhaber, die geistlichen Herren, fiel, dehnte sich zuletzt bis zu den Nieren aus. Höfler.)

War die Opfergarbe hergerichtet, so wurde der Opferholzstoß durch das Notfeuer entzündet und die Gabe zu Ehren der Gottheit verbrannt. Auch das übrige, nicht zum Brandopfer bestimmte Fleisch (brat) wurde über einem anderen Feuer am Spieße gebraten und dann stückweise (Stuckfleisch, Schlagbraten) ausgehauen und unter den Sippengenossen ausgelost. Da gab es Ruckbraten (mit dem Ruckbein), Diechbraten (mit dem Diechbein, Schenkelbein), Brustbraten (mit dem Brustbein) und Kehlbraten (mit dem Kehlbein). Diese Knochenbezeichnungen und eine Menge anderer (Schale, Pfanne, Blatt, Hüfte etc.) lassen auf eine sorgfältige anatomische Beobachtung des $\mathrm{Kn}$ ochenger üstes schließen. Man wußte aber auch das harte Bein von dem beim Schnitte knarrenden Knarpel (Knorpel) wohl zu unterscheiden und $\mathrm{zu}$ benennen und hatte ebenso für die nicht brätigen (fleischigen) Weichteile besondere Benennungen. Man sprach von Mark, von Bändern (althochd. bant, bentir), von Fasern (althochd. fusa, faso), von Sehnen (althochd. scnawa), die mit den Nerven zusammengeworfen wurden, und wie wir oben gesehen haben, auch von Adern (althd. âdara), worunter man alle Rohrgänge für den Lebenssaft, für Luft, Wasser und Blut zusammenfaßte.

Wenn ich mir auch nicht verhehlen kann, daß die im Vorangehenden geschilderte Opferanatomie der alten Kulturvölker noch manche Lücken aufweist, und wenn sie sich auch fast ausschließlich auf Haus- und Wildtiere bezieht, so ist doch so viel sicher, daß dieselbe sehr viel zur Entstehung und Weiterentwickelung anatomischer Kenntnisse von den Innenorganen des tierischen Körpers beigetragen und in zweiter Linie vergleichende Vorstellungen von der Beschaffenheit des menschlichen Körpers erweckt hat. Kann man doch täglich noch im Verkehr mit dem Volke hören, wie dieses oder jenes Tier, namentlich aber das Schwein, im „Innern ganz wie der Mensch beschaffen sei". 


\section{Opferschau-Anatomie.}

Auf das engste mit der Opferanatomie verbunden und ohne diese nicht denkbar ist die Opferschau-Anatomie, welche man als eine Vorstufe der topographischen und pathologischen Anatomie betrachten kann, weil hier der Opferpriester nicht bloß die Körperteile im Groben zu zerlegen, sondern auch genau auf ihre Lage und ihr Aussehen außen und im Durchschnitt zu achten hatte, um daraus auf diese oder jene künftigen Ereignisse, auf Glück oder Unglück zu schließen.

Die Befragung der Gottheit aus den Eingeweiden geopferter Tiere geht bis in die ältesten Zeiten der Kulturvölker zurück. Daß die alten Babylonier diesem Verfahren gehuldigt haben, erfahren wir schon aus der bekannten Stelle Hesekiel 21, 21: „Der König von Babel wird sich an die Wegscheide stellen, vorn an den zwei Wegen, daß er ihm wahrsagen lasse, mit den Pfeilen um das Loos schieße, seinen Abgott frage und schaue die Leber an." Einen direkten Belag fand ich in einer Inschrift des Königs Agum-Kakrumi: „Da befragte ich den König (Gott) Samas vermittelst eines Lammes des Opferschauers." Wenn einmal die tausende von Tontäfelchen aus der Bibliothek Assurbanipals entziffert sind, wird sich wahrscheinlich auch die ganze babylonisch-assyrische Opferschau-Anatomie enthüllen. Vorerst sei nur noch kurz der auf mesopotamischem Boden aufgefundenen Ziegenleber aus Terracotta Erwähnung getan, welche zu auguralen Zwecken gedient hat und im nächsten Abschnitt näher besprochen werden wird.

Über die ägyptische Opferschau äußert sich G. Wilkinson in seinem Werke ,Manners and Customs of the ancient Egyptians, Lond. I841, Vol. I, p. 143: „The inspection of the entrails of victims was deemed highly important among the Egyptians."

Durch ganz Kleinasien war das augurale Opferschauwesen verbreitet, namentlich war die Stadt Telmessos in Karien durch die hochentwickelte Disziplin ihrer Opferschauer berühmt. *)

Von Kleinasien auf Griechenland übergegangen entwickelte sich diese Disziplin zu hoher Blüte. Wie in Karien Telmessos, so zeichnete sich in Griechenland Elis im Peloponnes durch das Ansehen seiner Hieroskopie aus, so daß sich noch Cicero**) über

*) Cicero, de divinat. lib. I, 4I, S. 20 I.

*) Cicero, de divin. lib. I, 4I, S. 201. 
dieselbe in rühmenden Worten äußern konnte: „Itemque Elis in Peloponneso familias duas certas habet, Iamidarum unam, Clytidarum alteram, haruspicinac nobilitate praestantes." Daß die in Olympia im Dienste des Zeus ansässigen Iamiden als erfahrene Opferschauer in besonderem Rufe standen, wird auch von Pindar (Ol. 8, 2 f.) bezeugt.

Während in vorhomerischer Zeit aus dem Verlauf des Opfers und den zurückgebliebenen Aschenresten geweissagt wurde, geschah dies nach Homer aus der normalen oder nicht normalen Beschaffenheit des Opfertieres überhaupt und aus der Lage und Beschaffenheit der Eingeweide, vor allem der Leber. Im Suchen nach dem Urheber dieser Opferschausitte verfielen die Griechen auf denselben Heros, dem sie auch die Erfindung des Feuerzündens zuschrieben. Bei Äschylos (Prom. 494) rühmt Prometheus von sich, er habe den Sterblichen angezeigt, welche Glätte und Farbe die Eingeweide haben müßsten, um den Göttern wohlgefällig zu sein, namentlich die mannigfachen Wohlgestalten der Gallenblase und des $\lambda o ́ \beta 0 s$.

Schömann*) sucht die Entstehung der Hieroskopie psychologisch zu erklären. „Fand sich in den für die Götter bestimmten Eingeweiden irgend etwas Fehlerhaftes, Abnormes, Ungesundes, so mußte dies bedenklich máchen, ob ein solches Opfer auch den Göttern angenehm sei.“ „War nun aus solchen Gründen einmal der Glaube an die Bedeutsamkeit der Eingeweide entstanden, so verfiel man dann bald auch auf genauere Bestimmungen; man unterschied die verschiedenen Teile der Eingeweide und die verschiedenen Abnormitäten, die bei jedem vorkommen möchten und sammelte vermeintliche Erfahrungen über die Bedeutsamkeit eines jeden, so daß hieraus ein künstliches Lehrgebäude der Hieroskopie entstand, dessen abstruse Feinheiten nur dem Unterrichteten bekannt waren, wenn es gleich auch gewisse allgemeine Sätze gab, die jeder kannte und danach zu beurteilen imstande war, ob das Opfer von erwünschter oder unerwünschter Beschaffenheit sei."

Nicht alle Tierarten wurden gleicherweise zur Eingeweideschau herbeigezogen, am häufigsten Rinder, Kälber, Böcke, Ziegen, Schafe, Lämmer und Schweine; Hunde niemals. Über die Art der Opferschau findet sich eine Notiz in Schol. Aristoph. Vesp. 834:

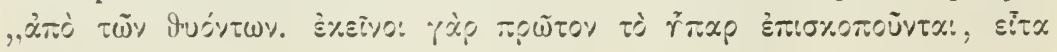

") G. F. Schömann a. a. O., 2. Bu., S. $29+f$ f. 


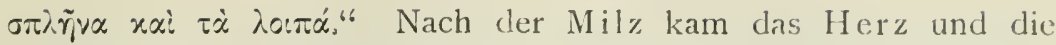
L unge an die Reihe. Die Leber aber und die Gallenblase wurden immer zuerst besichtigt. Die Jamiden in Olympia aber weissagten nicht bloß aus den Eingewciden der Opfertiere, sondern auch aus den Häuten, die sie zerschnitten und aus den Opferst ücken, die sie verbrannten. *)

"Als das wichtigste unter den Eingeweiden wurde die Leber betrachtet, nicht bloß deswegen, weil ihre normale oder abnorme Beschaffenheit am leichtesten in die Augren fiel, sondern mehr noch, weil man sie als Hauptorgan des animalischen I,ebens ansah, in welchem das Blut, der eigentliche Träger des Lebens, bereitet und von dort aus durch den ganzen Körper verbreitet werde".***) Bei Philostr. V Apoll. VIII, 7, I5 heißt es: ", $\mathrm{H} \pi x p$ हेy

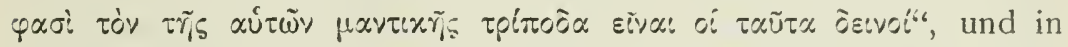
dem Dialog Hermippus de astrologia, ed. Bloch, Hav. 1830: "rर $\gamma \dot{\alpha} \rho$

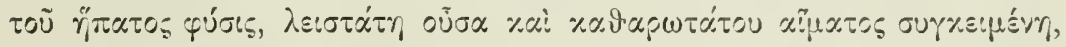

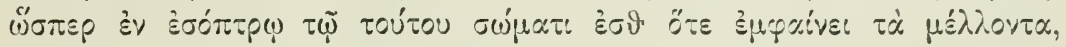

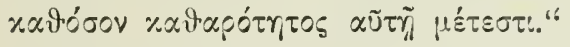

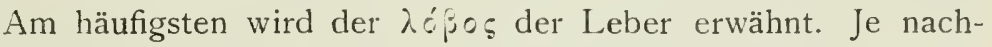
dem dieser beschaffen war, fehlte oder sich als mangelhaft erwies, erblickte man gute oder schlimme Vorzeichen. Als sehr schlimm

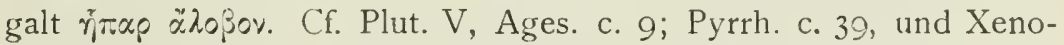
phon Hellen. III, 4, I 5. Euripides läßt den vor seinem Tode opfernden Ägisthes keinen $\lambda o ́ \beta o s$ finden. Dem Kimon zeigte vor seinem

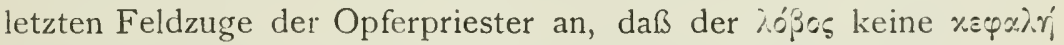
habe. - Auch andere Teile der Leber, die rú’a: (Pforten), die

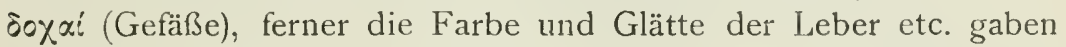
wichtige Aufschlüsse. Allmählich hatten sich in der Sprache der griechischen Opferschauer eine Menge Bezeichnungen für einzelne Leberteile eingebürgert, die den Uneingeweihten späterer Zeit immer unverständlicher wurden. Außer dem ióßos, den $\pi \dot{u} \lambda \alpha \varkappa$ und den

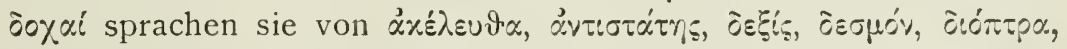

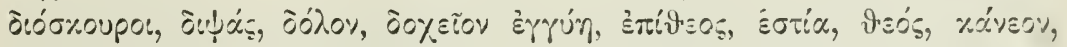

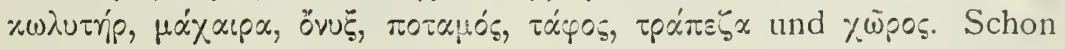
ältere Schriftsteller über das Opferschauwesen der alten Griechen haben sich Mühe gegeben, über die Bedeutung dieser rätselhaften Benennungen Aufschluß zu gewinnen. Ich nenne vor allem den

*) G. F. Schömann a. a. O., II., 2jS.

*) G. F. Schömann a. ג. O., II.. 291. 
oben erwähnten Phil. Jac. Hartmann (de origine anatomes, p. $16 \mathrm{ff}$.), J. Müller (de extipiciis) und Corn. Cunz (de Graecorum extipiciis). Durch Schol. Nicandr. Ther. 560 wurden sie nicht klüger. Denn

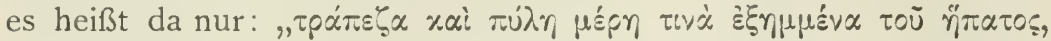

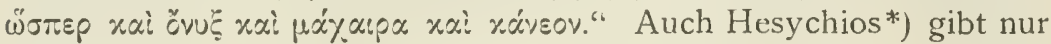

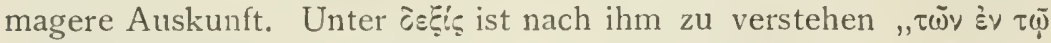

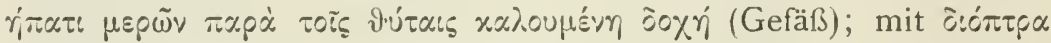

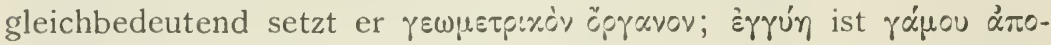

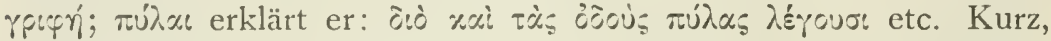
für den Forscher nach dem Wesen der altgriechischen OpferschauAnatomie ist durch alles dies nicht viel gewonnen.

Nun ist es ungemein interessant, daß sich auch der große Anatom Vesal mit dieser dunklen Frage beschäftigt hat. Ihm sind die besonderen Namen, welche die Griechen einzelnen Schafsleberteilen gegeben haben, wohl bekannt, aber wenn er sich veranlaßt fühlte, bei vieren derselben den lateinischen Namen beizusetzen, so stützte er sich dabei nicht auf die Form, sondern auf die angenommene Physiologie dieser einzelnen Teile.

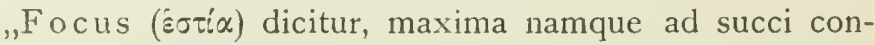
coctionem facit, quemadmodum concoquendis cibariis focus;

Mensa ( $\rho^{\prime} \alpha \varepsilon_{\zeta \zeta} \alpha$ ), quod mensae vices gerit, nam membrorum alimenta in ipsa apponuntur;

Culter ( $\mu \dot{\alpha} \gamma \alpha: p \alpha)$, dividit enim, segregat inter se humores, aut si quid crassius distribuendum est, id secat atque commutat;

A uriga (rivio\%०5) nomine appellatur, nam naturales vires jam excoctas humores bene regunt atque in melius recta ducunt."

Wir sehen also, Vesal geht von der alten Annahme des Gekochtwerdens des Speisebreis in der Leber aus, läßt es aber im übrigen ganz unentschieden, welche einzelne Leberteile unter den vier aufgeführten Namen gemeint sind.

Über die $\pi u^{\prime} \lambda \eta$ ( $\pi \dot{\prime} \lambda \alpha$ ) sich zu äußern, hat Vesal augenscheinlich nicht für nötig gefunden, denn dieser Name wurde schon von der Zeit des Hippocrates her für den Abschnitt der Leber gebraucht, den wir heute noch als porta hepatis bezeichnen. Um aber einzelne der anderen griechischen Worte auf bestimmte Leberabschnitte zu deuten, dazu bedurfte es des Zusammenwirkens eines

") Hesychii Alexandrini Lexicon ex recens. Maur. Schmidt, Jen. MDCCCLXV. 
Philologen (Dr. Deecke) und eines Anatomen (Prof. Dr. L. Stieda). Die Veranlassung für den Straßburger Philologen Deecke bildete die im Jahre 1877 bei Piacenza erfolgte Auffindung einer aus Bronze verfertigten Leber, von welcher im nächsten Abschnitt des Näheren die Rede sein wird. Von Deecke zuerst für ein etruskisches templum gehalten, wurde das seltsame Gebilde bald darauf von demselben Forscher als eine Tierleber mit sorgfältiger Wiedergabe der Partien auf der unteren (hinteren) Fläche erkannt. Das Ergebnis seiner Forschungen war nun, daß die Griechen (und die Etrusker) $\mathrm{zu}$ auguralen $Z_{w e c k e n}$ nur die Leber vom Rind (auch Kalb), vom Schaf und der Ziege verwendet haben und daß sich wenigstens einzelne der alten Bezeichnungen recht wohl auf einzelne Partien einer solchen Tierleber deuten lassen, wie schon Corn. Cunz zur Erklärung der alten Namen die Zeichnung einer Schafsleber verwendet hatte.

Der $\lambda o ́ \beta \circ \zeta$ (auch $\left.x \varepsilon \varphi \alpha \lambda \eta^{\prime}\right)$ der Griechen ist von Deecke auf das gedeutet worden, was die Römer mit „,caput fibrarum" bezeichnet haben. Als diese $\chi \varepsilon \varphi \varphi \lambda \lambda \eta^{\prime}$ hat Prof. Stieda den processus pyramidalis (processus candatus der Autoren) festgestellt, welcher beim Rind, Schaf und bei der Ziege der Hinterfläche des rechten Leberlappens als stumpfe Pyramide aufsitzt und besonders stark bei der Rindsleber entwickelt ist.

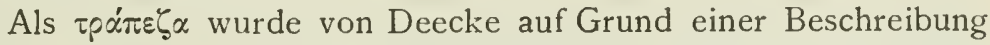
Nicanders der Teil des rechten Leberlappens erklärt, auf welchem sich der oben genannte processus pyramidalis erhebt, eine Deutung, welche von dem Anatomen Stieda nicht beanstandet wurde.

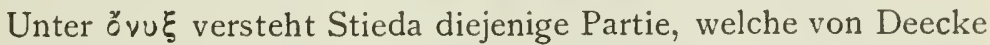
in der Bronzeleber (siehe nächsten Abschnitt) als 1/4 Ellipsoid bezeichnet wurde. Der Name övo $\xi$ ist insofern ganz geschickt gewählt, weil das Gebilde wirklich mit einer Daumenspitze Ähnlichkeit hat. Es ist der processus papillaris der Rinds-, Schafs- und Ziegenleber.

Die $\varepsilon \sigma \tau i \alpha$ verlegt Deecke in den oben breiteren Teil des zwischen beiden Leberlappen eingeschobenen Keils, auf welchem sich der ơv $v \xi$ erhebt. Nach Stieda kann es wohl nichts anderes sein, als der Lob. Spiegelii (Lob. posterior).

Was nun weiter die $\mu \alpha^{\prime} x \alpha i p x$, das \%óveov und den rivioxos betrifft, so ist eine Erklärung vorerst und vielleicht auch für spätere Zeiten aussichtslos. Es handelt sich nach Stieda wahrscheinlich um seltenere Varietäten an der Schafsleber, die ja an und für sich 
zu Varietäten sehr geneigt ist. Es dürfte daher angezeigt sein, ein ,ignoramus" offen auszusprechen und auf ein event. günstigeres späteres Zusammenarbeiten der Philologie mit der wissenschaftlichen Anatomie zu hoffen.

K. O. Müller*) will es dahingestellt sein lassen, ob die griechische Opferschau unmittelbar von Asien resp. Kleinasien, oder mittelbar von den Etruskern überkommen ist. Als das ältere, im Norden und Nordwesten Griechenlands ansässige Volk werden wohl die Etrusker einen namhaften Einfluß auf die religiöse Kultur der Griechen ausgeübt haben, daneben aber ist der rege Verkehr, in welchem die Griechen mit Kleinasien und sogar mit dem mesopotamischen und persischen Innerasien standen, wohl $\mathrm{zu}$ beachten. Daß übrigens die Etrusker zu Lehrmeistern in der Opferschau wohl geeignet waren, wie sie ja historisch als die Lehrmeister der Römer im ganzen Sakral- und Auguralwesen nachgewiesen sind, dafür spricht das Zeugnis, das ihnen Cicero ausstellt, wenn er***) sagt: „Etrusci autem quod religione imbuti studiosius crebrius hostias immolabant, extorum cognitioni se maxime dediderunt."

Neben den oben erwähnten hostiae animales hatten sie hostiae consultatoriae, um den Willen und Rat der Götter aus den Eingeweiden zu erkennen. Die Befragung als primärer Zweck des Opfers (consultatoria sacrificia) kann sogar als rein etruskisch bezeichnet werden, ${ }^{*} *$ ) während bei den vorderasiatischen Völkern die Weissagung erst sekundär zu dem Opfer hinzukam.

K. O. Müller $\dagger$ ) hält es für wahrscheinlich, daß die verschiedenen Eingeweide verschiedenen Göttern angehörend gedacht wurden. Man weiß wenigstens, daß die Galle nach der Lehre der etruskischen haruspices dem Neptun gehörte und auf Glück oder Unglück durch Wasser schließen ließ. Und aus einer Stelle bei Cicero $\dagger$ ) ist zu entnehmen, daß es ein Eingeweide gab, dessen Beschaffenheit über Gefahr durch Feuer Aufschluß gab. Auch hatten die Eingeweide ihre verschiedenen Seiten (wie ein templum), die Leber z. B. eine pars familiaris und eine pars hostilis; strotzende Adern der feindlichen Seite bedeuteten Unglück. Überhaupt war

") Die Etrusker, II., S. 185.

") Cic. de divin. I., 42.

***) K. Eckermann a. a. O., 2. Bd., S. 18 ; l.

†) K. O. Müller a. a. O. II., S. 178 .

t†) Cic. de divin. II., 13, 32 . 
die Leber, wie bei den Griechen, das wichtigste Divinationsorgan, das in allererster Linie beachtet wurde. Die Lappen hießen in der Sprache der Griechen $\tau \dot{\alpha} \alpha \ddot{x}$ p $\alpha$, die oben erwähnte pyramidenförmige Protuberanz auf der Unterseite des rechten Lappens nannten sie caput hepatis. Der Mangel des caput bedeutete Untergang, die Verdopplung Entzweiung, ein Schnitt darin (caput fissum) Aufhebung des gegenwärtigen Zustandes.

Andere Eingeweide wurden erst in zweiter und dritter Linie zur Weissagung herangezogen, das $\mathrm{Herz}$ z. B. erst nach dem Kriege des Pyrrhus beobachtet. Alle Eingeweide aber wurden nach äußerlicher sorgfältiger Besichtigung zuerst gesotten, wobei auf etwaiges starkes Schrumpfen als ein böses Zeichen sorgfältig geachtet wurde, und dann kunstgerecht zugeschnitten den Göttern als Brandopfer dargebracht.

Unsere Kenntnis von der römischen Opferschau-Anatomie wäre umfassender, als die von jedem anderen Kulturvolke, wenn nicht leider die Schrift des P. Nigidius „de extis“ (Gell. Ió, 6) verloren gegangen wäre. So sind uns nur Bruchstücke überliefert worden, aus denen wir uns ein annähernd richtiges Bild dieser wichtigen Disziplin der Römer konstruieren können. Das meiste und wertvollste Material hat uns Cicero in seiner mehrfach zitierten Schrift „De divinatione“ hinterlassen. Wir ersehen daraus, daß die Römer das ganze Opferschauwesen mit der damit verbundenen Wahrsagung von den Etruskern übernommen haben.*) Es gab, wie wir weiter aus Livius 40, 29, I4 erfahren, ein collegium victimariorum, dessen Mitglieder von den Magistraten bei den Opfern verwendet wurden; die eigentlichen Opferschauer und Wahrsager aus den inneren Organen der Opfertiere waren die extipices oder haruspices. Schon darüber, ob das Opfer den Göttern angenehm sei, oder nicht, hatten die haruspices durch Besehen der exta zu entscheiden; in zweiter Linie kam dann erst die Beantwortung der Fragen, welche durch das Opfer an die Gottheit gestellt wurden. Dies mußte natürlich eine peinlich-sorgfältige Besichtigung der exta bezüglich ihrer äußeren und inneren Beschaffenheit zur Folge haben.

Wie schon oben erwähnt, waren die entscheidenden exta der Rangordnung nach die Leber, die Gallenblase mit Galle, die Lunge, das Herz und das Netz. (Das Wort scrutinium [Erfahrung] ist aus der ursprünglichen Bedeutung "Gekröse“ in den

") Cicero de div. lib. 1, 2, S. I2. 
gewöhnlichen Sprachgebrauch übergegangen.) Da das ganze Opferschauwesen von den Etruskern übernommen wurde, so ist es nur natürlich, daß auch bei den Römern die L e ber als wichtigstes extum die erste Stelle einnimmt. Auch die Römer unterschieden eine pars inimica und eine pars familiaris; ferner wurde das fissum auf jeder Fläche besonders beobachtet, vor allem aber wurde auf das caput jecoris geachtet. „Fissum familiare et vitale tractant,“ sagt Cicero.*) „Caput jecoris in omni parte diligentissine considerant; si vero id non est inventum, nihil putant accidere potuisse fristius." War das caput doppelt, so galt dies als Zeichen der Entzweiung, war es bloß gespalten, so schloß man auf ein Ende des gegenwärtigen Zustandes. Gewöhnlich benützte man eine Schafsoder Ziegenleber, oder ein ,tauri opimi jecur“, aber auch die Leber und Gallenblase eines Huhns wurde zur Wahrsagung herbeigezogen, wie aus der Bemerkung Ciceros (1. c.) hervorgeht: „non dicam gallinuceum fel (sunt enim, qui vel argutissima haec exta esse dicunt".

Es gilt nun, die verschiedenen Kunstausdrücke der haruspices über ihre Leberbefunde mit den Ergebnissen der wissenschaftlichen Anatomie in Einklang zu bringen. Darüber, daß das Wort „fibra“

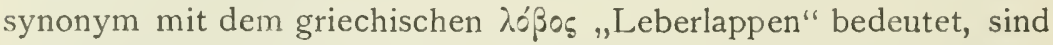
alle Philologen und Anatomen einig. Ebenso kann wohl kein Zweifel darüber obwalten, daß unter dem „, caput jecoris" ( $\alpha \varepsilon \varphi \alpha \lambda \eta^{\prime}$ der Griechen) der processus pyramidalis auf der Unterseite des rechten Leberlappens zu verstehen ist. Was aber die zwei weiteren technischen Ausdrücke „fissum" und „,cella e“ betrifft, die Deecke**) philologisch zu erklären bemüht ist, so befindet er sich augenscheinlich im Irrtum. Fissum soll, wie das griechische $\delta เ x \sigma \propto \alpha \dot{\gamma} \gamma \eta$, die Einund Austrittsspalte eines Blutgefäßes bedeuten. Da aber das fissum, wie oben erwähnt, auf jeder Leberfäche besonders beobachtet wurde und auf der Vorderfäche der Leber kein Blutgefäß einoder ausmündet, so kann es sich, dem gewöhnlichen Sinn des Wortes fissum (Trennung, Furche) entsprechend, nur um die Trennungsfurche handeln, welche auf der Vorderfäche das ligamentum suspensorium, auf der Hinterfläche das ligam. teres (mit der fossa longitudinalis sinistra) bilden. - Weiter sagt Deecke, der lateinische

") Cicero a. a. O., lib. II, 12, S. 3401.

$\left.{ }^{* *}\right)$ Etrusk. Forschungen und Studien von Deecke und Pauli, 2. Heft, Stuttgart 1882 . 
sakrale Name für $\pi u ́\rangle \eta$ sei .,cella" gewesen. Deecke bezieht sich dabei auf eine Stelle bei Ph. J. Hartmann (s. oben), wo es heißt: „Diversae sunt Venac, quas haruspices cellas iccunt, hostium, animalium, amicorum et alia hujusmodi. Cum ergo accipiunt jecinora, intelligunt, quae cella nec eat, quae pars saliat, igitur dum vident de hostili parte venarum pulsus emergere, significare proelium recognoscunt." (Vetus interpres Lucani in Pharsal. apud Brissonium L. 1 de formulis.) Stieda ) ist vollständig im Rechte, wenn er sagt, daß hier "cella" nicht die Bedeutung von $\pi u ́\rangle . \eta$, sondern die eines Blutgefäßes resp. eines Raumes habe, den ein durchschnittenes Blutgefäß (hier die Venen) einnehme. Der Ausdruck sei sogar recht gut gewählt, denn wenn man die Leber und die einzelnen Lappen durchschneidet, was die alten haruspices sicher getan haben, so sehe man eben Löcher und das seien die cellae.

Gegenüber der vorwiegenden Bedeutung der Leber spielten die übrigen exta eine untergeordnete Rolle. Bei der Lunge wurde offenbar auf das Vorhandensein tiefer Einziehungen geachtet, cf. Cic. L. c.: "Quid enim habet haruspex, cur pulmo incisus etiam in bonis extis dirimat tempus et proferet diem?" - Auch das Herz wurde auf Lage, Größe, Fettbelag etc. auf das Sorgfältigste untersucht und nicht immer in normalem Zustande befunden; wenn aber Cicero wiederholt (1. c. I, 52, S. IO9 und II, ${ }^{\circ}$ I2, S. 29) berichtet: „In extis bovis opimi cor non fuit," so ist nach dem Zweifel, den er dem ganzen Opferschauwesen überhaupt entgegenbringt, zu schließen, daß er diese Märe nicht geglaubt, sondern für einen Trug der haruspices gehalten hat.

"Quid habent (exta) naturale," ruft er aus, **) „quo declarari possit, quid futurum sit?" Er kann es nicht begreifen, daß das einemal Feuersgefahr, ein andermal eine Erbschaft, ein drittesmal Verluste durch eine Leber, ein Herz oder eine Lunge angezeigt werden sollten. Andere denkende Männer vermochten es auch nicht, und bekannt ist ja das geflügelte Wort, daß kein haruspex einem anderen begegnen könne, ohne zu lachen. Die Versuche des Kaisers Claudius, ${ }^{* *}$ ) durch ein Senatus consultum der Opferschaudisziplin wieder aufzuhelfen, sprechen deutlich von dem Verfall, in den dieselbe schon damals geraten war.

*) L. Stieda a. a. O., S. 27.

"*) De divin. II., I 2 p. 340 .

***) Tacit. Annal. I I, I 5 . 
Die Nachrichten über die Opferschau-Anatomie der Kelten sind so dürftig, als die über ihr Opferwesen überhaupt, wenn auch gerade diese wenigen Überlieferungen auf ein ausgedehntes Opferwesen schließen lassen. Die Druiden lehrten ja, Opfer seien der Gottheit willkommene Gaben, aber kein Opfer durfte gebracht werden, aufer durch Vermittlung der Druiden. ${ }^{*}$ ) Strabo, Diodor und Tacitus bezeugen den Druiden die Kenntnis der haruspicina. Ganz speziell waren es die zur Eubutesklasse gehörenden Druiden, welche als die privilegierten Erforscher der Zukunft galten. Lampridius (Vita Alexandri Severi I, c. 27, p. 276) nennt die Vascones als die Kundigsten unter den haruspices und bestätigt damit den Ausspruch des Livius $(\mathrm{V}, 34)$ : „Augurandi studio Galli praeter ceteros callent."

Strabo (IV, I97) und Diodor (V, 3I) wollen erfahren haben, daß in kritischen Augenblicken ein Mensch geopfert worden sei, indem man ihn durch einen Stich über dem Zwerchfell getötet habe, worauf dann namentlich aus der Art des Hervorströmens des Blutes geweissagt worden sei. In den allermeisten Fällen aber waren es Tiere, deren Eingeweide zur Vorhersage benutzt wurden. Dieser Brauch setzt sich sogar bis in die christliche Zeit hinein fort. Noch Ivo (XI, 9 und 64) kennt die Darbringung von Opfertieren und die Tätigkeit der haruspices. Ivo spricht (XI, 4) von "magorum et haruspicum libri et notae, quas "characteres" vocant". Die Opferschau war mit schweren Strafen bedroht, aber noch in dem Capitularium vom Jahre 730 ist von dieser Art von Divination die Rede, und die heidnischen prophetischen Bücher blieben immer noch in Gallien im Umlauf.**)

Nach welchen Prinzipien bei der keltischen Opferschau verfahren wurde, welche Organe man besonders bevorzugte und welche Eigenschaften als günstig oder ungünstig galten, darüber fehlen uns genauere Berichte.

Auch die Opferschau-Anatomie der Germanen, wie wir sie kennen, muß gegenüber der gut bekannten Opfer-Anatomie als ein mageres Bruchstück bezeichnet werden. Einiges ist sicher festgestellt, manches andere ist bloß wahrscheinlich. Sicher ist, daß bei der Opferung Kriegsgefangener aus der Art, wie das Blut

*) Dr. C. Barth, die Druiden der Kelten und die Priester der alten Deutschen. Erlang. I 826, S. 96.

") K. Eckermann a. a. O. Bd. III, S. $78 \mathrm{f}$. 
herausströmte, geweissagt wurde, sicher ist auch, daß die edlen für die Gottheit bestimmten Innenteile der Tiere nur dann dargebracht werden durften, wenn sie bei genauer Besichtigung frei von pathalogischen Veränderungen und frei von Eingeweidewürmern und anderen Innenschmarotzern befunden wurden. Solche Opfertiere hieß man ,zehbar" (althochd. zëbar = Opfertier, das geopfert werden kann). Der Gehirnegelwurm, Würmer in der Leber und andere Schmarotzer, die dem Gode gewiß nicht entgingen, machten das Eingeweide „unzehbar".

Im übrigen wurde aus den losgelösten Teilen aus der sogen. „Losung" geweissagt. Höfler hält es für wahrscheinlich, daß zunächst die Lage der Organe und das bei der allgemeinen Stille wohl hörbare Geräusch bei Herausnahme derselben bestimmend gewirkt haben; nächstdem aber die allgemeine Blutfülle und der Blutreichtum der einzelnen Organe (weiße Leber sogen. Milchleber, Brustbeinröte etc.). Weissagung aus der verschiedenen Blutfülle der Vorder- und Hinterteile des Gänsebrustbeins war nach Jahn*) in Deutschland noch lange ebenso gebräuchlich, als die Weissagung aus den ins Wasser abtropfenden Fettteilen.

Eine andere Vorhersage beim altgermanischen Opfer gründete sich auf die Lage der Milz. Und ganz zuletzt, wenn der Opferschmaus vorbei war, wahrsagte man noch (althochd. liezen) aus dem Opfer (althochd. hlaut), indem man die Knochenabfälle in die Tierhaut sammelte und das Innengeräusch behorchte.

Wenn ich nunmehr in kurzem die Opferschau-Anatomie der Hebräer erst in letzter Reihe erwähne, so geschieht es aus dem Grunde, weil dieselbe eine gesonderte Stellung einnimmt. Das Weissagen aus den Eingeweiden der Opfertiere war dem gläubigen Hebräer ein Greuel, um so strenger hielt er an den mosaischen Satzungen bezüglich der Beschaffenheit der inneren Teile der Opfertiere. Seine Opferschau-Anatomie war eine rein rituelle, darauf hinzielend, daß ja nicht ein Tier geopfert oder verzehrt werden sollte, das diese oder jene im Gesetz bezeichneten pathologischen Veränderungen an den inneren Organen aufwies. So entwickelten sich mit der Zeit bei den Opferschlächtern ziemlich genaue Kenntnisse von der normalen und pathologischen Anatomie der Schlachttiere. Die Mischna**) nennt als arepha, d. h. zerrissenes Tier, ein

") Deutsche Opfergebräuche S. 234.

*) J. Preuf a. a. O., Handbuch der Geschichte der Medizin, Bd. I, S. I I 3 ff. 
solches, bei welchem sich Verletzungen an inneren Organen finden, die, wenn das Tier nicht geschlachtet worden wäre, den Tod desselben in absehbarer Zeit verursacht hätten, nämlich: Perforation des oesophagus, Abreißung der trachea, Perforation der Hirnhaut, perforierende Herzwunden, Bruch der Wirbelsäule mit Trennung des Rückenmarks, vollständige Entfernung der Leber, Perforation oder Defekte der Lunge, Perforation des Magens oder Darmkanals, Perforation der Gallenblase. Dagegen gaiten merkwürdigerweise der Mischna nicht als lebensgefährlich: Entfernung der Milz, der Nieren, des uterus, größerer Leberteile, fistulöse Kommunikation $z$ wischen Netzmagen und Blättermagen, Tatsachen, die auf einen hohen Stand der in Alexandria erworbenen VeterinärAnatomie und Veterinär-Chirurgie der hebräischen Ärzte schließen lassen.

\section{Primitive anatomische Bildnisse.}

a. Körperteile in der Bilderschrift.

Als die ältesten bildlichen Darstellungen von Körperteilen sind die Hieroglyphen in Gestalt äußerer und innerer Organe zu betrachten. Schon die Sumerer, die ins 4. bis 5. Jahrtausend v. Ch. zurückreichenden Vorläufer der Babylonier und Assyrer, hatten in ihrer Schrift reichlich Bilder von Körperteilen, doch bleibt nach v. Oefele für den Nichtfachmann der Ersatz dieser Bilder durch die spätere Keilschrift unverständlich.

Einen viel besseren Einblick über die Verwertung von Körperteilen gewinnen wir in der ägy ptischen Hieroglyphenschrift. Schon in dem phonetischen Teile der Hieroglyphenschrift, welchen man als alphabetischen bezeichnet, finden sich Bilder des Mundes, des Auges, des Knies, des Arms, der Hand etc.; noch viel häufiger aber stoßen wir auf Bilder von Körperteilen in den zahlreichen Silben- und Wortzeichen. Ganz besonders wichtig für unsere Frage sind die zu dem ideographischen Elemente der Hieroglyphen gehörenden, hinter den lautlich geschriebenen Wörtern stehenden Determinativa, weil man die in der Schrift erwähnten Körperteile sofort erkennen kann. Bei inneren Organen ist die Erklärung des Dargestellten schwieriger, doch gibt es auch einige, die man leicht versteht. Das Herz z. B. erscheint in Gestalt eines auf stumpfer Spitze stehenden, breiten, kurzen 
Kegels, dem zwei Henkel und oben ein Hals angesetzt sind, so daß das Ganze einer Urne gleicht, wie es nachstehende Figur sichtbar macht*):

Die Lunge figuriert in den ägyptischen Hieroglyphen immer als 6-lappig in Analogie mit der 6-lappigen Säugetierlunge, welche man eben lange vor der 5-lappigen Menschenlunge kennen gelernt hatte.

b. Bildliche Darstellungen aus der Opfer-Anatomie reihen sich dem Alter nach an die Hieroglyphen-Anatomie an und mögen wohl einst ziemlich häufig gewesen sein, doch konnte ich in der ganzen mir zugänglichen Literatur nur einige wenige derartige Bilder in dem mehrfach erwähnten Werke von Wilkinson finden. Dort sind auf einem Textbilde nach einem altthebanischen Wandgemälde neun Teile eines Rindes als besonders gewählte Opferstücke gezeichnet. Fig. a) stellt dar ein Hinterviertel, b) ein Oberschenkelstück mit dem Schenkelknochen, e) ein Rippenstück, f) ein Schwanzstück mit dem Schwanz, g) wahrscheinlich ein Schulterstück und h) wieder ein anderes Rippenstück.

Was uns aber ganz besonders interessiert, sind Abbildungen dreier innerer Organe.

Fig. c) zeigt das Herz in der gewöhnlichen Form seiner Darstellung. Der Zapfen an der Basis des Kegels soll wahrscheinlich die durchschnittenen großen Blutgefäße darstellen.

Fig. d) zeigt die durch einen gebogenen Strang miteinander verbundenen Nieren und zwar nicht in der gewöhnlichen Bohnenform, sondern beerenförmig. Ohne Zweifel kann dieses Nierenbild als das älteste bekannte angesehen werden.

Fig. i) kann der ganzen Form nach nur die Leber sein, allerdings mit Andeutung dreier Lappen. Wenn die weiter unten zu beschreibende babylonische Auguralleber wirklich das ihr zugeschriebene Alter hat (3. Jahrtausend v. Ch.), so folgt jedenfalls die thebanische Opferleber an zweiter Stelle. Doch sind hierüber noch genauere Untersuchungen abzuwarten.

*) Nach Horapollon sollen die Ägypter, um das Herz darzustellen, auch einen Ibis gezeichnet haben, das heilige Tier des Hermes, des Gebieters über alle Eigenschaften des Geistes und des Gemütes. Mit Rücksicht auf die dem Herzen zugeschriebenen Eigenschaften habe man der oben gezeichneten Hieroglyphe die des Ibis gleichgesetzt. Nach Ebers ist es vielleicht möglich, daß man den Ibisvogel auch äußerlich mit dem Herzen zusammengebracht hat, weil die Ibismumien in der Tat einem menschlichen oder tierischen Herzen ähnlich sehen. 
c. Bildliche Darstellungen aus der OpferschauAnatomie.

In den letzten Jahrzehnten des 19. Jahrhunderts wurde die wissenschaftliche Welt mit drei merkwürdigen plastischen Werken aus der Zeit der Blüte der auguralen Opferschau bekannt.

Im Jahre 1877 fand ein Bauer in der Gegend von Piacenza, also auf altetruskischem Boden, beim Pflügen ein Bronzegerät von ganz eigentümlicher Form, ähnlich einem der Länge nach durchschnittenen Ei mit einer nahezu ebenen und einer zweiten konvexen Fläche, I2,5 cm lang und im Maximum $8 \mathrm{~cm}$ breit. Das Stück gelangte später in den Besitz des Grafen Francesco Caracciolo, der es abzeichnen, photographieren und in Gips abformen ließ. Kapitän Vittorio Poggi, der es erstmals beschrieb, erklärte es für ein altetruskisches Amulet, der Straßburger Archäologe Deecke aber, der nachträglich damit bekannt wurde, wollte sofort die Nachbildung eines templum darin erkennen, d. h. eines zu auguralen Zwecken abgesteckten und nach den 4 Himmelsgegenden orientierten Raums. Er gründete seine Ansicht darauf, daß er in den Inschriften der I6 abgeteilten Randfelder auf der ebenen Fläche des Objektes die Namen von 16 etruskischen Gottheiten entziffert hatte, und gab diese Erklärung in einer eigenen Abhandlung*) in die Öffentlichlieit. Er dachte sich, daß das Objekt dem Augur, welcher es in der linken Hand hielt, als Mittel gedient habe, die Zukunft zu erforschen, indem dasselbe ein verkleinertes Bild der auf dem Wasser schwimmenden Erde dargestellt habe. Über die Bedeutung der übrigen Linien und Figuren auf der ebenen Fläche war er durchaus im Unklaren, ebenso über die Löcher auf beiden Seiten und die Querfurche auf der konvexen Fläche. - Eine andere Ansicht gewann Deecke erst, als er von Prof. G. Körte-Rostock darauf aufmerksam gemacht worden war, daß sich im Museum der Stadt Volterra eine Alabasterurne mit einer Deckelfigur befinde, welche ein dem Bronzeobjekte ähnliches Geräte in der Hand halte und daß dieses Geräte in Volterra von jeher für eine Leber gehalten worden sei. Vergleiche mit frischen Kalbs- und Schafslebern ergaben die Richtiglieit letzterer Ansicht, und so mußte auch das Bronzeobjekt für eine Tierleber und zwar speziell eine Schafsleber erklärt werden, dazu bestimmt, einesteils dem haruspex selbst

*) Dr. Deecke, Etrusk. Forschungen, 4. Heft. Stuttgar1 Alb. Heitz, 188o, mit Tafeln. 
zur Richtschnur bei seinen Weissagungen, andernteils etwaigen Schülern als Lehrobjekt zu dienen.

Nun wurden auf einmal auch die beiden Flächen mit ihren Linien und Figuren klar, so daß das Ergebnis der erneuten Untersuchung in einer zweiten Abhandlung*) niedergelegt werden konnte. Was früher als obere Fläche gedeutet worden war, wurde jetzt zur unteren und umgekehrt. Der auf der konvexen Oberfläche in annähernd sagittaler Richtung verlaufende Streifen entpuppte sich als ligamentum suspensorium, durch welches das ganze Gebilde in zwei Abschnitte, einen rechten und einen linken, geteilt wird. Von den 3 Erhöhungen auf dem rechten Abschnitt der Unterseite erliannte Deecke die dreiseitige Pyramide als eine der Säugetierleber eigentümliche pyramidale Protuberanz, welche er fälschlich Lob. Spigelii nannte, die aber in Wirklichkeit als processus pyramidalis (process. caudatus der neueren Autoren) zu bezeichnen ist. - Den seiner Länge nach fest aufliegenden, an der Basis kugelförmig abgerundeten Kegel, mit der Spitze nach hinten faßte er ebenfalls richtig als Gallenblase auf, ebenso richtig war die Deutung des sogen. ${ }^{1 / 4}$ Ellipsoids als processus papillaris des lobus (posterior) Spigelii, der wegen seiner häufigen Ähnlichkeit mit einer Fingerspitze oder einem Fingernagel von den Alten ¿̌vu६ genannt wurde.

Prof. Dr. L. Stieda hat in seiner Abhandlung „Archäologischanatomische Studien" die Deeckeschen Angaben nachgeprüft und richtig befunden, nur in Bezug auf die Erklärung des Lochs an der Spitze der Pyramide und der 3 Löcher auf der konvexen Oberfläche will er sich eines bestimmten Urteils enthalten. Er gibt wohl die Möglichkeit zu, daß das Loch am Vorderrande der Bronzeleber die vena umbilicalis andeuten, die zwei Löcher am hinteren Leberrand mit der an der Leber vorbeistreichenden vena cava inferior in Verbindung gebracht werden können, aber Alles nur vielleicht. Ebenso läßt er die Möglichkeit offen, daß das Loch an der Spitze der Pyramide ein unter dem process. pyramidalis verlaufendes Blutgefäß andeuten sollte.

Was die oben erwähnte Alabasterleber von Volterra betrifft, so wurde auch hier von Stieda die Deutung Deeckes als richtig befunden. Auf dem Deckel der Alabasterurne liegt, auf den 6 Tafeln.

*) Deecke u. Pauli, Etrusk. Forschungen und Studien, 2. Heft, Stuttg. I $8 \delta_{2}$, 
linken Arm gestützt, eine männliche Gestalt, die in der linken Hand eine auf einem Kissen ruhende Leber hält. Die konvexe Oberfläche derselben ist nach unten, die plane resp. konkave nach oben gerichtet; infolgedessen erscheint der vordere, ventrale Rand nach vorn dem Beschauer zugekehrt und der rechte Lappen nach links, der linke nach rechts gewendet. Man erkennt deutlich den Einschnitt im vorderen Rande, die kegelförmige Erhöhung und die dreiseitige Pyramide, während die dritte, auf der Bronzeleber sichtbare Erhöhung, der processus papillaris, wenn auch vielleicht vorhanden, auf der Photographie nicht zu sehen ist. Ebenso fehlen die Löcher, das Liniensystem und die Inschriften. Trotzdem ist nicht zu zweifeln, daß auch diese Schafsleber-Nachbildung, deren Alter nicht bestimmt werden kann, zu haruspicinen Zwecken gedient hat.

Als die merkwürdigste Lebernachbildung muß schon ihres Alters wegen die von Babylon gelten. Das Objekt, verfertigt aus bloß an der Sonne getrocknetem Ton, wurde von Mr. E. A. Vallis Budge 1889 in Bagdad erworben, nachdem es auf einem Platze wenige Meilen von Hillah gefunden worden war. Vallis Budge legte seiner ersten Mitteilung eine genaue Skizze von der Größe des Objektes bei und zwar beträgt dieselbe von rechts nach links (frontal) $13,5 \mathrm{~cm}$, die größte Dicke der rechten Hälfte $13 \mathrm{~cm}$, der linken Hälfte $12 \mathrm{~cm}$. Da das Gebilde somit in frontaler Richtung fast ebenso groß ist, als in sagittaler, so erscheint es fast viereckig mit einem hinteren konvexen und einem vorderen konkaven, stark eingeschnittenen Rande. Nach der Beschreibung Stiedas*) erkennt man auf der unteren (hinteren) Fläche wieder, wie bei der Bronzeleber, die dreiseitige, dem hinteren Rand des rechten Lappens nahe liegende Pyramide, den proc. pyramidalis der Säugetierleber; ferner wieder die Keule oder den Kegel mit ihrem verdickten, nach vorn gerichteten Abschnitt, nämlich die Gallenblase, und endlich wiederum links von der Pyramide das ${ }^{1}$, Ellipsoid Deeckes in Gestalt eines kleinen, flachen Vorsprungs, den process. papillaris der Säugetierleber.

Die ganze untere Fläche ist durch ein Netzwerk von geraden Linien in viereckige Felder eingeteilt; außerdem sieht man viele Löcher, die teilweise durch die ganze Lebersubstanz durchgehen, teilweise bloß als Grübchen erscheinen.

") L. Sticdil a. a. (), S. I I fi. 
Das interessante Objekt wurde erstmals abgebildet in Cuneiform Texts from Babylonian Tablets in the British Museum Part. IV, London I898, B. 89-4, 268. Im Jahre I 899 erschien von dem Assyrologen A. Boissier in Genf eine Abhandlung mit schematischen Abbildungen, ${ }^{*}$ ) worin dieser Gelehrte gegenüber der ursprünglichen englischen Annahme einer Menschenleber-Darstellung erstmals die richtige Erklärung abgab, daß es sich um eine Tierleber und zwar um die Leber eines Schafs handle. Besonders bestimmend war ihm für diese Erklärung das Vorhandensein des process. pyramidalis und der als spitzer Keil dargestellten Gallenblase. Der proc. pyramidalis ist ihm dasselbe. was die Griechen, die Etrusker und die Römer als Kopf bezeichnet haben, ein Wort, das auch schon in den assyrischen omina häufig erwähnt wird. - Das mit VI

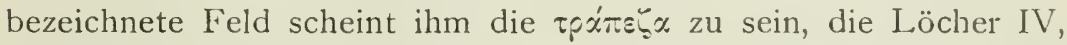
V, VII und VIII wagt er nicht zu erklären, dieselben sind aber nach Stieda nichts anderes, als die Andeutungen von Blutgefäßen, deren lumina nach Durchschneidung der Leber sichtbar werden.

Als Fachmann geht Boissier auch auf die Keilinschriften ein, mit welchen die Unterseite der babylonischen Leber bedeckt ist. Die Inschriften auf der Gallenblase bedeuten, der Gott Nergal werde die feindliche Armee vernichten, der Gott Rammân werde einen starken Regen schicken. Die übrigen Inschriften auf der Unterseite sind vielfach gar nicht zu entziffern oder nur mit geringer Deutlichkeit. Was Boissier als sicheres Ergebnis der Entzifferung veröffentlicht, ist folgendes: Vielfach kommt das Wort „Ruine“ vor ; dann folgen Sätze, die sich auf künftige Zustände des Landes, vorzugsweise aber auf das Geschick des Königs beziehen:

Der Vater wird sterben...

Die Stadt mit dem Feinde. .

Der Feind wird die Stadt nehmen ...

Überschwemmung ...

Die Söhne des Königs ...

Unglücl für das Heer des Feindes ...

Es wird Wohlstand im Lande sein.

Revolte gegen den König...

Rammân wird donnern...

Der Viehstand wird zugrunde gehen ...

Die Gemahlin des Königs in das Land des Feindes...

Die Armee des Feindes wird zerstören ...

*) Note sur un Monument babylonien se rapportant à l'extipicine, Genér 
Boissier findet in den hier wiedergegebenen Bruchstücken von Sätzen ganz banale, beinahe kindische Phrasen, den Schluß derselben Phrasen hat er in den aur der Vorderseite eingeritzten Inschriften entziffert. Diese sogen. Phrasen aber sind doch außerordentlich wertvoll, weil sie uns erkennen lassen, in welcher Weise der altbabylonische Opferschauer einzelne Teile der Leber zu Prophezeiungen verwendet hat, und weil sie den Schluß erlauben, daß auch die I6, je einer Gottheit zugeteilten Randinschriften auf der etruskischen Bronzeleber zu Prophezeiungen im Sinne der betreffenden Gottheiten verwertet worden sind.*)

\section{d. Bilder von menschlichen Körperteilen}

als Weihgeschenke.

Ein helles Licht auf das, wenn auch primitive, anatomische Wissen und Können der alten Kulturvölker werfen die aus dem verschiedensten Material geformten Nachbildungen der verschiedenen äußeren und inneren Körperteile, welche von Kranken oder Krankgewesenen in den Heiligtümern bestimmter Heilgötter niedergelegt oder aufgehängt wurden. Über dieses interessante Kapitel aus der Kulturgeschichte der Menschheit besitzen wir eine alte, aus dem Jahre 1 ; 86 stammende Altorfer Inauguraldissertation von J. Jac. Frey unter dem Titel: „De more gentium Diis simulacra membrorum consecrandi." Frey ist der Ansicht (S.4),

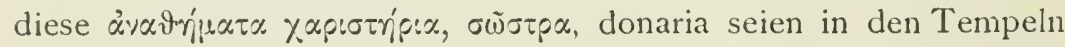
aufgehängt worden, nicht nur zum Dank für Befreiung von Beschwerden und Gefahren. sondern auch um den Bitten um Genesung mehr Nachdruck zu geben, ja sogar teilweise nur deswegen, um den vorerst noch gesunden Körper durch Weihung eines Körperteils an die Gottheit vor Krankheit zu schützen.

Die in der historischen Ausstellung in Düsseldorf I 898 sichtbare Photographie eines Penis mit bildlicher Darstellung auf der Eichel und Keilinschrift auf dem Schafte deutet mit großer Wahrscheinlichkeit auf ein babylon isch-assyrisches Weihgeschenk, über dessen Alter aber nichts verlautet.

Was die Weihung von Augen und Ohren betrifft, so führt Frey als eine alleinstehende Ansicht die von Clemens Alexander an, nach welcher die alten Ägypter dadurch das Allessehen und

*) Im Jahre igor hat A. Boissier (Note sur un nouveau document Babylonien se rapportant à l'extispicine, Geneve 1901) eine zweite babylonische Augurenleber aus Terracotti beschrieben. 
Alleshören der Götter haben andeuten wollen. Diese Ansicht ist durchauts verfehlt, vielmehr ist mit aller Bestimmtheit anzunehmen, daß die altägyptischen Weihgeschenke wie bei anderen Völkern auch nur Privatinteressen gedient*) haben. Ein $\mathrm{Ohr}$ aus Terracotta und eine Steintafel mit zwei ausgemeiselten Ohren, beides Weihgeschenke aus Theben, sind in dem Werke von G. Wilkinson**) abgebildet. Letzterer führt des weiteren an, daß Ohren, Augen, verkrümmte Gliedmaßen und andere Körperglieder der Gottheit nach erfolgter Heilung dargebracht worden seien, kann aber für diese Behauptung keinen anderen Beweis liefern, als die Angabe, dals dieser Brauch jetzt noch bei den Nachkommen der alten Ägypter vorhanden sei.

Eine weitere Zeichnung eines als Weihgeschenk dargebrachten elfenbeinernen Vorderarms nebst Hand könnte momentan zu der Ansicht verleiten, daß damit eine Verkrümmung des Vorderarms angedeutet werden solle, doch ist es weit natürlicher, anzunehmen, daß der betreffende Elfenbeinschnitzer es verschmäht hat, die natürliche Krümmung des Zahns zu verändern.

Ein sehr interessanter Fall von Nachbildung bestimmter Körperteile resp. pathologischer Veränderungen an denselben ist uns aus der althebräischen Geschichte im I. Buch Sam. cap. 5 und 6 erhalten. Nachdem die Philister die Israeliten geschlagen und ihnen die Bundeslade abgenommen hatten, wurde ihr Land durch Mäuse verwüstet, sie selbst aber von gesucht, einer schweren Krankheit, von welcher viele Tausende schnell dahingerafft wurden. Die Vulgata übersetzt I. Sam. c. 5, v. I 3: „percutiebantur in secretiori parte natium." Die Priester und Wahrsager der Philister, befragt, was gegen diese schwere Kalamität zu tun sei, gaben den Rat, die Bundeslade in das Land der Hebräer zurückzuführen und in einem besonderen Kästchen je nach der Zahl der Philisterfürsten 5 goldene Mäuse und 5 goldene על על mitzugeben (I. Sam. c. 6). Die Vulgata übersetzt: „Juxta numerum provinciarum quinque anos aureos facietis et quinque mures aureos", und Luther übersetzt ,fünf goldene Ärse." De Wette aber***) in Anlehnung an die etymologische Bedeutung des Wortes $y$ übersetzt

*) Der Heilgott Imhotep, der ägypt. Äskulap, hatte Heiligtümer an verschiedenen Stätten.

*) a. a. O. Vol. III. S. 395 .

***) De Wette, die heil. Schrift des Alten und Neuen Testaments, 3. Ausgabe, Mohir, Heidelberg 1839 . 
1. Sam. 5, 6: „Und die Hand Gottes schlug sie mit Beulen, Asdod und sein Gebiet"; v. I2: „Und die Leute, welche nicht starben, wurden geschlagen mit Beulen"“; Cap. 6, v. 4: „Und die Priester und Wahrsager sprachen: „Nach der Zahl der Fürsten 5 goldene Beulen und 5 goldene Mäuse“; v. 17: „Das sind aber die goldenen Geschwülste, welche die Philister dem Jahveh entrichteten als Schuldopfer". Das Wort $\zeta \Xi \mathcal{y}$ bedeutet in der Tat eine Erhöhung, eine Geschwulst, somit ist mit großer Wahrscheinlichkeit zu schließen, daß die Philister damals von einer Bubonenpest-Epidemie heimgesucht worden sind, eine Annahme, die um so wahrscheinlicher ist, als die Hebräer kurze Zeit, nachdem die Bundeslade wieder zu ihnen gelangt war, ebenfalls (durch Ansteckung) massenhaft von derselben Krankheit befallen wurden und starben. Wegen der secretiores partes an ,anus" zu denken, liegt gar keine Veranlassung vor, denn auch die Inguinalgegend gehört zu den secretiores partes, und wenn die Vulgata von nates spricht, wo die $\boldsymbol{D}^{\cdot} \boldsymbol{\zeta} \Sigma \boldsymbol{V}$ aufgetreten sein sollen, so müßten letztere breite Condylome gewesen sein, an denen aber nicht Tausende schnell dahinstarben. Somit handelt es sich um den in der Geschichte der pathologischen Anatomie einzig dastehenden Fall von plastischer Nachbildung von Bubonen.

Über die altgriechischen Weihgeschenke in Form von nachgebildeten Körperteilen existiert jetzt schon eine kleine Literatur, die voraussichtlich in nächster Zeit durch weitere Ausgrabungen in den Tempeln griechischer Heilgötter (z. B. auf Kos) vermehrt werden dürfte. Schon J. Grimm*) berührt dieses Gebiet und führt namentlich Böotien an, wo es gebräuchlich gewesen sei, die metallene Nachbildung des erkrankt gewesenen Glieds aus Dankbarkeit für erfolgte Heilung im Tempel aufzustellen oder auf-

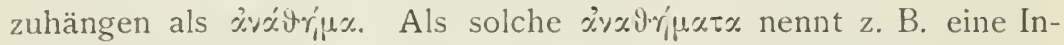

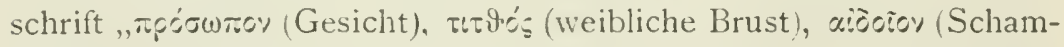
glied). \% (Hand) etc. Aus solchen IVeihgeschenken von edlen Metall wurden hernach heilige Gefäße verfertigt.

Nach Frey erzählt der Scholiast zu Aristophanes, als die Athener wegen Vernachlässigung des Bachusdienstes von einer schweren

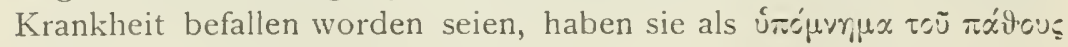
mehrere Phalli gemacht und dieselben in feierlichem Aufzug herumgetragen. Frey selbst gibt an. in der Sammlung des kaiserlichen

-) Deutsche Mythologie, 2. Ausgabe, 2. Bd., S. 1131. 
Rats Ebner von Eschenbach vier solche bronzene Phalli gesehen zu haben.

General Louis Palma di Cesnola hat in seinem Buche „Cyprus, its ancient cities, tombs and temples (London 1872 )" S. 158 eine Reihe von Weihgeschenken, alle von Golgoi stammend, abgebildet „,eyes, ears, noses, faces, lips, thumbs, feet and other portions of the human body, rudely carved in stone."

A. Cunze*) führt in dem unten genannten Buche nur Füße an.

E. Reich**) teilt die griechischen Weihgeschenke ein in Nachbildungen von Sachen, von Götter- und von Menschenbildern, wobei aber die zwei letzteren Rubriken in eine zusammenfallen, da ja auch die Götter in menschlicher Form dargestellt wurden.

A. Körte ${ }^{* * *}$ ) schildert in einer Abhandlung, was alles im Tempelbezirk eines Heiligtums gefunden worden ist. Uns interessieren hier weniger die Darstellungen der Geheilten, die entweder allein oder im Verein mit den Ihrigen ihren Dank durch Opfer darbringen, als die Nachbildungen der kranken Glieder, sogar in Gold und Silber, und die Darstellung der Heilung durch den Gott selbst. Stieda $\dagger$ ) bekämpft mit Recht die Ansicht Körtes, daß Weihgeschenke immer von Genesenen dargebracht worden seien, während im Gegenteil in den allermeisten Fällen der Kranke mit Darbringung einer Nachbildung seines kranken Körperteils Hilfe erbeten habe. Daß dies wirklich der Fall gewesen ist, begründet Stieda damit, daß neben anderen Darstellungen auch ein Bild gefunden wurde, auf welchem ein Mann ein kolossales, durch Krampfadern entstelltes Bein mit den Händen umfaßt.

Die et $\mathrm{r}$ uskis che $\mathrm{n}$ und die $\mathrm{r}$ ö $\mathrm{m}$ is $\mathrm{ch}$ e $\mathrm{n}$ Weihgeschenke können nicht wohl gesondert zur Betrachtung kommen, weil es bei vielen derartigen Objekten in den Sammlungen Roms und anderer Städte unklar ist, ob sie von etruskischem oder römischem Boden stammen, und weil ja nachgewiesenermaßen die Römer auch bezüglich der Darbringung von Donarien die Nachfolger der Etrusker gewesen sind.

*) Reise nach der Insel Lesbos, Hannover i 865 .

**) Griech. Weilhgeschenke, Wien I890, Heft VIII der Ablandlung des archizol.epigraphischen Seminars in Wien.

$\left.{ }_{* * *}\right)$ Bezirk eines Heilgottes. Mitteilungen des k. d. archäol. Instit. in Athen, Bd. XVIII I 89;, Athen, S. 23 I ff.

$\dagger$ ) Anatomisches über altitalische Weihgeschenke, Bergmanu, Wiesbaden I90I, S. 65 . 
Schon Dr. J. Frey*) spricht in seiner Dissertation von den altitalischen Gliedernachbildungen (Ohren, Finger, Füße etc.), die sich in verschiedenen Museen Europas befinden. Der gelehrte Tomasinus erzählt von einem Kopfe mit Nachbildung des Gesichts, sowie von einem mit dem Unterschenkel verbundenen Bronzefuße ältester Arbeit. Noch weitere solche Nachbildungen führt Montefalcone an: zwei Olıren, ein Auge, ein Finger mit einer schwer zu lesenden Inschrift, ein anderer F inger mit F ingernagel, weiter eine Hand mit daran gebundenem Fuß, endlich 9 F üße teils ganz, teils zerbrochen, die alle teils zum Aufhängen, teils zum Befestigen an der Wand bestimmt waren. Montefalcone schreibt die Weihung der einzelnen Glieder denjenigen Göttern zu, welche als Schutzgötter dieser Glieder gegolten haben, so die Finger der Minerva, die Füßse dem Mercur, die Augen dem Apollo etc.

Als oberster Heilgott übrigens wurde Äskulap verehrt; ihm wurden die meisten Donaria geweiht, ganz besonders ragte unter diesen Weihgeschenken die Zahl der gestifteten Gliedmaßen hervor. - Die zweite Stelle nach Äskulap nahm die Minerva ein, die medica dea (ú:sí, $\pi \alpha \omega v \varepsilon i \alpha$ ); ihr wurden auch silberne Ohren geweiht. - Zuweilen wurde auch die Diana angerufen und ihr Geschenke geweiht, denn auch sie galt als Göttin der Gesundheit. hr wird eine Hand aus gebranntem Ton zugeschrieben, die mit anderen Gegenständen in dem heiligen Haine bei Aricia ausgegraben wurde. Auch zwei in Marmor gemeiselte, der Diana geweihte Fußsolhlen wurden gefunden, die nach der Ansicht des Pausanias unzweifelhaft aus Dankbarkeit für eine glücklich zurückgelegte Reise gestiftet worden waren.

Von weiterer Literatur ist zu nennen das Buch von Dr. M. A beken „Mittelitalien in der Zeit der römischen Herrschaft nach seinen Denkmälern dargestellt; Stettin und Tübingen I 843, mit I I Tafeln", worin auch der im Museo Gregoriano befindlichen Nachbildungen einzelner Glieder (Beine, Brüste etc.) gedacht wird.

In dem Buche von G. Dennis, "The cities and cimeteries of Etruria, London I 893" ist von der reichen Sammlung von Bronzealtertümern die Rede, die nach Ablassen des kleinen Sees des Monte Falterone 1836 entdeckt wurden, Köpfe und Gliedmaßen, verschiedene Teile des menschlichen Körpers, aber auch

$$
\text { ") a. a. O. S. } 9 \text { f. }
$$


gan ze Figuren mit deutlichen Anzeichen einer vorhandenen äußeren oder inneren Krankheit.

In dem Werke von Jules Martha "L'art etrusque, Paris $1889^{\prime \prime}$ ist von verschiedenen Weihgeschenken aus Bronze, nicht aber von solchen aus Terracotta die Rede, obgleich diese nachgewiesenermaßen sehr zahlreich vorhanden sind.

In dem von Dr. Fridrichs (Kleine Kunst und Industrie im Altertum, Düsseldorf I 871 ) herausgegebenen Verzeichnis der im Berliner Museum befindlichen antiken Weihgeschenke sind auch

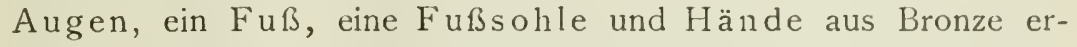
wähnt. - Auch in dem von $\mathrm{Homolle}$ geschriebenen Artikel „Donarium" des Dictionnaire des antiquités Grecques et Romaines par Daremberg et Saylio, Paris I 892, Tome II sind erwähnt ,yeux, oreilles, poitrines, seins, ventres, parties sexuelles, bras et mains."

Schließlich ist noch zu erwähnen die Beschreibung des DianaHeiligtums in Nemi (Verhandlungen der 40. Versammlung deutscher Philologen und Schulmänner in Görlitz 2.-5. Oktober I 889, Leipzig 1890). Es kamen da zur Sprache die außerordentlich vielen kleinen Terracotten mit Darstellungen der vulva und des penis; aber auch Beine, Füß $ß \mathrm{e}, \mathrm{Hände}$, Nasen und Augen wurden gefunden; als besonders merkwürdig erschien eine weibliche Figur mit geöffneter Brust nebst Oberteil des Unterleibs, so daß die Eingeweide zu erkennen sind.

In jüngster Zeit hat sich Prof. L. Stieda der dankbaren Aufgabe unterzogen, in einer eigenen, schon oben erwähnten Abhandlung die altitalischen Weihgeschenke vom anatomischen Standpunkte aus zu besprechen. Stieda studierte

I. die Sammlungen des Museo nazionale in Rom, wo besonders die auf der Tiberinsel bei Rom gefundenen Weihgeschenke zu Ehren des Äskulap die Aufmerksamkeit erregen;

2. die Sammlungen des Magazino archeologico in Rom, mit den Funden bei Ausgrabung des Minervatempels;

3. die Sammlungen des etruskischen Museums in der Villa di Papa Giulio in Rom, mit den Weihgeschenken aus Civita Lavinia und Civita Casellanea;

4. eine Anzahl Altertümer aus Veji.

Was er gesehen hat, waren teils Darstellungen ganzer und unversehrter menschlicher Körper, teils Nachbildungen einzelner äußerer 
und innerer Körperteile oder zusammenhängender Eingeweide im situs viscerum. Darstellungen ganzer, unversehrter Körper interessieren in erster Linie den Künstler; für uns können nur die in die zweite Rubrik fallenden Objelite in Betracht kommen. Was dis Material betrifft, aus welchem dieselben hergestellt waren, so bestanden sie häufig aus Bronze und Marmor, weitaus in der Mehrzahl aber aus Terracotta. Ob es auch Nachbildungen aus Wachs und Holz gegeben hat, wie wohl anzunehmen ist, bleibt vorerst noch unentschieden. - Die Terracotten wurden wahrscheinlich handwerksmäßig hergestellt unter Benützung bestimmter Formen; nachher wurden sie mit roter Farbe bemalt. - Der Zeit nach stammen die Terracotten aus den letzten vorchristlichen Jahrhunderten. - Daß die altitalischen Völker (Etrusker und Römer) in den Nachbildungen innerer Organe menschliche Organe darstellen wollten, darüber kann kein Zweifel bestehen; daß sie aber wirklich menschliche Eingeweide als Vorbilder gehabt haben, dagegen verwahrt sich Stieda mit allem Nachdruck. Sie konnten ja keine Anschauung vom Inneren des Menschen haben, weil sie keine Anatomie hatten; so entnahmen sie denn ihre Vorbilder der Anatomie der Haustiere, deren innere Organe dann die des Menschen vorstellen sollten.

Um nun auf die einzelnen $\mathrm{K}$ örperteile überzugehen, deren Stieda eine große Anzahl photographisch aufnehmen ließ (siehe die Tafeln zu seiner Abhandlung), so hat er vollkommen Recht, wenn. er die als Weihgeschenle deponierten Köpfe, Gesichter und Gesichtsteile nur vom anatomischen Standpunkt aus betrachtet, weil sie ja nicht von Künstlern aus künstlerischem Antrieb, sondern handwerksmäßig auf Bestellung von seiten Solcher hergestellt wurden, welche mit Leiden des Kopfes oder bestimmter Teile des Gesichts behaftet waren.

Man findet ganze und halbe Köpfe, erstere hohl mit einem Loch auf der Rückseite zum Aufhängen an der Wand, letztere in sagittalem Schnitt durch einen ganzen Kopf hergestellt. Daß es primitiv hergestellte Portraits waren, sieht man an der Verschiedenheit der Gesichtsbildung und der Haartracht; in einem Museum in Rom soll sich sogar die Darstellung eines kranken Kopfes finden.

Von Gesichtern findet man ganze und Halbmasken; von Gesichtsteilen einzelne Augen, Ohren, Nasen, Lippen. Krankhaft veränderte Gesichter hat Stieda nicht gefunden. 
Sehr zahlreich finden sich Hände, meist alle 5 Finger gestreckt, wobei die Konturen der Linien, der Nägel etc. gut zur Geltung kommen. Interessant ist eine von Stieda gesehene Hand mit Nachbildung einer Geschwulst des Handtellers. Es gibt rechte und linke Hände; was aber Männcr- und was Weiberhände sein sollen, ist schwer zu bestimmen. Von ähnlichen Votivhänden in Deutschland führt Stieda an die von Heddernheim und die von Darmstadt; eine weitere befindet sich in Wien und eine vierte in Avenches (Schweiz).

Unterschenkel hat Stieda in den italienischen Museen keine gesehen, sondern nur Füße, rechte und linke, mit deutlicher Ausführung der Nägel. Nach seiner Ansicht sind diese Füße vielfach nicht mit Rücksicht auf ein Fußleiden, sondern aus Dankbarkeit für glücklich zurückgelegte Reisen gestiftet worden.

Von einzelnen Skeletteilen hat Stieda nur einen im vatikanischen Museum aufgestellten Brustkorb aus Marmor gesehen. An demselben sind die Schlüsselbeine, das Brustbein, die Rippen und die ersten Lendenwirbel erkennbar (s. Stieda, Taf. II/III, Fig. 6), kein Kopf, kein Hals, Rückenfläche platt, rauh, wie weggebrochen. Stieda hält es für ganz sicher, daß das Stück nicht als anatomisches Präparat resp. Phantom aufzufassen sei, aber Braun,*) welcher letztere Ansicht aufgestellt hat, hat vielleicht doch Recht, wenn man die Tatsache berücksichtigt, daß Galen bei seinen Vorlesungen neben Zeichnungen und Präparaten auch Nachbildungen in Bronze und Marmor benützt hat.**) Schließlich sieht sich Stieda veranlaßst, das Stück für gar kein Weihgeschenk zu erklären, da es ihm einen modernen Eindruck mache und vielleicht aus einem Sargdeckel oder einer Wand herausgebrochen sei.

Für den Mediziner die wichtigsten Weihgeschenke sind unstreitig die bildlichen Darstellungen innerer Organe aus sehr alter Zeit. Stieda hält die in Rom gesehenen Objekte für die ältesten plastischen Nachbildungen menschlicher Eingeweide (mindestens 2000 Jahre alt). Dies wäre richtig, wenn diesen Weihgeschenken wirklich menschliche Organe als Vorbilder zugrunde gelegen hätten. Wenn diese Vorbilder aber in tierischen Organen

*) Ruinen und Museen Roms, Braunschweig I854.

**) Robert Fuchs, im Handb. d. Gesch, d. Medizin, I., 397. Puschmann, Gesch. des medizinischen Unterrichts von den ältesten Zeiten bis zur Gegenwart, Leipzig I 889, S. 85 t. 
bestanden, was höchst wahrscheinlich ist, so ist die babylonische Augurenleber immer noch die älteste derartige Nachbildung.*)

Man kennt I I Stücke bildlicher Darstellung von Eingeweiden an bekleideten oder unbekleideten Menschenkörpern mit geöffneter Leibeshöhle (Situs viscerum).

I. Ein $30 \mathrm{~cm}$ hohes Stück aus dem Bonner Kunstmuseum (Stieda, Tafel III, Fig. 8) mit geöffneter Brust- und Bauchhöhle (ohne Zwerchfell), Herz, von beiden Lungen flankiert, Leber, dreilappig (tierartig), zwei bohnenförmige Nieren, der gewundene Darmkanal und die $\mathrm{H}$ arnblase. Alles äußerst roh.

2. Ein nur $14 \mathrm{~cm}$ hohes Stück, ebenfalls in Bonn. Bruchstück eines Rumpfes mit geöffneter Leibeshöhle, darin ebenfalls, wenn auch undeutlich zu erkennen, Herz, Lungen, dreilappige Leber, Nieren, Darmschlingen, Harnblase.

3. Ein $12-15 \mathrm{~cm}$ hohes Stück, aus Veji stammend, im Besitz von Stieda (s. Stieda, Tafel II, Fig. 5). Unterleib teilweise durch Gewänder verhüllt, Oberleib eröffnet. Herz, Lungen, dreilappige Leber, einige Darmschlingen, manche Teile zerbrochen.

4. Ebenfalls aus Veji stammendes, $53 \mathrm{~cm}$ hohes Stück, in Besitz von Stieda (s. Stieda, Tafel III, Fig. 9). Bruchstück einer weiblichen Figur mit geöffneter Leibeshöhle. Erhalten die rechte Schulter, die rechte Brust. In der geöffneten Leibeshöhle Reste von Eingeweiden meist undeutlich erkennbar. Deutlich sichtbar rechte Niere und einige Darmschlingen.

5. Im Mus. nazion. in Rom Bruchstück eines Rumpfs mit geöffneter Leibeshöhle. Eingeweide zerbrochen, undeutlich zu erkennen Herz, Lungen, dreilappige Leber, Magen, beide Nieren, Darmschlingen, Harnblase, vielleicht auch Milz.

6. Mus. nazion. in Rom. Ebenfalls Bruchstück eines Rumpfs mit offener Leibeshöhle. (Stieda, Tafel IV/V, Fig. 12.) Links und rechts Reste der abgeschnittenen Rippenknorpel. H er z Lungen als zwei merkwürdigerweise durch eine Brücke vereinigte Wülste, Magen, dreilappige Leber, Darmstück, Harnblase.

") Nachträglich erfahre ich, daß die Mehrzalıl der von Stieda abgebildeten Donarien schon 1898 in Turin ausgestellt und von F. Giacosa (Magistr. Salernitani nondum editi, Torino I goI) abgebildet worden ist. 
7. Mus. nazion. in Rom. Sehr stark verstümmeltes Bruchstück. Die einzelnen Teile in der geöffneten Leibeshöhle nicht mehr zu erkennen.

8. und 9. Rümpfe im etruskisch. Museum. In der geöffneten Leibeshöhle nichts mehr zu unterscheiden.

10. Gewandfigur aus Nemi stammend, mit geöffneter Leibeshöhle. Im Innern verschiedene undeutliche Höcker und Wülste.

11. Bruchstück eines Marmorrumpfes mit offener Leibeshöhle. Vatik. Museum in Rom (s. Stieda, Tafel II/III, Fig. 7). Schon früher vielfach von den Archäologen beschrieben. Beide Lungenwülste oben durch ein Verbindungsstück vereinigt, das sich durch seine Querfurchen als Trachea ausweist. Herz fehlt, wahrscheinlich herausgebrochen; dreilappige Leber, Magendarmschlingen. Wurde von Braun ebenfalls, wie der oben erwähnte marmorne Brustkorb, für ein anatomisches Phantom erklärt. Stieda aber fragt diesmal mit Recht, wozu denn in diesem Fall der Körper bekleidet dargestellt worden wäre.

Außer diesen Rümpfen mit geöffneter Leibeshöhle hat Stieda in Rom Tafeln mit Gruppen von Eingeweiden gesehen, worüber nach seiner Meinung bisher in der ganzen Literatur nirgends eine Bemerkung zu finden war.*) Nur im Mus. naz. in Rom waren diese Tafeln unter dem Namen ,viscere" bekannt. Die Tafeln sind platt, oval, oben abgerundet, unten spitz zulaufend. Länge I 5 bis $20 \mathrm{~cm}$, Breite unten $15 \mathrm{~cm}$, Dicke $1-2 \mathrm{~cm}$. Entweder sind die Organe der Brust- und der Bauchhöhle, oder nur die der letzteren dargestellt. Bei den Museumsdienern laufen letztere unter dem Namen ,bude!le“ = Därme. Von solchen Stücken hat Stieda in seiner Abhandlung 12 verzeichnet.

1. Tafel im Mus. naz. (Stieda, Tafel IV/V, Fig. I 7). Herz und beide Lungen, darunter Andeutung eines Zwerchfelles, dann dreilappige Leber, Magen, Darmwindungen, $\mathrm{H}$ ar n bla se. Links der spindelförmige Körper vielleicht die Milz.

2. Ebenfalls im Mus. naz., der vorigen ähnlich. Herz, Lungen, Zwerch fell, dreilappige Leber, Magen, Darmschlingen, Harnblase.

*) Cf. übrigens die oben erwähnte Schrift von P. Giacosa. 
3. Mus. naz. (Stieda, Tafel IVV, Fig. I6). Wülste sehr flach. Herz, Lungen, Andeutung des Zwerchfelles, dreilappige Leber, undeutlicher Magen, Darmschlinge, links eine spindelförmige Milz.

4. Tafeln aus Veji mit Eingeweiden der Brust- und Bauchhöhle (Stieda, Tafel IV V, Fig. IO, I1, 14, 15, 26, 28). Überall Herz, Lungen, $Z$ werchfellandeutung, dreilappige Leber, Darmwindungen, Harnblase.

5. Tafeln aus Veji mit ausschließlicher Darstellung von Baucheingeweiden: Magen, Darm, Nieren, Milz, Harnblase (Stieda, Tafel IV/V, Fig. 27, 28).

6. Im Mus. naz. eine Tafel mit einem Konvolut von Darmschlingen (Stieda, Tafel IV/V, Fig. I3).

Außerdem hat Stieda im Mus. naz. noch eine Tafel gesehen, auf welcher der Kehlkopf und die Luftröhre dargestellt war. Von männlichen Geschlechtsorganen sind Darstellungen des Penis mit dem Hodensack vielfach vorhanden. Auf Tafel IV/V, Fig. 23 bildet Stieda einen Penis mit sehr langem Präputium ab.

Weibliche Geschlechtsorgane sind ebenfalls zu Donarien nachgebildet worden. Im etrusk. Museum finden sich Darstellungen des pudendum muliebre mit mons Veneris, rima pudendi und clitoris. - Auch weibliche Brüste sind recht häufig unter den Weihgeschenken in Form von Halbkugeln, hohl, mit einem Loch zum Aufhängen. Brustwarze immer deutlich. Größe: 6,5 bis $10 \mathrm{~cm}$ Durchmesser, Höhe $5,0-7,5 \mathrm{~cm}$.

Eigentümliche Gebilde von dunkler Bedeutung sind die von Stieda auf Tafel IV/V, Fig. 20, 2I, 24 und 25 wiedergegebenen Körper. Dieselben sind platt, auf der einen Fläche leicht gewölbt, $15-20 \mathrm{~cm}$ ang, 9-I $2 \mathrm{~cm}$ breit, etwa $5 \mathrm{~cm}$ dick, hinten mit einem Loch zum Aufhängen, die vordere Fläche mit parallelen Querwülsten. Das eine (obere) Ende des Körpers leicht abgerundet, das andere (untere) mit quer gestellter spaltförmiger Vertiefung. An Fig. 22 und 25 sieht man seitlich eiförmige Körper aufsitzen, die auch einzeln in verschiedener Größe, 9-10 cm lang, $5-6 \mathrm{~cm}$ breit, vorkommen können (Stieda, Fig. 24). Dr. L. Neugebauer hält jene größeren Körper für prolabierte uteri. Diese Ansicht ist in das Werk von Ploß (das Weib in der Natur- und Völkerkunde, Leipzig 1885) übergegangen. In der 2. Auflage des Ploßschen Werkes (Leipzig I887) spricht Bartels nicht von einem umgestülpten, prolabierten uterus, sondern nach einem im Mus. archeol. in Florenz befindlichen Stücke 
einfach von einem uterus. Stieda schließt die Darstellung eines pathologischen Zustandes, also eines prolabierten uterus mit umgestülpter, gerunzelter Scheide aus; ebenso verwirft er die Ansicht, daß der immer nur einseitig vorkommende Nebenkörper einen Eierstock darstellen solle, denn warum immer nur einer? Er hält vielmehr den Hauptkörper für die vagina, deren Besichtigung an der Lebenden mit keiner Schwierigkeit verbunden gewesen sei, in dem Nebenkörper aber will er die Blase dargestellt erkennen, eine Ansicht, die am meisten Wahrscheinlichkeit für sich hat.

Die Sitte, in Krankheitsfällen Nachbildungen der betroffenen Körperteile in den Heiligtümern der Heilgottheiten zu deponieren, ist auch bei den Germanen schon in alten Zeiten nachgewiesen. Jac. Grimm*) ist der Ansicht, die Sitte der Votivtafeln mit nachgebildeten Gliedern können die Römer nach Deutschland gebracht haben, wenn man nicht annehmen wolle, daß die Germanen die Sitte schon früher selbständig gehabt haben. Als Beweis für letzteres führt Grimm eine Stelle aus Gregor v. Tours an: „membra secundum quod unum quemque dolor attigisset, sculpebant in ligno" und dann weiter: ,visi enim in eo barbari gentili superstitione mira auri argentique dona, modo fercula ad potum vomitumque ebrii afferre, cultumque, quo nihil insanius, istic simulacrum inanis dei, ac ut quemque affecti membri dolor presserat, sculpebat in ligno suspendebatque opitulaturo idolo". Dies geschah in Ripuarien im 6. Jahrh.). Ferner führt Grimm eine Stelle aus Eligius XXXI an: ,pedum similitudines, quos per bivia ponunt, fieri vetate, et ubi inveneritis, igne cremate." Weiter spricht für die alteingewurzelte Sitte der $\int 29$ des indiculus paganiarum et superstitionum, der „de ligneis pedibus vel manibus pagano ritu" handelt. Einer Gelähmten wird im Traum bedeutet , ut instar semivivae manum ceream formando exprimeret et ad sanctae Idae tumulum deferret." (Anfang des IO. Jahrhunderts.)

Der Germane stellte das Glied im Tempel oder an der Wegscheide auf, um dadurch Genesung zu erwirken (opitulaturo idolo). „Was den Bekehrern greuelhaft, heidnisch vorkam, gestattete später die Kirche. An berühmten Wallfahrtsorten findet man $\mathrm{Hände}$, F üße aus Holz oder Wachs aufgehängt oder angeheftet." Schon J. J. Frey spricht von dem aus dem germanischen Heidentum in das Christentum übergegangenen Gebrauche. „Nun sah man in

") Deutsche Mythologie, 2. Bd., S. I13 Ift. 
christlichen Kirchen und Kapellen geweihte Nachbildungen von Füßen, Händen, Ohren, Nasen und Körperteilen, die sonst von den Kleidern bedeckt sind. Sie waren von $\mathrm{Holz}$, Wachs, Silber oder Gold." (Ja diese Nachbildungen leidender Glieder, die in den ältesten Zciten nur bei menschlichen Krankheiten im Brauch waren, wurden im Laufe der Zeit auch auf Tierkrankheiten ausgedehnt, namentlich in Bayern und den angrenzenden deutsch-österreichischen Ländern.)

Für das katholische Bayern und Österreich ist dieser Brauch von M. Höfler, für das katholische Oberschwaben von M. Buck nachgewiesen. Ganz besonders hat demselben eine Forscherin auf dem Gebiete der Ethnologie, Frl. Marie Eysn in Salzburg (jetzt Frau Professor Andree in München) nachgespürt und eine ganz respektable Sammlung solcher Donarien zusammengebracht. Der Güte und Liebenswürdigkeit derselben verdanke ich folgende briefliche Mitteilung: „Meine Votivsammlung besteht aus tönernen, eisernen, silbernen, hölzernen und wächsernen Weihgeschenken. Jede Art zeigt Nachbildung von menschlichen Körperteilen, auch von inneren Organen. Die Bärmutterkröte besitze ich in mehr als 30 Formen, von Eisen, Silber und Wachs. Sie wird heute noch bei uns als „Bärmutter" gegen Unterleibsleiden der Frauen geopfert. Darüber erschien diesen Sommer (1902) eine eingehende Abhandlung von dem Straßburger Dozenten Dr. Blind. „ढ̈ber hölzerne und tönerne Votivgaben" veröffentlichte ich eine Abhandlung mit Zeichnungen in Dr. Weinholds Zeitschrift für Völkerkunde 190 I, S. 18If. Ich habe die hölzerne Bärmutter in allen Größen, auch viele blutrote, die bei starken Blutungen geopfert werden. Aus Südtirol besitze ich auch eine hölzerne $\mathrm{Z}$ unge, die mir sonst noch nirgends vorgekommen ist. Die eisernen Votivfiguren (von denen ich keine inneren Organe besitze, die Kröten ausgenommen) haben bereits eine kleine Literatur. - In manchen unserer Wallfahrtskapellen findet man in Wachs noch alle Körperteile des Mannes und der Frau dargebracht, von inneren Organen (in Wachs) Trachea (zuweilen mit der Schilddrüse daran), Herz, Lunge, Leber, Magen, Blase; leider sind die hölzernen im Verschwinden, die eisernen (deren Herstellungszeit sich leider dem Urteil entzieht, obwohl manche ganz prähistorisch aussehen) sind jetzt im Besitz bestimmter Kirchen oft bei Tausenden und werden an Gläubige um wenige Pfennige zur Opferung entliehen." 
Die in deutschen Ländern seit ältester Zeit gebräuchliche Nachbildung der Gebärmutter in Form einer Kröte ist eine zu auffallende Erscheinung, als daß sie nicht schon längst die Aufmerksamkeit der Ethnologen erregt hätte. Fr. v. Hellwald (Globus I 893, S. 22I) war auffallenderweise der Ansicht, die Sitte müsse für Deutschland schon deswegen für importiert gelten, ,,weil die Kröte die hier zu Lande gar nicht vorkommende, also vom Volke gar nicht gekannte Schildkröte vorstellen sollte". Es wäre interessant gewesen, zu erfahren, was v. Hellwald zu diesem seltsamen Schluß veranlaßt hat, dessen Untergrund schon deswegen hinfällig ist, weil in Deutschland eine Schildkröte, nämlich die Sumpfschildkröte (Emys europaea) früher sehr häufig war. Viel größeren Anspruch auf Beachtung hat daher die Erklärung M. Höflers, der auf die elbische, giftige Natur der Kröte hinweist, welcher aus diesem Grunde die Erregung von Krankheiten, namentlich von Unterleibsleiden (mit Abgang von Schleim) zugeschrieben worden sei. Es will mir aber doch dünken, daß auch die Gestalt der Kröte eine Rolle gespielt hat, wenn die Alten in der Kröte mit ihrem breiten Hinterkörper, den ausgebreiteten Hinterbeinen und dem breitschlitzigen Maul eine Ähnlichkeit mit dem Gebärmutterkörper, den damit verbundenen Tuben und dem vorn offenen Muttermund gefunden haben.

Daß Formähnlichkeiten in der Phantasie des Volkes eine Rolle spielen, beweist die in Südtirol übliche Nachbildung der Gebärmutter in Form einer stachligen Kastanienfrucht. Über diese Opferbärmutter als Stachelkugel hat M. Höfler in der Zeitschrift des Vereins für Völkerkunde in Berlin (IgOI, Heft I, S. 82) geschrieben: „Findet das Volk in den alten medizinischen Kräuterund Heilbüchern kein Vorbild, um ein Organvotiv danach herstellen zu können, so greift es auf die ihm bekannteren inneren Organe der schlachtbaren Haustiere über und entlehnt sich aus der Anatomia culinaris oder der Veterinärmedizin seine Vorbilder.“ „Die bei der Umstülpung des entbundenen und vorgefallenen Tragsacks der Kuh sichtbare frucht-(kalb-)ähnliche Geschwulst, die mit blumenkohlartigen, gestielten, leicht blutenden Warzen (Rosen = decidua serotina) wie mit Blutegeln besetzt ist, heißt Igelkalb (Igel = Egel). Das Muttersiechtum, wegen dessen also ein Igel (Kastanie) als Votivgabe geopfert wird, ist demnach der Muttervorfall (vielleicht auch Gebärmutterkrebs, d. Verf.), und wegen dieses leidenden Organzustandes, der mit dem Egelkalb (uterus prolapsus der Kuh) 
verglichen wird, greift die Volksetymologie zum „Kästen-Igel“, um die Krankheit abbilden zu können."

Ein sehr interessantes hölzernes Votivbild hat Dr. M. Höfler aus der Sammlung von Frau Professor Andree erhalten und im Janus (Januar I90I) mit Abbildung beschrieben, nämlich eine $22 \mathrm{~cm}$ lange und I $\mathrm{cm}$ breite Nachbildung der Trachea, der Lungen, des Herzens, der Leber und eines Teils des Darmtraktus. Die jedenfalls seinerzeit von einem Dorfkünstler hergestellte Figur ist bemalt, die quergeringelte Trachea weiß, die lappigen Lungen hellrot, die Herzkugel blutigrot, die Leber braun. Unter der Leber, welche ganz im humoralpathologischen Sinne mit dem Herzen zusammenhängend dargestellt ist, um ihr das aus dem Speisebrei bereitete Blut zuzuführen, hängen drei Zipfel, welche die Gedärme vorstellen sollen.

Die übrigen Stücke aus der Sammlung von Frau Professor Andree sind, wie ich dem Briefe derselben entnehme, von Professor Stieda teils gezeichnet, teils photographisch aufgenommen worden und sollen von ihm in einer demnächst zu erwartenden Abhandlung besprochen werden.

II.

\section{Anfänge einer wissenschaftlichen Anatomie.}

I. Altertum.

Wenn wir auf die Geschichte der Anatomie zurückblicken, so finden wir schon in den frühesten Zeiten bei Laien und Ärzten $\mathrm{Haß}$ und Verachtung gegen die Anatomie als eine des Menschen unwürdige Beschäftigung, schlimmer als die Gewohnheit der Aas aufsuchenden Hunde. Den Griechen und Römern galt es als etwas Schreckliches, mit Leichnamen umzugehen, und bei den semitischen Völkern mußte sich einer peinlichen Reinigung unterziehen, wer einen Toten berührt hatte. So ist denn die Abneigung gegen die Anatomie von der Natur des Menschen abzuleiten, welchem Alles zuwider ist, was ihn an den Tod erinnert.

Wir haben oben gesehen, daß sich bei den Priestern infolge der vielen, mit peinlicher Opferschau verbundenen Opfer allmählich eine Summe anatomischer Kenntnisse festgelegt hat, und können annehmen, daß im Laufe der Zeit Vieles von diesen Kenntnissen auf das Volk übergegangen ist, das die Zuschauer bei den Opferhandlungen gebildet hat. Es muß so, allerdings auf dem tierischen 
Körper aufgebaut, allmählich eine Art systematischer Anatomie entstanden und nach und nach zum Gemeingut geworden sein. Die Anfänge einer wissenschaftlichen Anatomie aber datieren erst aus der Zeit, als sich da und dort priesterliche Ärzteschulen gebildet hatten, in welchen ja auch die Anfänge der wissenschaftlichen Medizin überhaupt zu suchen sind.

Als ältestes unter priesterlichem Einfluß stehendes Kulturvolk A'siens gelten die bis in das 5. Jahrtausend v. Ch. zurückreichenden Sumerer. Ihrer an Bildern von Körperteilen reichen Bilderschrift ist eben Erwähnung getan worden, ein eigentliches anatomisches System ihrer Priesterärzte kennen wir nicht, wohl aber haben die bisherigen Untersuchungen ihrer Schrift und Sprache einen Einblick in ihre anatomisch-physiologischen Vorstellungen gestattet.*)

Der belebte Körper besteht aus Seele und Leib. Von letzterem ist das Herz Sitz des Verstandes, die Leber das Zentralorgan für das Blut, Herz und Leber zusammen sind = Seele und Leib. Das Ohr ist das Zentralorgan des Willens, das Blut aber, von welchem man ein helles (arterielles) als Blut des Tages und ein dunkles (venöses) als Blut der Nacht unterscheidet, ist das Belebende des ganzen Körpers. Das Hauptgewicht wird auf das Blut und seine Bewegung gelegt, die Atmung wird zwar nicht geleugnet, aber als sekundär stehende Funktion kaum erwähnt. Arterien, Venen, Nerven und Sehnen werden nicht unterschieden, sondern gelten als ein einziges System.

Die hämatische Grundanschauung der sumerischen Anatomie und Physiologie machte sich auch bei ihren Nachfolgern, den Babyloniern und Assyrern geltend. "Das Zweistromland", sagt v. Oefele, ${ }^{* *}$ ) ,wie Ägypten in der Nähe der Wüste, vielfach nur fruchtbar durch Überschwemmung seiner Flüsse, ließ in Analogieschlüssen die Notwendigkeit des bewegten Blutes für das Leben des Körpers verstehen. Wie der Boden unfruchtbare, undurchfeuchtbare Steine neben Humus besitzt, so wurden im Körper Hartteile (Skelett) neben blutdurchtränkten Weichteilen unterschieden. Wie ferner die für die Pflanzenwelt schädliche übermäßige Hitze durch Winde gekühlt wird, so spielt die Atmung gegenüber der eingepflanzten Wärme des Körpers ihre Rolle." „Nach uraltem Typus halten die Göttergestalten ein Gefäß, aus

") v. Oefele, im Handb. d. Gesch. d. Med., Bd. I, S. 57 t.

") v. Oefele, 1. c. S. 55 f. 
dem ein doppelter oder vierfacher Wasserstrom quillt." Es ist dies die humoralpathologische Andeutung der Spendung des Lebens.

Da nun auch die Gestirne als Götter gedacht wurden, so ist es nur natürlich, daß ihnen auch ein Einfluß auf den menschlichen Körper zugeschrieben wurde. Der Zusammenhang des Sonnenstandes und der Sternaufgänge mit den Jahreszeiten, die wechselnde Stellung zwischen Fixsternen und Planeten und der Einfluß der Jahreszeit und Witterung auf das Auftreten bestimmter Krankheitsformen führten in teils ausgesprochener, teils nicht ausgesprochener Analogie zur Lehre vom parallelen Verlauf der Lebensvorgänge im Makrokosmos und Mikrokosmos. So kam es zu der Lehre von den vier Elementen im Makrokosmos und Mikrokosmos in paarigem Gegensatz von trocken und feucht, heiß und kalt, und zur Aufstellung von Beziehungen dieser Elemente und ihrer Qualitäten im allgemeinen und im besonderen zu dem Laufe der Gestirne.

Wir wissen, daß im Jahre $7 \delta 7$ v. Ch. der Dienst des babylonischen Heilgottes $\mathrm{Nabu}$ in Assyrien eingeführt worden ist und können daraus schließen, daß von dieser Zeit an auch in Assyrien ein Kollegium von Priesterärzten mit den anatomischen Kenntnissen damaliger Zeit bestanden hat; von dem zu erwartenden wissenschaftlich-anatomischen Material aber ist das allermeiste noch in den aus Ninive ausgegrabenen Tafelresten der Bibliothek der Assurbanipal enthalten und harrt noch der Entzifferung durch die Gelehrten des britischen Museums.

Von einer medisch-persischen Anatomie konnte während der ganzen Dauer des Perserreichs schon deswegen keine Rede sein, da von den ältesten Zeiten an die Scheu vor Berührung mit Unreinem eine unbegrenzte war, jede Leiche aber als absolut unrein galt. - Was von zwei medischeı Königen Sabor und Gürges als Beförderern der Anatomie erzählt wird, ist in das Reich der Sage zu verweisen.

Von anatomischen Vorstellungen der vorarischen Inder, der Drawiden, ist nichts bekannt. Was die älteste Anatomie der arischen Inder betrifft, so konnte sie nur sehr primitiv sein, da das brahmanische Gesetz jede Beschäftigung mit Leichen verbot. Auffallend und auf gemeinsame indogermanische Vorstellungen zurückzuführen ist die von Häser*) nachgewiesene Ähnlichkeit dieser

-) Geschichte der Medizin I., $60 \%$. 
altindischen Anatomie mit der altgermanischen. (Wie sich später die indische Anatomie trotz der brahmanischen Gesetze wciter entwickelt hat, davon soll unten in dem Abschnitt über das Mittelalter die Rede sein.)

Eigentümlich wechselnde Schicksale hat die Anatomie in Ägypten durchgemacht. Plinius (Nat. hist. XIX, c. 5) berichtet, die ägyptischen Könige haben selbst anatomische Untersuchungen zur Erkennung von Krankheiten veranlaßt. Nach Manetho soll Athotis, der Sohn und Nachfolger des Menes, des Begründers der ersten ägyptischen Königsdynastie, Arzt gewesen sein und anatomische Bücher verfaßt haben. Dasselbe findet sich bei Eusebius (Pamph. de Athosti, ed. Scalig. p. I4) berichtet. Nach v. Oefele*) kann damit Itath, der 3. König der I. Dynastie, der Verfasser der unter Chasty gefundenen Bücher, gemeint sein. M. Müller meint übrigens, diese Abfassung anatomischer Bücher durch einen König sei nur eine volksetymologische Verwechslung mit dem Berichte der Abfassung durch den Gott Thoth.

Unter Chasty, dem 5. König der ersten Dynastie, soll nach Papyr. Ebers 103, I und Papyr. Brugsch I5, I die Lufthaltigkeit der Leichenarterien und die Bluthaltigkeit der Venen gefunden und damit der erste Schritt zur pneumatischen Dogmatik der Medizin (gegenüber der hämatisch-humoralen) getan worden sein. Die offizielle Anerkennung der Pneumalehre und die Scheidung der Arterien und Venen geschah, nachdem an Sendi, den 5. König der 2. Dynastie, die anatomisch-physiologische Schrift über diese Scheidung der beiden Gefäßarten gelangt war.

Der erste vollgeschichtliche König ist Snofru, der erste König der 2. Dynastie. Zu seiner Zeit war die Einbalsamierung der Leichen erst teilweise im Gebrauch,**) während noch bis in die 5. Dynastie hinein Zerstücklung der Leiche beim I. oder 2. Begräbnis***) stattfand. v. Oefele erblickt in dieser Periode der Entfernung aller Weichteile von dem Skelette den Höhepunkt der altägyptischen Anatomie, dem gegenüber die Sitte des Einbalsamierens schon einen Rückgang bedeute. Daß aber gerade dieses Einbalsamieren durch die Hand geschulter Priesterärzte $\dagger$ ) notwendig zur Erweiterung

*) v. Oefele 1. c. Bd, I, S. 65.

**) v. Oefele 1. c., S. 68.

***) Bei letzterem wurde sogar das Fleisch von den Knochen abgeschabt.

†) Cf. Genes. I, 2 „Die Ärzte balsamierten Jakob ein.“ 
der anatomischen Kenntnisse und zur Begründung einer wissenschaftliclıen Anatomie führen mußte, hat schon Hyrtl in seiner wiederholt angeführten Dissertation behauptet, wenn er auch die Roheit des Verfahrens im allgemeinen nicht verkennen wollte.

Der älteste, nicht ägyptische Bericht über das Einbalsamierungsverfahren stammt von Herodot, dem Vater der Geschichte. Dort heißt es II, 86: „In Ägypten sind gewisse Personen durch das Gesetz zur Ausübung dieser Kunst als ihres eigenen Geschäfts bestimmt. - Wenn nun ein Leichnam zu ihnen gebracht wird, zeigen sie drei verschiedene Mumienmodelle aus $\mathrm{Holz}$ mit entsprechender Bemalung, ein sehr fein ausgeführtes, teures, ein minder feines, wohlfeileres, und ein drittes zum niedrigsten Preise. Nachdem die Sorte ausgewählt und der Preis bedungen ist, ziehen sich die Bringer der Leiche zurück und überlassen letztere den Einbalsamierern."

Bei der ersten Sorte begannen diese mit der Herausnahme des Gehirns durch die Nasenöffnung vermittelst einer gekrümmten eisernen Sonde, wobei sie nach und nach die Schädelhöhle entleerten und dafür bestimmte Spezereien hineinbrachten. Dann machten sie einen Einschnitt an der Seite mit einem scharfen äthiopischen Steine und zogen die Eingeweide durch diese Öffnung heraus. Hatten sie dieselben gereinigt und mit Palmwein gewaschen, so bedeckten sie dieselben mit gestoßenen aromatischen Mitteln. Hierauf füllten sie die Leibeshöhle mit Pulver aus Myrrhe, Kassia und anderen Substanzen mit Ausnahme von Weihrauch und nähten dann die Öffnung zu. War dies geschehen, so legten sie den Leichnam auf 70 Tage in Natron. War der 7o. Tag vorüber, so wurde der Leichnam gewaschen und mit feinen Leinwandbinden umwickelt, die auf der is neren Seite mit Gummi bestrichen waren; hierauf wurde er in einen hölzernen Behälter in Form eines Menschen gelegt, dieser geschlossen und in einen Raum des Hauses gebracht, wo er aufrecht an die Wand gestellt wurde.

Bei der mittleren Stufe füllten die Einbalsamierer, ohne einen Einschnitt zu machen und die Eingeweide zu entfernen, Spritzen mit Zedernöl und injizierten letzteres in die Bauchhöhle, sorgten dafür, daß die Flüssigkeit nicht auslief und legten den Körper auf eine bestimmte Anzahl von Tagen in Salz. Die Wirkung des Zedernöls war eine so starke, daß alle inneren Teile in einen Zustand von Aufösung (?) gebracht wurden. Das Natron ferner löste das Fleisch auf, so daß schließlich nichts als Haut und Knochen übrig 
blieb. Ein weiteres Verfahren wurde mit dem Leichnam nicht vorgenommen.

Bei der dritten Stufe für Arme wurde der Körper bloß durch eine Injektion von Syrmaea (?) vor Verwesung geschülzt, auf 70 Tage in Salz gelegt und darauf den Angehörigen zurückgegeben.

Diodor Sicul I, 9I führt ebenfalls drei Stufen des Einbalsamierungsverfahrens an und gibt von der ersten Stufe eine ergänzende, teilweise auch abweichende Beschreibung. Zuerst zeichnete Einer, welcher der Schreiber genannt wurde, auf der linken Seite den zu machenden Schnitt vor. Dieser wurde von einem zweiten,

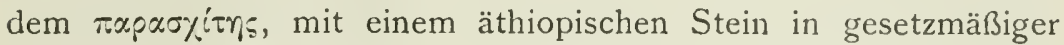
Länge ausgeführt, worauf der Schnittführer sofort hinwegrannte, verfolgt von den Anwesenden, welche ihm Steine nachwarfen und Verwünschungen nachriefen. (Diodor erklärt dies aus dem Haß, den jeder auf sich zog, der Gewalttätigkeit gegen einen menschlichen Körper ausübte.) Die Einbalsamierer selbst aber erfreuten sich der größten Hochachtung. - Sobald der Schnitt gemacht war, führte einer seine Hand in die Öffnung und zog alle Eingeweide heraus mit Ausnahme des Herzens und der Nieren. Ein Anderer wusch die Eingeweide mit Palmwein und aromatischen Stoffen. Schließlich, nachdem der Leichnam mehr als 30 Tage mit Zedernöl und anderen Dingen behandelt worden war, wurde er mit Myrrhen, Zimt und anderen Stoffen balsamiert, welche nicht nur die Fäulnis aufhielten, sondern auch dem Körper Wohlgeruch verliehen.

Diodor weicht darin von Herodot $a b$, daß er bei der ersten Einbalsamierungsstufe nicht alle Eingeweide herausnehmen, sondern Herz und Nieren zurückbleiben läßt. Darin stimmen aber beide alten Schriftsteller überein, daß sie über das Schicksal der herausgenommenen Eingeweide nichts mitteilen. Plutarch erzählt irrtümlicherweise, man habe dieselben in den Fluß geworfen. Am nächsten der Wahrheit kommt Porphyrius (de abstinentia IV, IO), wenn er sagt, die Eingeweide seien alle in ein Gefäß gelegt worden. In Wirklichkeit aber ist durch Funde und Untersuchungen nachgewiesen, daß nicht alle Eingeweide in einem Gefäß, sondern verteilt in 4 Gefäßen (Kanopen) untergebracht wurden. Der Inhalt je eines dieser Kanopen war je einer bestimmten Gottheit geweiht. Das Gefäß mit dem Deckel in Form des menschlichen Kopfes des Amset enthielt den Magen und die großen Eingeweide; das 
mit dem Cynocephaluskopf des Hapi die kleinen Eingeweide; das mit dem Schakalkopf des Smautf die Lunge und das Herz; das mit dem habichtsköpfigen Kebhsnof die Leber und die Gallenblase. Es gab aber auch Fälle, wo die Eingeweide, nachdem sie gereinigt und balsamiert waren, durch die Einschnittsöffnung wieder in die Leibeshöhle zurückgebracht wurden.

Auch bezüglich der Art der Herausnahme des Gehirns bestehen verschiedene Ansichten. Im Gegensatz zu Herodot behauptet nämlich Gryphius (Tractatus de Mumiis, Vratislaw, p. 45), dessen Quelle mir nicht bekannt ist, die Ägypter haben das Gehirn nicht durch die Nase, sondern durch das große Hinterhauptloch entfernt. War dies so, wofür freilich keine sichere Bürgschaft besteht, so würde dies die Summe der praktisch-anatomischen Kenntnisse, die schon durch das Herausnehmen der einzelnen Eingeweide aus dem Seitenschnitt bewiesen ist, noch ansehnlicher gestalten.

Verdient auch die Mitteilung Plutarchs Glauben, daß die alten Ägypter bei ihren festlichen Gelagen ein Skelett aufzustellen pflegten, um an die menschliche Vergänglichkeit erinnert zu werden? Die Gelehrten stritten sich darüber, ob dies wirkliche Skelette, oder bloß Nachbildungen von Holz etc. gewesen seien. Haller hält an der wirklichen Slieletnatur fest und führt als Parallele die Juden an, welche bei Festgelagen ebenfalls Skelete aufgestellt haben sollen. (?) Der wichtigste Beweis für wirkliche Skelete ist der, daß in einer Mumie eine kupferne Nachbildung eines Skelets gefunden wurde, ebenso die Abbildungen auf Urnen, Gemmen und Marmorreliefs.

Jedenfalls ist in dem Voranstehenden der Beweis geliefert, daß die alten ägyptischen Priesterärzte in der Anatomie, besonders in der topographischen Anatomie, schon ganz respektable Kenntnisse gehabt haben müssen. Wäre dies nicht so gewesen, so hätten sie sich nicht getrauen können, in verschiedenen Krankheiten die Arteriotomie auszuführen (Hyrtl). Unter allen Umständen würde man sich einer großen Täuschung hingeben, wenn man daraus auf eine noch während des mittleren Reichs herrschende Armut an anatomischen Begriffen schließen würde, daß vielfach gleichlautende Bezeichnungen für verschiedene Körperteile existieren, so für Herz und Magen, Zunge und Zäpfchen, Stirne und Nabel, Mund und vulva, Nasenmuschel und Ohrmuschel etc., während doch sicher anzunehmen ist, dałs die Ägypter damaliger Zeit diese Körperteile 
wohl zu unterscheiden wußten. v. Oefele*) verweist mit Recht darauf, daß solche gleichlautende Benennungen auch in anderen Sprachen vorkommen und daß heute noch in der wissenschaftlichen Anatomie 2. B. das Wort tuba mehrdeutig ist.

v. Töply führt in seiner Geschichte der Anatomie (1. c. S. 161) das an, was über die Gefäßlehre der Ägypter, die vielleicht schon vom 4. Jahrtausend v. Ch. bis auf die Zeit des Ramses II ( 1324 bis 1258 v. Ch.) sich erstreckt, Genaueres bekannt ist. - Nach dem "Geheimbuch des Arztes" gehen vom Herzen alle "metu" aus, worunter sowohl Gänge, Gefäße, Adern, als auch Nerven und Muskeln zu verstehen sind. metu gibt es: 4 in der Nase (2 für Schleim, 2 für Blut), 4 an den Schläfen (und für die Augen), $4 \mathrm{im}$ Kopf, 2 zum Jochbein, je 2 zum rechten Ohr (für den Lebenshauch) und zum linken Ohr (für den Todeshauch), 6 zu beiden Armen, $6 \mathrm{zu}$ den Füßen, 2 zu den Hoden, 2 zu den Nieren, 4 zur Leber für Feuchtigkeit und Luft, 4 zum Mastdarm und zur Milz, 2 zur Blase (Harnleiter), 4 in den After. - Nach dem Buch „Vom Vertreiben der "uchedu" soll der Mensch 12 Herzgefäße mit Ausbreitung in alle Glieder haben. „Sie kommen in ihrer Gesamtheit von seinem Herzen und verteilen sich in seiner Nase, sich sammelnd in ihrer Gesamtheit in seinen beiden Hinterbacken." - Zieht man aber den Papyrus Brugsch zu Rate, so ,,hat der Kopf 32 Adern, von ihm aus schöpfen sie den Atem nach der Brust, so daß sie den Atem allen Gliedern geben." Es scheint wohl in diesen verschiedenen Angaben eine große Unklarheit zu herrschen, die sich aber vielleicht als geringer herausstellen würde, wenn wir in jedem einzelnen Fall genau wüßten, was die alten ägyptischen Autoren unter "Adern" (metu) verstanden haben.

Während der Periode von Pfammetik bis Alexander d. G. weist die ägyptische Anatomie keine wesentlichen Unterschiede gegenüber der alten Lehre auf. Während der Ptolemäerzeit dagegen findet sie in den hieroglyphisch abgefaßten Tempelrezepten und den griechisch geschriebenen Papyri dieser Periode keine Erwähnung. Auch in der Anatomie der Kopten, welche in der früheren Periode von der ägyptischen nicht wesentlich abwich, ist jetzt eine Degeneration der früheren Lehren zu bemerken, so daß jetzt z. B. von 300 Adern, die vom Nabel ausgehen, die Rede sein konnte. ${ }^{* *}$ )

*) v. Oefele a. a. O., S. 84.

"*) v. Oefele a. a. O., S. 103-106. 
Was die griechischen Naturphilosophen über die Anatomie des menschlichen Körpers wußten oder dachten, erinnert teils an die humoralpathologische Keilschriftmedizin, teils an die Pneumalchre der Ägypter. Der tiefsinnige Pythagoras $(575$ bis 500 v. Ch.) fühlte sich als Arzt veranlaßt, tierische Körper zu untersuchen und über die Zeugung und das Werden der Körper seine Ansichten zu äußern. Nach der Ansicht seines Anhängers Philolaos v. Kroton besteht der Körper aus Warmem und wird gebildet in der gleichfalls warmen Gebärmutter. Die Galle ist Fleischsaft und hat mit der Leber nichts zu tun. Der Schleim wird

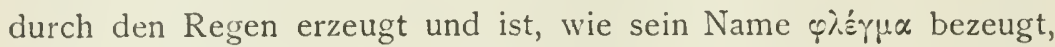
warm. Das Menschliche verlegte dieser Denker in das Gehirn, das Tierische in das Herz und das Pflanzliche in den Nabel.*) Ein weiterer Nachfolger des Pythagoras, Alkmäon v. Kroton, soll nach Chalkidios sich um die Anatomie des Auges verdient gemacht haben. Zeller, Windelband und Häser nehmen überhaupt an, daß er Tierselitionen gemacht habe. Merkwürdigerweise hatte er auch eine Ahnung von einem vom Gehirn ausgehenden Nervensystem, indem er außer dem Tastsinn rópo: (Gänge) annahm, die von den Sinnesorganen zum Gehirn, dem Sitz der Seele, laufen. Den Adern ( $\left.\varphi \lambda € \beta \varepsilon_{5}\right)$, welche er bei den Selitionen nahezu blutleer fand, stellte er blutführende Adern ( $\alpha$ íóṕṕoot) gegenüber; den Ursprung aller Adern aber führte er auf den Kopf zurück. Was er jedoch als äptr,p: $\eta$ aufführt, ist nicht eine Arterie, sondern die Luftröhre.**) - Der stark von Alkmäon beeinflußte Empedoiles ron Akragas (ca. 495-435 v. Ch.) lehrte, die Seele sei im Blut und bewege sich im Blut durch Kanäle für die Sinnesorgane, die Haut und die Nahrung. Indem sich das Blut in der Brust senke, bewirke es das Nachströmen der Luft, während das sich hebende Blut die Luft austreibe. Teilweise erfolge auch eine Atmung durch die Haut. Rob. Fuchs***) berichtet weiter von ihm, daß er den Zusammenhang der Knochen und Weichteile zu ergründen versucht habe, was zu dieser Zeit schon ein sehr bemerkenswerter Anfang einer Muskel- und Bänderlehre gewesen wäre.

Diogenes v. Apollonia (ca. 430 v. Ch.) lehrte, es gebe

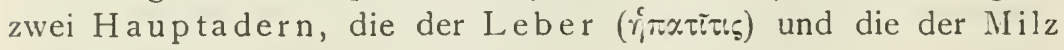

*) R. Fuchs in Handb. der Gesch. d. Med., Bd. I, S. I72.

**) R. Fuclıs, 1. c. S. I 72.

*.) R. Fuchs, 1. c. S. 173 . 


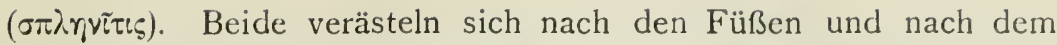
Kopfe und berühren auch das Herz. Die Adern führen nach seiner Ansicht ohne Unterschied Blut und Luft. Daneben gibt er schwache Andeutungen von einer Aorta, einer Vena cava, einer Carotis und Ingularis. *)

Von dem Arzt und Atomistiker Democritos v. Abdera wird berichtet, daß er sich viel mit der Anatomie der Tiere beschäftigt und über die Anatomie des Chamäleons eine besondere Schrift hinterlassen habe. Wie die Naturphilosophen vor ihm beschäftigte er sich auch mit der Frage über Zeugung und Entwicklung des Menschen, sprach von männlichen und weiblichen samenbildenden Organen, und ließ vom Embryo zuerst den Nabel sich bilden als Fruchthalter, dann Kopf und Bauch und schließlich die inneren Teile.**)

Eigentümliche Ansichten über die Entwickelung hatte auch Anaxagoras von Klazomenai (ca. $500-428$ v. Ch.). Nach ihm gibt nur der Mann den Keim, das Weib nur die Stätte zur Umformung. Zuerst bildet sich das Gehirn. Knaben gehen aus dem rechten Hoden hervor und liegen im rechten Uterushorn, bei den Mädchen ist es umgekehrt. Es ist dies ein Beweis, daß er seine anatomischen Untersuchungen nur an Tieren gemacht hat, doch ist ihm als Verdienst anzurechnen, daß er bei Gehirnuntersuchungen die seitlichen Ventrikel entdeckt hat. - Als weitere Vorgänger des Hippokrates sind noch Demokedes von Kroton und Euryphon aus $\mathrm{Knidos}$ zu nennen, beides der Anatomie, wenn auch wahrscheinlich nur der tierischen, kundige Ärzte.

Im großen Ganzen aber beschränkte sich das hauptsächlichste anatomische Wissen dieser Arzt-Philosophen vor Hippokrates auf die Knochenlehre und die wichtigsten Organe der Körperhöhlen, während über Muskeln, Gefäße und Nerven nur dunkle und lückenhafte Vorstellungen bestanden. Ein Schritt weiter in der wissenschaftlichen Anatomie wurde in den Leiden Asklepiadenschulen in $\mathrm{Knidos}$ und auf $\mathrm{Kos}$ gewonnen, die sich lange um die Palme des ärztlichen Ruhmes stritten, bis endlich der Sieg der Koischen Schule zufiel. Beide beschäftigten sich neben Erforschung und Behandlung der Krankheiten auch mit A natomie, ganz besonders wird der knidischen Schule von Galen

") R. Fuchs 1. c. S. I7I.

*") R. Fuchs 1. c. S. 176. 
(II, 900) das Zeugnis ausgestellt, daß sie in der Anatomie gutes geleistet habe. Doch hatte diese Schule ihre eigentümlichen Kunst-

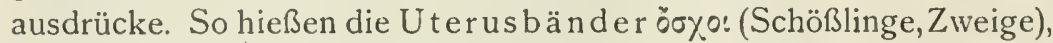
der Lendenmuskel $\alpha \lambda \omega ́ \pi \eta \xi$ (Fuchs) etc. In der knidischen, von

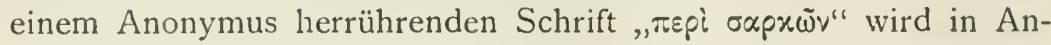
lehnung an Heraklit und Parmenides das Warme als Grund aller Dinge angegeben; die Körperteile entstehen aus den Fäulnismengen der Erde, die sich in Fettes, Klebriges, Kaltes, Feuchtes verwandele durch die Einwirkung der göttlichen Wärme. - Am meisten fortschrittlich erscheint die Schrift $\pi \varepsilon p i$ à்̃́vwv, in der die Drüsen, ihre Lage und Funktion beschrieben werden. Drüsen sitzen in den Eingeweiden, in den Nieren, im Hals, im Kopf und in der Achselhöhle. Die größte Drüse ist das Gehirn. - Bei allem Fortschritt aber zeigt sich doch eine auffallende Abhängigkeit von der Keilschriftmedizin, hauptsächlich in der knidischen Schrift , $\pi \varepsilon p ?$ \&ßjōo$\mu \alpha \dot{\delta} \omega v "$ ", worin nachgewiesen wird, daß die Sieben (Planeten) das All und alle Körpervorgänge beherrschen, also die alte Übertragung der kosmischen Theorie auf den Mikrokosmos, den Menschen.

Außer den angeführten knidischen Schriften sind mit den eigentlichen hippokratischen Schriften auch solche von Sophisten verbunden, d. h. von solchen Literaten, welche nicht dem Stande der Ärzte, sondern dem der Philosophen und Redner angehörten. Eine solche, von unbekanntem Autor herrührende Schrift aus dem

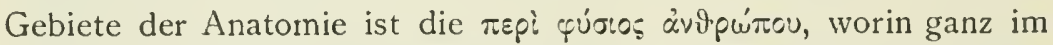
Sinne der Keilschriftmedizin die Zusammensetzung des Menschen aus 4 Qualitäten (warm, kalt, feucht, trocken) in Form von Blut, Schleim, gelber und schwarzer Galle gelehrt und die wechselseitige $\mathrm{Zu}$ - und Abnahme der Säfte mit der Jahreszeit verfochten wird.

Der koischen Schule können sicher oder wenigstens wahrscheinlich zugeschrieben werden folgende Schr.ften:

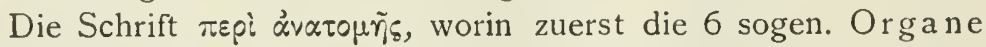
der Mitte, nämlich die Luftröhre, die Lunge, das Herz, die Nieren und die Blase und weiter die Speiseröhre, der Magen, das Zwerchfell, die Milz und die Därme besprochen werden.*)

Die Schrift $\pi \varepsilon p i$ xapoìns enthält eine eingehende Beschreibung des Herzens und seiner Verrichtungen; und die Abhandlung $\pi \varepsilon p l$

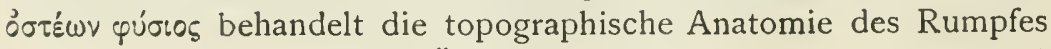
mit den Adern und ihren Ästen, den Nerven und den Sehnen.**)

") Rob. Fuchs a. a. O. S. 224.

**) Rob. Fuchs a. a. O. S. 225. 
Was wir von der Anatomie des Hippokrates und seiner Schule wissen, ist in dem niedergelegt, das dem Hippokrates selbst zugeschrieben wird. Die Asklepiaden gewannen ihre anatomischen Kenntnisse auf verschiedenen Wegen:*)

I. durch mündliche oder schriftliche Überlieferung;

2. durch Zuschauen bei Opfern und Hausschlachtungen;

3. durch Zuschauen in der Palästra;

4. durch Beobachtung von Verletzungen im Krieg und Frieden;

5. durch Beobachtung von unbeerdigten Leichnamen und Leichenresten;

6. durch Tieranatomie.

$\mathrm{Daß}$ letztere eine Hauptrolle spielte, ist durch verschiedene Stellen belegt, worin Vergleiche zwischen tierischen und menschlichen Organen angestellt werden. Ganz auf tierischer Anatomie beruht die Lehre vom zweihörnigen uterus. Die oben erwähnten Vergleiche sprechen aber auch für die Existenz einer Menschenanatomie, denn woher käme z. B. die genaue Beschreibung des humerus, der Wirbelsäule, des Zwerchfells, der Bänder, Sehnen und Nervenstränge? Freilich laufen über die Lage der inneren Organe viele Irrtümer mit unter. Planmäßige Sektionen von Menschen mögen wohl sehr selten gewesen sein, während gelegentliche Untersuchungen partieller Art ziemlich häufig gewesen sein mögen. Anatomische Lehrbücher sollen die Asklepiaden nach Galen (II, 280) nicht gehabt haben, das erste derartige Werk soll von Diocles verfaßt worden sein.

Um nun speziell auf die hippokratische Anatomie einzugehen, so stoßen wir schon in der Osteologie neben allem ernsten Streben nach Wahrheit auf manche Lücken und Irrtümer. Am Schädel sind beschrieben die Schädelknochen mit ihren Suturen, die Stirnhöhlen, das Perikranium, die äußere und innere Platte, sowie die Diploe, die Nasenknochen und Nasenknorpel, das Siebbein und die Kiefer.

Auffallende Mängel zeigt die Beschreibung der Wirbelsäule. Während der Zahnfortsatz des zweiten Halswirbels beschrieben ist, wird der erste Wirbel gar nicht erwähnt. Die ganze Wirbelzahl soll höchstens $18-22$ betragen. Von Rippen werden sieben echte und mehrere unechte angeführt, die Schlüsselbeine und ihre

") R. Fuchs a. a. O. S. $2 ; 6$. 
Verbindung mit dem Brustbein beschrieben, das Akromion aber für einen selbständigen Knochen ähnlich dem Schulterblatt ange. sehen. Zur leichteren Gelenkverbindung der Knochen unter einander dient die Gelenkschmiere.

Von den Muskeln (vulgo Fleisch) kennt Hippokrates die Schläfenmuskeln und Masseteren, die Humerusmuskeln und Sehnen, den Deltamuskel und den großen Brustmuskel, die Hand- und die Fingerbeuger, die Glutäen, die Schenkelmuskeln, die Fibulasehne und die Achillessehne, sowie die Rückenmuskeln. Sehnen und Nerven führen den gemeinsamen Namen veũpa.

Von den Verdauungsorganen unterscheidet er als zwei Höhlen den Magen und die Därme. Ersterer wird durch Adern und Fasern mit den Nieren verbunden und geht in das 12 Ellen lange \% $\tilde{\omega}$. ov über, an das sich endlich der Mastdarm anschließt. Das Peritoneum als Überzug der Unterleibsorgane und Auskleidung der Leibeshöhle ist bekannt. Gelegentlich ist auch von dem Leerdarm (vĩot:s), dem Mesenterium und Mesokolon die Rede.

Die Leber gilt im Sinne der damaligen Anschauung als Quelle des Blutes. Links in der Leibeshöhle liegt die einer Fußsohle ähnliche Milz.

Von Drüsen sind nur die Mandeln, die Lymphdrüsen des Halses, die Mesenterialdrüsen und Brustdrüsen bekannt, während die Schilddrüse und die Bauchspeicheldrüse gar nicht, die Parotis nur selten erwähnt wird. Die Hauptdrüse ist das Gehirn.

Als Atmungsorgane kommen zur Sprache der Kehldeckel, die Luftröhre und die Bronchien. Die aschgraue, wie ein Wespennest aussehende Lunge hat 5 Zipfel. Die Luft geht zu den Lungen, der feinste Teil durch Mund und Nase ins Gehirn und von der Lunge durch die Adern zum Herz.

Vom Schlund an geht das Getränk nicht in die Lunge, sondern teils in den Magen, teils in das Pericardium, um das Herz abzukühlen.

Das Herz selbst ist pyramidenförmig, umgeben von einem feinen Häutchen und einer zwischen beiden sich befindenden urinartigen Flüssigkeit. Es sind zwei Kammern vorhanden, eine rechte und eine linke, beide miteinander kommunizierend, die linke geräumiger und schlaffer als die rechte. Die linke Kammer ist juftleer und nährt sich von dem feinsten Bestandteile des Blutes aus der rechten Kammer. Die halbmondförmigen Klappen schließen 
so gut, daß weder Luft noch Wasser eindringen kann. Daß dic Herzohren nicht zum Hören dienen, wird extra hervorgehoben.

Was die Adern ( heit der Vorstellungen in den hippokratischen Schriften für die Unklarheit, die noch herrschte. Die früheste Ansicht war, die Adern entspringen im Kopfe; später (im Anschluß an Diogenes v. Apollonia) ließ man sie von der aorta und der vena cava ausgehen. Die àperpix gelten als ganz luftührende Adern. Leber und Milz entsenden die vena cava und die aorta abdominalis, dann Verzweigungen in den übrigen Organen. Für den Speicher des Blutes wurde die rechte Herzkammer angesehen, doch ist nirgends näher beschrieben, wie sie das Blut erhält. Der linken Herzkammer dagegen wird eine Wärme zugeschrieben, die das an sich kalte Blut erwärmt, worauf es dann durch das hämmernde Herz in die Adern getrieben wird.

Wie oben erwähnt, figuriert das Gehirn in den hippokratischen Schriften als eine mit kalter Flüssigkeit gefüllte, größte Drüse des menschlichen Körpers, aber in der Schrift „de morbo" gilt diese Drüse bereits als Sitz des Denkvermögens, des Gefühls und der Bewegung. Es werden die zwei durch eine dazwischen liegende Haut mit einander verbundenen Gehirnhälften, die harte und die weiche Hirnhaut ( $\left.\mu \tilde{r}_{i} \cdot \gamma_{\xi}\right)$ beschrieben, dann kommt wieder eine absonderliche Behauptung, nämlich die, daß der vom ganzen Körper abgesonderte Samen im Gehirn aufgespeichert und von da zu den Hoden geleitet werde.

Von Gehirnnerven sind bekannt der acusticus, der trigeminus und der vagus; von Rückenmarksnerven der plexus brachialis, der n. ulnaris, die nn. intercostales und der n. ischiadicus. Was für eine Funktion aber diese Nerven haben, wird nicht gesagt.

Von den Sinnesorganen wird nur das Auge, das Ohr und die Nase besprochen. Das Auge hat 3 Häute, die weiße, die innere (Iris) und die spinnwebenartige. Vor der Pupille liegt die Hornhaut. Zwischen Auge und Gehirn bestehen mehrere Verbindungen ( $\left.\varphi_{\lambda} \varepsilon_{\beta} \varepsilon_{\xi}\right)$, darunter der Sehnerv. Die Sehflüssigkeit mit ihren Stoffteilchen dringt durch die pi.厃ßss in das Gehirn und erzeugt dort Gesichtseindrücke. Vom Ohr sind Felsenbein und Trommelfell bekannt; das Labyrinth ist schon von Empedocles entdeckt worden. Der Ton kommt durch den von dem Knochen (Felsenbein) erzeugten Widerhall zustande, außerdem aber gibt es 
in der Umgebung des Ohrs leere Hohlräume, durch die der Schall zum Gehirn geleitet wird. - Ein n. olfactorius ist nicht bekannt. Es wurde angenommen, daß der Geruch der Stoffe einfach durch das Siebbein in das Gehirn dringe.

Höchst unklar und lückenhaft ist die Kenntnis von dem Urogenitalapparat. Den Nieren wird das Anziehen der Flüssigkeit zugeschrieben. Von Samenbläschen und vasa deferentia findet sich nur eine Andeutung. - Die weiblichen Genitalien sind unter Berücksichtigung der Tieranatomie ziemlich genau beschrieben, so der zweihörnig gedachte Uterus ( $\mu \tilde{\gamma} \tau p \alpha t)$, die Uterusbänder und die äußeren Genitalien. Die Ovarien aber finden keine Erwähnung.*)

Von unmittelbaren Nachfolgern des Hippokrates erwähnt Galen (II, 282; XV, 1357) in erster Linie den Arzt Diocles von

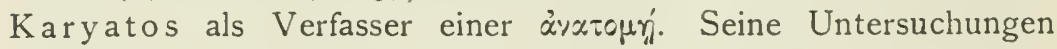
erstreckten sich auf Lunge, Herz, die rópot (Gänge) zwischen Gallenblase und Leber, die Blinddarmklappe, die Ureteren und den Pförtner. Der Sitz der Seele ist im Herz und zwar in dem Pneuma der linken Kammer. Von hier gehen die beiden

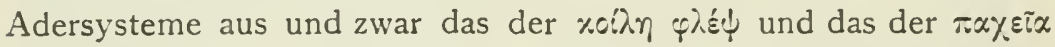
áprrpix (Aorta). Die Aorta ist blutüberfüllt, enthält aber auch Pneuma, das zum Gehirn geht. In diesem dient die rechte Hemisphäre für die sinnlichen Wahrnehmungen, die linke für den Verstand.

Ein Zeitgenosse des Diocles (und des Aristoteles) war der Arzt und Anatom Praxagoras. Von ihm rühmt Galen (XV, I35), daß er den Unterschied zwischen Venen und Arterien klar hervorgehoben und letztere in Verbindung mit dem Puls gebracht habe. Er kannte auch das terlängerte Mark als ein Anhängsel des Rückenmarks gegen das Gehirn zu und scheint die empfindungsleitende Funktion der Nerven geahnt zu haben, wenn er auch immer noch, befangen in den Vorstellungen seiner Zeit, das Zentrum der Empfindung in das Herz verlegte.

Schließlich sind noch als tüchtige Anatomen dieser Periode zu nennen Xenophon v. Kos, Pleistonikos und Philotimos. Letzterer beschrieb die übrigens schon früher bekannten Tuben unter dem Namen ró̀.t.o..**)

*) Rob. Fuchs a. a. O., S. $238 \pi$.

*) Rob. Fuchs a. a. O., S. 272 f. 
Ganz besonders interessant ist es, die Vorstellungen kennen zu lernen, welche die zwei grolien Philosophen Plato und Aristoteles über die Anatomie des Menschen gehabt haben.*) Obgleich Plato kein Arzt war, erkannte er doch den hohen Wert anatomischer Untersuchungen, kam aber über die von ihm gewonnenen Ideen nicht hinaus zu einem klaren Einblick in die anatomischen Verhältnisse. Das Herz hielt er für eine Verknotungsstelle der noch nicht unterschiedenen Adern und die Quelle des durch alle Glieder getriebenen Blutes. Weil das Herz heiß ist, bedarf es einer Abkühlung durch die Lungen, welche das $\pi v \tilde{u} \mu \alpha$ und die Getränke aufnehmen, um dann letztere nach den Nieren und der Blase weiter zu befördern. Der feste Teil der Nahrung gelangt durch die Speiseröhre in die Bauchhöhle. (Also keine Erwähnung des Magens.) Die dichte, glatte, glänzende Leber

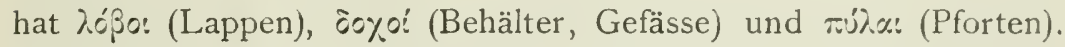
Die Milz dagegen ist hohl und ein Behälter für die durch Krankheiten erzeugten Unreinigkeiten. Knochen und Weichteile (Muskeln) sind aus dem Mark resp. Blut hervorgegangen, der edelste Teil des Marks aber ist das Gehirn als Samenbereitungsstätte. Alles in Allem mehr Dichtung als Wahrheit!*) — Ein solches Zeugnis sollte über den berühmten Naturforscher und vergleichenden Anatomen Aristoteles (384-322 v. Ch.) nicht abgegeben werden dürfen; zwar sind seine áv gegangen, was aber von seinen anatomischen Anschauungen erhalten ist, enthält eine Menge Irrtümer, die man dem Begründer der wissenschaftlichen Zoologie nur deswegen zugute halten muß, weil ihm nicht das Material zu Gebote stand, um die Forschungen der Hippokratiker weiter auszubilden. Ja und in seiner Nichtunterscheidung der Venen und Arterien steht er sogar hinter den oben genannten Hippokratikern zurück. Er kennt wohl die verschiedene Färbung des venösen und arteriellen Blutes, hat aber augenscheinlich die aorta für blutleer gehalten. Im Herz, von dem alle Adern und Nerven ausgehen, nahm er drei Kammern an. Das Gehirn, eine blutlose, kalte und empfindungslose Drüse, nimmt bloß den Vorder- und den Mittelteil des Schädels ein; das Hinterhaupt hielt er für leer. Im Gegensatz zum Gehirn ist das Rückenmark von warmer Beschaffenheit. - Ungenau ist seine Beschreibung der Hand- und Fußknochen, ungenau die gemeinsame Bezeichnung

*) Rob. Fuchs a. a. O., S. $287 \mathrm{ff}$. 
Tópo: für Nerven, Sehnen, Bänder, Darm und Ureter; falsch ist die Beschreibung der Nieren als gelappt und des Uterus als zweihörnig, Mängel, die deutlich ihre Entstehung aus der Tieranatomie erkennen lassen. Über die anatomischen Leistungen seines Neffen $\mathrm{K}$ allisthenes v. Olinthos und des Klearchos v. Soloi, des Verfassers , $\pi \varepsilon p i \quad \sigma \varkappa \varepsilon \lambda \varepsilon \tau \omega r "$ sind wir nicht hinreichend unterrichtet.

Von den nachhippokratischen Empirikern haben sich mehrere als Anatomen einen Namen gemacht. Merkwürdig ist die Ansicht des Serapion (ca. 220 v. Ch.), daß der Uterus im Körper herumwandere. - Von Apollonios v. Kition besitzen wir ein mit zahlreichen bunten Bildern geziertes, mit byzantinischen Zutaten

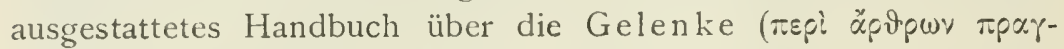

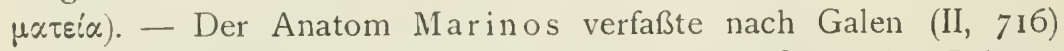

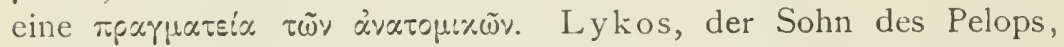
schrieb ein anatomisches Lehrbuch $\pi \varepsilon \rho ! ~ \mu u \omega \tilde{v}$, das aber später von Galen (XVIII, IOO) als lücken- und fehlerhaft scharf angefeindet wurde. Dagegen rühmt Galen $(X V, 136)$ von Aristogenes aus Knidos, dem Leibarzt des makedonischen Königs Antigonus Gonatus, daß er in der Anatomie, namentlich des Schädels, sehr bewandert gewesen sei.

Ihren Höhepunkt erreichte die altgriechische wissenschaftliche Anatomie an der von Ptolemaeos I 320 v. Chr. gestifteten ersten anatomischen Schule zu Alexandria, welcher als Koryphäen . die Anatomen Herophilos, Eudemos und Erasistratos angehörten. Von ihren Schriften ist nichts bekannt; was wir von ihrer ruhmvollen Tätigkeit wissen, ist das durch Celsus, Rufus Ephesius und Galenos Überlieferte. Wenn freilich von Celsus (de medicina in prooemio) und von Tertullian (de anima) diesen Männern die Sektion Lebender zugeschrieben wird, so würde diese Tatsache ihren Ruhm wesentlich einschränken. Doch haben neuere Untersuchungen**) erwiesen, daß es sich zum mindesten um Übertreibung, wenn nicht gar vollständige Erfindung handelt, die den beiden oben genannten Berichterstattern zur Last fällt. Absolut sicher dagegen steht die Tatsache der Sektion Toter (cf. Plin. Nat. Hist. 10, 5, 86 und Galen. II, 895, 900). Auch die in Alexandria herrschende Sektionstechnik ist uns durch Celsus ( $I, I)$ bekannt. Es wurde zuerst die Bauchhöhle und dann der Thorax geöffnet.

") Rob. Fuchs a. a. O., S. 309 f., 319.

**) Rob. Fuchs a. a. O. S. 286. 
Daneben aber kamen beim Unterricht auch Demonstrationen von Präparaten und andere Anschauungsmittel zur Anwendung.

Das Hauptergebnis dieser anatomischen Studien war, daß nunmehr Arterien und Venen streng auseinander gehalten wurden; auch die Chylusgefässe des Darmkanals waren schon bekannt. - Spezielles Verdienst des Herophilos ist seine vorzügliche Beschreibung des Gehirns (plexus chorioidei, torcular Herophili, calamus scriptorius), des Zwölffingerdarms, der Leber, der Arteria pulmonaria, der Genitalien und des Auges, wenn er auch bei letzterem in dem alten Irrtum befangen war, der Sehnerv diene als rópos für das Pneuma. - Erasistratos (geb. ca. 330 v. Ch.) ist der Entdecker des Wesens und Zweckes der Nerven. Nachdem er so weit gekommen war, erkannte er auch die Bedeutung des größeren Reichtums des Menschenhirns an Windungen gegenüber dem Tierhirn, glaubte aber, das Seelenzentrum in die $\mu \tilde{r} v\llcorner\gamma \xi$ und in das kleine, für sich überhäutete Gehirn verlegen zu müssen. Dasselbe Wechselspiel zwischen Wahrheitserkenntnis und Befangensein in alten Anschauungen wiederholt sich auch auf einem anderen Gebiete. Erasistratos gebührt der Ruhm, zuerst eine Ahnung von dem Blutkreislauf gehabt zu haben; daneben aber hielt er immer noch an der Lufthaltigkeit der Arterien fest und ließ den Pneumalauf vom Herzen, den Blutlauf von der Leber beginnen. Wie hochbedeutsam die Tätigkeit des Erasistratos als Anatom war, ergibt sich aus der Geschichte der von ihm begründeten Schule. Erasistratos war freilich nicht bloß Anatom, sondern auch und in erster Linie ein bahnbrechender Meisterarzt. Aber seine Schule, die noch im 2. Jahrhundert n. Ch. in Rom zahlreiche Anhänger hatte, verfiel gerade deswegen allmählich der Mißachtung, weil sie später die Grundlage jeder wissenschaftlichen Medizin, die Anatomie und Physiologie, vernachlässigte.

Von dem Ableben der großen Alexandriner Anatomen an bis zu dem Auftreten des Galenos ist mit wenigen Ausnahmen die altgriechische Anatomie im Niedergang begriffen. Während dieser Zeit hatten sich zahlreiche griechische Ärzte in Rom niedergelassen, zuerst Archagathos (2I9 v. Ch.), später immer neue, die teils den alten dogmatischen Lehren des Hippokrates, teils der Schule der Empiriker sich zuneigten. Im Gegensatz zu diesen beiden Lehren, namentlich der Humoralpathologie des Hippokrates, hatte sich unter der Führung des Griechen Asklepiades die 
Schule der Methodiker, der Anhänger einer Solidarpathologie, gebildet. Es waren keineswegs ungebildete Ärzte, die dieser Richtung angehörten, aber auf das Studium der Anatomie scheinen sie keinen Wert gelegt zu haben. Auch der hervorragende Methodiker Soranos aus Ephesus (ca. I I n. Ch.) hat kein anatomisches Werk, sondern nur eine a natomisch-physiologische Nomen-

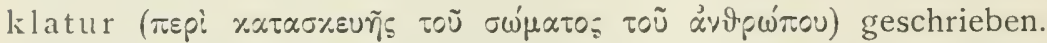
Das einzig wirklich Anatomische, die Beschreibung der weiblichen Genitalien, bildet bloß die Einleitung zu seinem Hebammenbuch und läßt aus der Mangelhaftigkeit dieser Beschreibung erkennen, daß er keine eigenen gründlichen Untersuchungen angestellt hat. Der Uterus z. B. hat die Konsistenz der Lunge oder der Zunge,

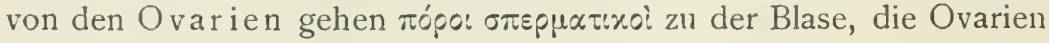

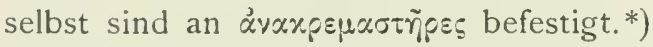

Welchem Verfasser und welcher Zeit die altgriechischen anatomischen Tafeln angehören, welche nach einer Pariser Handschrift zum erstenmale herausgegeben worden sind**), läßt sich nicht mit Sicherheit bestimmen. Fuchs glaubt, daß sie einer frühen byzantinischen Zeit angehören.

Auch von den Pneumatikern ging kein belebender Einfluß auf die Weitergestaltung der Anatomie aus. Nach der Lehre des ersten Pneumatikers A thenaios (ca. 4I-54 n. Ch.) kommt zu den 4 Urbestandteilen des Körpers, nämlich dem Warmen und Kalten, dem Feuchten und Trockenen, noch das alles durchdringende Pneuma hinzu, das von der Lunge gegen das in den Herzkammern sitzende Warme ausgetauscht wird. Die Quelle des Blutes ist die Leber, Reinigungsorgan ist die Milz. Die Arterien enthalten mehr Pneuma als Blut, die Venen mehr Blut als Pneuma. Daraus folge, daß die Arterien im Herzen, die Venen in der Leber entspringen. - Die Ovarien hielt er, wie die männlichen Brustwarzen, für vollständig bedeutungslos und nur wegen der Analogie zu den Hoden gebildet. Aber auch von diesen hatte er eine unklare Vorstellung, denn der männliche Samen ist ihm nur ein Kochprodukt des Blutes. Und was den Uterus anbetrifft, so hielt er an der Zweihörnigkeit desselben fest und ließ die Knaben im rechten Horne, die Mädchen im linken sich bilden.***)

") Rob. Fuchs a. a. O. S. 342.

**) Rob. Fuchs, Deutsche med. Wochenschrift i 898 , No. I.

"*) Rob. Fuchs a. a. O. S. 360. 
Was von den griechischen Pneumatikern in Rom gesagt wurde, trifft auch für die Eklektiker zu. Ihre Anatomie weist keinen Fortschritt auf, sondern bewegt sich in althergebrachten Bahnen, voll von irrtümlichen, teilweise recht abenteuerlichen Meinungen. Da spricht z. B. Aretaios (2.-3. Jahrh. n. Ch.) immer noch von der Tierähnlichkeit und Wanderlust des Uterus; derselbe wird auch mit dem Darme verglichen, wobei aber als Eigentümlichkeit des ersteren erwähnt ist, daß die Innenwand sich abstoße. - Von einer Trennung der Nerven, Sehnen und Bänder ist immer noch keine Rede. - Die Bellinischen Röhren kennt Aretaios, beschreibt sie aber als landengenartige Höhlen für die Durchseihung des Urins. Der Darm besteht aus zwei kreuzweise über einander liegenden Häuten; die Verdauung erfolgt durch die Wärme des Magens und des Colons, worauf der Chylus der Leber zugeführt wird. *) - Der Ephesier Rhuphos (Rufus Ephesius), der ein Buch über die Benennung der Körperteile und ein anderes über die Knochen geschrieben hat, scheint große Neigung zu anatomischen Studien gehabt zu haben, denn er beklagt sich, daß man nur noch am lebenden Sklaven die Körperoberfäche studieren dürfe, im übrigen aber auf Tiersektionen (Affen) angewiesen sei. $\mathrm{Da}$ er übrigens ein genauer Beobachter war, geht daraus hervor, daß er die Kreuzung der Sehnerven, die 7 Augapfelhäute (mit Einschluß der Linsenkapsel) und die caruncula beschreiben konnte. **)

Der berühmteste der griechischen Ärzte in Rom, der Mann, welcher die Lehren der verschiedenen Schulen in sich vereinigte, war Galenos v. Pergamon (geb. I30 n. Ch.). Seinen, das Mittelalter überdauernden Ruhm als großer Arzt verdankt er nicht zum wenigsten seinem Eifer in anatomischen Studien, über welche er selbst in seinen Schriften (II, 221 und XVIII, 235) berichtet. Sein anatomisches Wissen und Können hatte er sich in Alexandria erworben.

Seine anatomischen Schriften, in welchen er sich vielfach an Marinos anlehnt, sind der Zeit der Entstehung nach folgende:

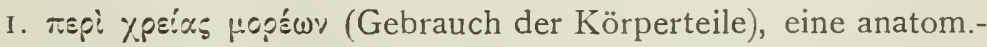
physiologische Untersuchung über die Nervenfunktionen.

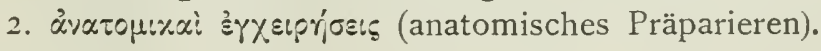

*) Rob. Fuchs a. a. O., S. 367 .

*) Rob. Fuchs a. a. O., S. 376 . 


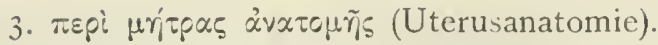

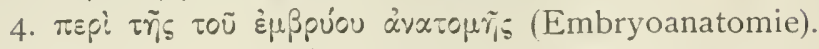

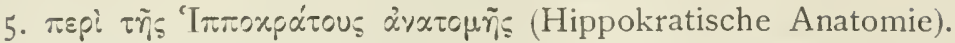

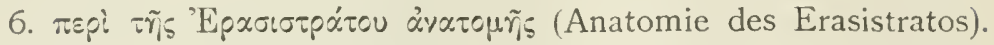

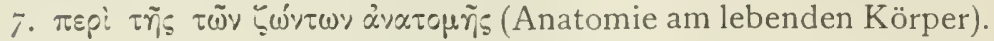

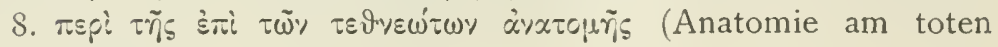
Körper).

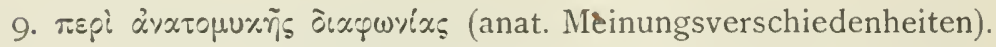

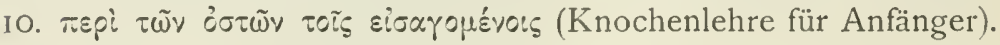

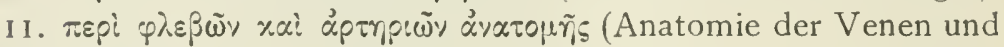
Arterien).

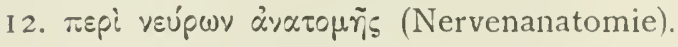

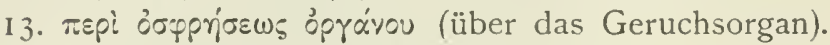

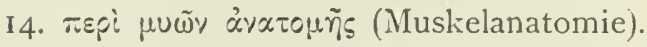

Die Objekte seiner anatomischen Studien waren fast ausschließlich Tiere, gewöhnlich Hunde und Affen (namentlich Macacus ecandatus). aber auch andere kleinere und größere Tiere, Fleisch- und Pflanzenfresser.

In der Knochenlehre beschreibt er den Schädel und seine Verbindung mit der Wirbelsäule durch den atlas, ferner das Periost, die Bänder und die Sehnen. - Von Muskeln kommen zur Beschreibung die Kopf- und Halsmuskeln (auch das platysma myoides), die musc. interossei, der m. popliteus, die Insertion der Achillessehne. - Die Zusammensetzung des oesophagus und der Därme aus verschiedenen Hautschichten hat er bei Fleisch- und Pflanzenfressern studiert. - Seine Zergliederung des Gehirns geht schon so weit, daß er 13 Teile unterscheiden kann (Balken, 2 Vorderkammern, 3. und 4. Ventrikel mit aquaeduct. Sylvii, fornix, Vierhügel, Zirbeldrüse, process. cerebelli ad corp. quadrigemina, proc. vermiformis, calamus scriptorius, hypophysis und infundibulum. Er kennt ferner 7 Paar Gehirnnerven, unterscheidet weiche Gehirnnerven, harte Rückenmarksnerven und mittelharte des verlängerten Marks. - Die R ückenmarksknoten kannte Galenos nicht. wohl aber den durch Ganglien verstärkten Sympathikus als eine Vereinigung von harten und weichen Nerven. Am Auge unterscheidet er 5 Häute und 4 Flüssigkeiten, zu denen er neben dem Kammerwasser auch die Linse, den Glaskörper und eine sogenannte Sehsubstanz zählte. - Über die Genitalien hatte er eigentümliche, Wahres und Falsches vermengende Ansichten. Die Ovarien hielt er für gleichwertig mit den Hoden; 
dem zweihörnigen Uterus aber stellt er als gleichwertig das scrotum gegenüber. - Ebensowenig hat er in der Anatomic der Verdauungs- und Zirkulationsorgane überall das Richtige erkannt; denn während er die Speisen im Magen dnrch eine

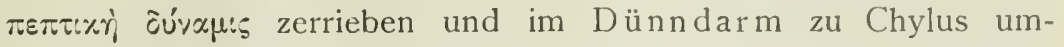
gewandelt werden läßt, schreibt er der Milz, welche eigentlich nur aus Platzmangel nicht neben der Leber liege, dic Eigenschaft zu, die dicken, erdigen Nahrungsteile aufzufressen und die daraus bereitete schwarze Galle dem Magen mitzuteilen. - Die 4 (nach der Tieranatomie konstruierten) Leberlappen erwärmen den Magen und machen ihn zur Verdauung geschickter. - Und was schließlich die Anatomie der Zirkulationsorgane betrifft, só hat Galenos zwar Manches gefunden, was ihn der Wahrheit des großen und kleinen Kreislaufs näher brachte, er steht aber doch*) dem Harveyschen Gesetze ferner, als Erasistratos. Nach seiner Ansicht führen sowohl Arterien als Venen Blut und Pneuma; aber auch er glaubt, daß der durch die Pfortader zugeführte Chylus in der Leber zu Blut werde, das nun teils durch die Hohlvene zur rechten Herzkammer, teils durch die übrigen Venen in den Körper geleitet werde; auch er glaubt, daß durch die Anastomosen der Scheidewand die Sättigung des Bluts mit dem Pneuma der linken Herzkammer zustande komme; ganz absonderlich aber ist vollends seine Ansicht, daß die qualmigen Rückstände des Bluts aus dem rechten Ventrikel durch die Halbmondklappen der Lungenarterie hindurch nach außen befördert werden.

Daß es diesem Manne Ernst mit der Anatomie war, kann mit Sicherheit daraus geschlossen werden, daß er Vivisektionen an Tieren vorgenommen hat. Wäre dies nicht der Fall gewesen, so könnte er nicht als eigene Beobachtung die Austreibung der Speisen aus dem Magen, die Urinabsonderung aus den Nieren, die Bluthaltigkeit des linken Ventrikels nebst den Herzkontraktionen, sowie die Lähmung nach Durchtrennung bestimmter Rückenmarksnerven anführen. Unter allen Umständen ist ihm das Zeugnis auszustellen, daß er die griechische Anatomie der alten Welt in würdigster Weise beschlossen und Werke hinterlassen hat, von denen viele nachfolgende Jahrhunderte gezehrt haben.

Von einer eigenen wissenschaftlichen Anatomie der Römer kann bis zum Auftreten des römischen Schriftstellers Celsus nicht

") Rob. Fuchs a. a. O., S. 398. 
wohl geredet werden. Der ganze theurgische Charakter der altitalisch-römischen Heilkunde, welche die Krankheiten als Schickungen der Götter betrachtete und demgemäß mit Gebeten, Beschwörungen und Opfern voranging, war einem wissenschaftlichen Streben nicht günstig, am wenigsten der Erforschung toter Körper, die von aller Welt mit Abscheu und Grausen betrachtet wurden. Die alten römischen Ärzte, namentlich die für die Kriege notwendigen Militärärzte, handelten nach rein empirischen Gesichtspunkten und müssen keine besondere Hochachtung genossen haben, sonst wären sie nicht so bald durch die seit Ende des 3. Jahrh. v. Chr. eingewanderten Griechenärzte verdrängt worden. Teils von letzteren, welche vielfach öffentliche Vorträge hielten, teils durch Studien in griechischen Hauptstädten erwarben sich die gebildeten Römer diejenige Summe anatomischer Kenntnisse, denen man in einzelnen ihrer Schriften begegnet. So sieht sich Cicero in seiner Schrift "de natura deorum" (lib. II, cp. 54-57) veranlaßt, als Beweis für das WaIten einer göttlichen Vernunft die bewundernswürdige Zusammensetzung des menschlichen Körpers anzuführen und als einzelne Organe aufzuzählen: die dentes in ore, lingua, tonsillae, palatium, stomachus, aspera arteria (Luftröhre) und deren operculum, pulmones, alvus, cor mit seinen venae und ventriculi, jecur mit den portae, bilis, renes, ossa, nervi (tendines, ligamenta), oculi, aures, nares, gustatus und tactus. Auch das VII. Buch der Nat. Hist. des C. Plinius Secundus enthält keine eigentliche wissenschaftliche Anatomie, sondern ist im Sinne einer somatischen Anthropologie unter Anlehnung an griechische Lehren geschrieben. So wäre denn der Römer Celsus (Zeitgenosse des Tiberius) als der einzige römische Anatom zu nennen, wenn man nicht wüßte, daß er durchweg aus griechischen Quellen geschöpft hat, und wenn man nicht aus dem Umstande, daß seïne Schrift über Anatomie nur einen Teil einer Enzyklopädie über alle Gebiete des Wissens gebildet hat, berechtigte $Z$ weifel erheben müßte, ob Celsus überhaupt Arzt und Anatom gewesen ist.*)

Das uns erhaltene IV. Buch seiner Enzyklopädie enthält als Anatomie eine kurze Übersicht über die Lage und Beschaffenheit der Körperteile, wobei Celsus nicht verfehlt, die Untersuchung von Leichen für notwendig zu erklären, um einen richtigen Begriff von den einzelnen Teilen und ihrer Lage zu bekommen. Er beschreibt:

-) Iwan Bloch, im Handbuch der Geschichte der Medizin. Band I, S. 417. 
I. die Luftröhre und die Lunğe, letztere wie eine Ochsenklaue aus zwei Teilen bestehend;

2. das Herz und das $Z$ werchfell;

3. die Leber, die Milz und die Nieren (mit Adern und Höhlen);

4. Speiseröhre und Magen;

5. die einzelnen Darmabschnitte;

6. das Peritoneum;

7. die Ureteren (venae);

8. die Blase, deren Lage bei Weibern und Männern verschieden ist;

9. den Uterus.

Ausführlicher ist die Osteologie behandelt, der Schädel mit seinen Nähten, die Nase mit dem Siebbein, das knöcherne Ohr, $36 \mathrm{Zähne,} 24$ Wirbel, Wirbelfortsätze, A tlasverbindung mit dem Schädel, Rippen, Brustbein, Schlüsselbein, obere und untere Extremitäten, Becken.

Celsus hebt auch den Unterschied zwischen Arterien und Venen hervor, ganz besonders ausführlich ist die Anatomie des Auges behandelt, wobei aber viele Irrtümer mit unterlaufen.

Wenn ich nunmehr als Endglied der Geschichte der Anatomie des Altertums die Anatomie des Talmud anführe, so ist vor allem zu bemerken, daß letzterer kein Lehrbuch der Anatomie bildet, sondern nur eine im Laufe der Zeit entstandene Sammlung von Schriftauslegungen und rabbinischen Verordnungen, in welcher auch anatomische Erörterungen, sei es aus dem Munde eines Rabbi oder eines Arztes, nur spärlich eingestreut sich finden. Die früher nur mündlich bis ins 2. Jahrh. n. Chr. fortgepflanzten Überlieferungen wurden von dem Rabbi Jehuda ha-nassi unter dem Namen, ,Mischna“ gesammelt und redigiert; eine andere Sammlung derart hat den Namen „Tosephtha" erhalten. Auslegungen dieser Schriften mit Abschweifungen auf alle Gebiete des Wissens wurden dann ihrerseits wieder unter Anschluß an die Sätze der Mischna geordnet und unter dem Namen „Gemara" vereinigt. Die ältere, jerusalemitische Gemara soll von Rabbi Jochannan im Anfang des 3. Jahrh., die jüngere babylonische von dem Rabbi Asche im 6. Jahrh. herrühren. Unter Talmud im engeren Sinne ist die Mischna und die babylonische Gemara zu verstehen.*)

-) J. Preub, im Handbuch der Geschichte der Medizin. Band I, S. III. 
Ob zu dem Grundstock der wissenschaftlichen Talmud-Anatomie auch die von Ägypten aus überkommene Sitte der Einbalsamierung einen Beitrag geliefert hat? Möglich ist dies schon, denn daß noch im r. Jahrh. n. Chr. einbalsamierte Leichname vornehmer Juden in Höhlen beigesetzt wurden und daß man in den Ruinen des von Salomo gegründeten Palmyra Grabgewölbe mit Mumien entdeckt hat, die sich in nichts von den ägyptischen unterschieden, wird von dem gelehrten Dr. C. Kazenelson*) berichtet. Das Meiste aber und das Wichtigste der Talmud-Anatomie stammt von jüdischen Ärzten, welche in Alexandria studiert haben. So wird von einem Arzte Thodos, der noch zur Zeit des Tempels lebte, erzählt, er habe von einer Anzahl von Wirbeln, die ihm vorgelegt wurden, erklärt, daß sie nicht alle von demselben Menschen stammen. - Eine besondere Berühmtheit erlangte der Rabbi Ismael, ebenfalls ein Angehöriger der Schule von Alexandria. Dieser gab sich die Mühe, ein im Talmud enthaltenes Fragment eines Registers aller menschlichen Knochen auf die Richtigkeit der Angaben zu prüfen. Schüler dieses Rabbi Ismael obduzierten den Körper einer hingerichteten Prostituierten, um die Zahl der Glieder des menschlichen Körpers zu bestimmen. Derselbe Rabbi Ismael berichtet auch von Vivisektionen, die in Alexandria an lebenden Verbrecherinnen vorgenommen worden seien.**)

In der Mischna des Rabbi Jehuda ha-nassi wird die Zahl der Knochen des menschlichen Körpers zu 248 angegeben, ja die Schüler des Rabbi Ismael, die in Alexandiria den Leichnam einer Prostituierten kochten, sollen sogar bei der Zerlegung 25I Knochen gefunden haben, was Rabbi Ismael damit erlilärte, daß das Weib an den Genitalien einige Knochen mehr habe. Zur Erklärung dieser auffallenden Differenz gegenüber der heutigen Anatomie nimmt Kazenelson an, daß die jüdischen Ärzte ihre Angaben aus der Untersuchung jugendlicher Leichen von I6-i 7 Jahren gewonnen haben, die sie nach damaliger Sitte nicht macerierten, sondern kochten, wobei sich die Epiphysen noch loslösten und sogar das Schulterblatt entsprechend zwei früh auftretenden Ossifikationspunkten in zwei Teile zerfiel.

*) Dr. C. Kazenelson, Die normale und pathol. Anatomie des Talnud. Ins Deutsche übersetzt von N. Hirschberg. Historisch-pharmak. Studien von Dr. Kobert, Halle 1896 , S. 182.

**) J. Preuß a. a. O., S. 112. 
Um nun weiter in die Talmud-Osteologie einzudringen, so konnte nach Kazenelson*) auch der Kopf des Oberarmknochens, der erst im 20. Lebensjahre mit der Diaphyse verschmilzt, beim Kochen einer 16-17jährigen Lciche sich loslösen und als selbständiger Knochen erscheinen, während die Schlüsselbeine ganz bleiben. - Auch die untere Epiphyse des Oberarms konnte sich bei einer jugendlichen Person durch das Kochen loslösen und so im Verein mit der oberen 3 Knochen des Oberarms vortäuschen. - Wenn die Talmudisten nur von $2 \mathrm{Knochen}$ des Vorderarms reden, so bezieht sich dies nur auf die Diaphysen, denn nach Loslösen der oberen und unteren Epiphyse der ulna und der unteren des radius würde sich, immer eine 16 - I7 Jahre alte Leiche vorausgesetzt, die Zahl der Knochen auf 5 vermehren.

An der Hand rechnet die heutige Anatomie 8 Knochen der Handwurzel, 5 der Mittelhand und I4 Phalangen, zusammen also mit dem Sesambein am Daumen 28 Knochen. Der Talmud rechnet aber 30 Knochen, weil er wahrscheinlich die sich loslösenden unteren Epiphysen des radius und der ulna dazu gerechnet hat.

Am Oberschenkel rechnet die Mischna außer dem Kopf und der Diaphyse noch die beiden Epicondylen als selbständige Knochen. Diese Epicondylen treten im Knie mit den beiden Epiphysen der Unterschenkelknochen und mit der Kniescheibe zusammen, so daß also 5 Knochen im Knie zu zählen wären. Im Hüftgelenk zählt die Mischna 3 Knochen, nämlich den Kopf des Oberschenkels und das beim Kochen eines I6jährigen in 2 Teile zerfallende os innominatum, welches nach der heutigen Anatomie allein aus 3 Knochen besteht. Die unteren Epiphysen der beiden Unterschenkelknochen, die erst im 20. Lebensjahre mit den Diaphysen verschmelzen, müssen ebenfalls als zwei selbständige Knochen gezählt worden sein. So kommt es, daß in der Mischna zu den 7 Fußwurzelknochen der heutigen Anatomie noch diese beiden unteren Epiphysen hinzugezählt wurden, außerdem die einen selbständigen Ossifikationspunkt bildende tuberositas ossis calcanei, so daß also die Zahl Io sich herausstellt.

Am Fuß zählt die heutige Anatomie 5 Mittelfußknochen, 14 Phalangen und das Sesambein am capitulum des Metatarsalknochens, zusammen 20. Die Mischna aber zählt 30 Knochen, weil sie die Ossifikationskerne an den Köpfchen der Mittelfußknochen

") Kazenelson a. a. O., S. 192 ff. 
und die basalen Ossifikationskerne der ersten Phalangen dazu rechnete, immer eine I6-I 7 jährige Leiche vorausgesetzt.*)

Von Rippen zählt die Mischna auffallender Weise bloß II, läßt aber das Brustbein (den „Herzschlüssel“) aus 6 Knochen bestehen, während die heutige Anatomie 3 Knochen zählt. Beim I6jährigen besteht das Brustbein noch aus 4 Stücken. Wenn also die Mischna 6 Knochen des Brustbcins zählt, so ist dies nach Kazenelson nur aus der Opferanatomie zu erklären, bei welcher die 2 ringförmig sich an das Brustbein anschließenden oberen Rippen zugleich mit diesem zusammen als „Herzschlüssel“ herausgenommen wurden. ${ }^{* *}$ )

Von Halswirbeln zählt der Talmud 8, weil zu den 7 eigentlichen Wirbeln noch das $\mathrm{Zungenbein} \mathrm{gerechnet} \mathrm{wurde.} \mathrm{Ebenso}$ abweichend von der heutigen Anatomie, welche 12 Brust- und 5 Lendenwirbel zählt, ist die talmudische Rechnung von achtzehn Knochen im Rückenlendenteil. Vielleicht wurde der erste Kreuzbeinwirbel, wie es hie und da der Fall ist, als selbständiger Wirbel gesehen und mitgezählt. Die übrigen 4 Kreuzbeinwirbel zusammen mit dem als einzigen Knochen aufgefaßten Steißbein bildeten dann die Zahl 5 .

Außerdem erzählt Midrasch rabba von einem sonderbaren mandelförmigen Knöchelchen Luz schel schedrah, das sich weder im Wasser auflösen, noch im Feuer verbrennen, noch durch den stärksten Hammerschlag zertrümmern lasse. ${ }^{* * *}$ )

*) Kazenelson a. a. O., S. 194ff.

"*) Kazenelson a. a. O., S. I97..

"**) Dieses „Judenknöchlein“" war auch den alten deutschen Anatomen belrannt. Kulmus, (Anatonie 1740) sagt, die Rabbiner träumen von einem besonderen Beinlein, das sie Lus nennen, welches am menschlichen Körper zu finden und so hart sein solle, daß es weder zerschlagen, noch durch Feuer oder eine andere Methode verdorben werden könne, sondern bis an den letzten Tag unverweslich dauere, woraus alsdann der ganze Mensch wieder solle gebildet und aufgeweckt werden. Über den Sitz dieses Beinleins aber seien die Juden nicht einig.

Auch A. v. Haller (Onomatologia medica II, S. 925) weiß über das Judenknöchlein zu berichten. „Es soll das ein besonders kleines Bein am menschlichen Körper sein, so lart und fest, daß es weder durch Feuer noch auf eine andere Weise vernichtet werden könne und die Juden sollen sich davon bereden, es bleibe bis an die Auferstehung der Toten unverändert und aus ihm werde bei der Auferstehung der ganze Mensch gleichsam wieder von neuem hervorgebracht; inzwischen sind sie noch nicht unter einander einig geworden, was das eigentlich für ein Knochen sei; denn einige behaupten, er liege zwischen verschiedenen 
Um die Osteologie mit dem Schädel zu schließen, so kannte die Mischna an dem Hirnschädel nur 3 Knochen, I. das Hinterhauptbein, 2. die gewissermaßen einen Ring bildenden, als Ganzes gedachten Scheitel- und Schläfenbeine mit dem Keilbein als Basis, 3. das Stirnbein. Am Gesichtsschädel dagegen zählte man 6 Knochen: 2 Oberkieferknochen, geschieden durch die Nasenhöhle, 2 Wangenknochen mit den vorspringenden Jochbögen, ein Pflugscharbein und ein Unterkiefer.*)

Am schlechtesten ist es mit der Muskellehre bestellt, da die Talmudisten augenscheinlich kein Interesse daran hatten, die einzelnen Muskeln zu spezifizieren, sondern nur im allgemeinen als Fleisch betrachteten.

Auch die Anatomie der inneren menschlichen Organe kommt im Talmud dürftig weg. Die Mehrzahl bilden Untersuchungen von Haus- und Herdentieren bezüglich ihrer Tauglichkeit oder Nichttauglichkeit zum Verzehren.**) Was sie vom Gehirn und Rückenmark wußten, ist kurz folgendes: das Gehirn

Wirbelbeinen (sic!), andere geben vor, er sitze im Nacken und wiederun andere setzen ihn ins Kreuzbein."

Sogar in die deutsche Volkssage ist der seltsame Knochen eingedrungen. A. Birlinger (Volkstūmliches aus Schwaben I, 122) fülırt aus Ertingen an, daß man dort von einem eigentünlichen Wirbelbein im Genick des Schweines unter dem Namen "Jungfer in Bade" spreche, weil dieses Wirbelbein aussehe, als sitze ein Mädchen im Zuber. Wer dieses Bein beim Essen bekomme, werde ausgelacht, denn das Mädchen sei eine Jüdin. (Cf. die Legende von Jesus und dem auf einem Zuber vor seinem Hause sitzenden Juden.)

M. Höfler ist sowohl dem "Judenknöchlein" als der "Jungfer im Bade" vom etlinologisch-anatomischen Standpunkt näher getreten. Er sieht in jenem dem Menschen zugeschriebenen rätselhaften Beine das sogen. "Kränzl" des Scliweins, das gesuchteste Stück des Ferkelbratens, nämlich den 1. und 2. Halswirbel. Bei einiger Phantasie könne man sich unter der Gelenkshöhle des atlas einen Zuber (Wanne) und unter dem in diesen Raum hineinragenden zapfenförmigen Fortsatz des epistropheus den herausschauenden Kopf eines Mädchens vorstellen. Die anatomischen Verhältnisse beim Schwein (lus = weibliches Schwein) seien vielleicht schon früher, ehe menschliche Leichen anatomisch untersucht wurden, auf den Menschen übertragen worden.

Möglich ist es ja schon, daß der verborgene Sitz des atlas mit seiner eigentümlichen Verbindung mit dem epistropheus den Untergrund der sonderbaren Märe von dem Wunderknochen zuerst bei den Juden und von diesen entlehnt im deutschen Volksmund gebildet hat.

") Kazenelson a. a. O., S. $202 \mathrm{f}$.

*) Kazenelson a. a. O., S. 217. 
ist umgeben von 2 Häuten, einer oberen an der Innenfläche des Schädels, und einer unteren, welche das Hirn beutelförmig einschließt. In dem Buch Sohar heißt es: „Der Schädel umgibt 3 Hohlräume, in welchen das Gehirn ruht. Das Gehirn sendet zu beiden Seiten seiner Verlängerung 32 Wege aus. Diese Wege durchkreuzen den ganzen Körper und verbinden alle Teile desselben mit dem Gehirn." Die frühere Bibelansicht, nach welcher das Herz als das Zentralorgan aller geistigen Tätigkeit galt, war zur Zeit der Talmudisten schon längst zu Gunsten des Gehirns überwunden. Was nach innen von den process. condyloidei liegt, wurde dem Gehirn, das außerhalb liegende dem Rückenmark zugeschrieben. Das in der Höhe der „bohnenförmigen Erhebungen“ (proc. condyl.) gelegene verlängerte Mark wurde dem Gehirn gleichgestellt. *)

Die Speicheldrüsen, die „,um die Mundhöhle herum, und unter der Zunge" liegen, waren den Talmudisten offenbar gut bekannt, galten ihnen aber nur als Mittel zur Befeuchtung der Mundhöhle und als "Quellen süßen Wassers", dazu bestimmt, den aufgenommenen Speisen einen besseren Geschmack zu geben. Es wird wohl von einer Ansammlung dieser Flüssigkeit von verschiedener Zusammensetzung in bestimmten Kanälen geredet, der Bau und die Lage der Speicheldrüsen im speziellen aber ist vollständig unbekannt.

Ebenso verhält es sich mit dem Schlundkopf. Man wußte, daf3 die in den Schlundkopf gelangten Speisen unwillkürlich in die Speiseröhre hinabgedrückt werden, hatte aber von dem Bau des Schlundkopfes keine Ahnung. - Besser waren die Talmudisten über den Bau der Speiseröhre unterrichtet, indem sie 2 Häute unterschieden, eine äußere rote (Muskelhaut) und eine innere weiße (Schleimhaut). Man kannte die Verbindung beider Häute durch lockeres Bindegewebe und gab an, daß die Längsfalten nur im oberen (Pharynx-)Teile fehlen.

Kommen wir aber jetzt zum Magen, den die alten Hebräer als den ersten der Diener bezeichnen, welche den ganzen Verdauungskanal ausmachen, so springt das Unzulängliche, Beschränkte der Talmud-Anatomie sofort wieder in die Augen. Die Talmudisten können ihre Ansichten gar nicht vom menschlichen Magen entnommen haben, denn sie sprechen von einem Vormagen (wie

-) Kazenelson a. a. O., S. 26 ;ff. 
bei einem Wiederkäuer), auf der linken Seite liegend und denselben Namen, wie der dritte Magen der Wiederkäuer (omasus, psalterium) führend. Er sollte die Funktion haben, die Speisen erst zu zerreiben; erst von da an sollten die Speisen in den eigentlichen Magen des Menschen gelangen, der aber auffallender Weise denselben Namen Kebata führt, wie der vierte Magen der Wiederkäuer.

Es folgen nun als weitere Teile des Verdauungskanals das

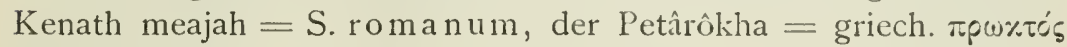
und schließlich der Izketa $=$ Sphincter ani. - Über das Peritoneum hatten die Talmudisten recht befriedigende Kenntnisse. Sie beschreiben es als eine dünne, sich ablösende Haut, welche mit Ausnahme des unteren Teils des Mastdarms die Unterleibsorgane überzieht und außerdem dasjenige Organ bildet, welches man als Netz bezeichnet.*)

Mangelhaft und unklar ist wieder die Kenntnis der Talmudisten von dem Bau und der Funktion der übrigen großen Unterleibsorgane. Über die äußeren und inneren Verhältnisse der Leber und über ihren Blutkreislauf wußten sie nichts. - Die Hohlvene hielten sie für die Lebensquelle der Leber, die ihr vom Herz aus das notwendige Blut zuführe. Umgeliehrt lehrte ein Rabbi Ischak unter Anlehnung an Galen, die Quelle des Blutes sei die Leber, wo dasselbe bereitet werde. - Von der Gallenblase wußte man, daß sie durch einen schmalen Gang mit der Leber verbunden sei.

Die mangelhafte Kenntnis von der Leber wird wieder ausgeglichen durch eine so genaue Beschreibung von der Anheftung der Bauchspeicheldrüse (Leberfinger, Leberanhang) an der Wirbelsäule, daß wir eine genaue Bekanntschaft mit diesem Organe vorallssetzen dürfen, und zwar zum ersten male während des ganzen Altertums bei den Talmudisten.

Auf der anderen Seite bestand vollständige Unklarheit über die Milz. Man sprach im Gegensatz zu Aretaios und Galenos, nach welchen die Milz die Leber von der schwarzen Galle reinigen sollte, von einer auflösenden Funktion der Milz, was diese aber auflösen sollte, wußte man nicht anzugeben. Auf keinen Fall schrieb man ihr eine große Bedeutung zu, denn nach der Mischna können Menschen und Tiere wohl ohne Milz leben.**)

*) Kazenelson a. a. O., S. $228 \mathrm{f}$.

"*) Kazenelson a. a. O., S. $244 \mathrm{f}$. 
Merkwürdig ist wieder die Sicherheit, mit welcher die in Alexandria ausgebildeten jüdischen Ärzte die normale und pathologische Anatomie der Nieren beherrschten, und zwar so weit, daß sie bei Tieren, bei denen die Notwendigkeit der Exstirpation einer Niere diagnostiziert war, die Operation mit großer Gewandtheit ausführten.*)

Wenden wir uns nummehr den Respirationsorganen zu, so stoßen wir auch hier auf recht respektable Kenntnisse bei den Talmudisten. Zwar der Trachea geschieht keine Erwähnung, von dem Kehlkopf aber als Stimmorgan wußten sie anzugeben, daß er aus 3 Teilen bestehe, nämlich dem großen Ring, den Helm (Schildknorpel) und dem Helmdach (Deckenknorpel). Sogar die kleinen corpuscula triticea waren ihnen bekannt. Sehr genaue Studien hatten sie auch über den Bau der Lunge gemacht. Sie unterschieden zwei Flügel, die durch eine vertikal vom Herzbeutel zur Wirbelsäule sich hinziehende Scheidewand getrennt seien. $\mathrm{Zu}$ jedem Flügel verlaufe ein $\mathrm{Hauptbronchus,}$ in welchen alle kleineren Bronchien einmünden, begleitet von den großen zu den Lungen gehenden Blutgefäßen, wobei aber ein Unterschied zwischen Arterien und Venen noch nicht gemacht wird. Gemäß ihren Studien an Wiederkäuerlungen nahmen die Talmudisten an jedem Lungenflügel einen Hauptlappen an, zu dem sich auf der rechten Seite 3, auf der linken 2 Nebenlappen (Ohren) zugesellten. Diese wurden weiter in obere, mittlere und untere eingeteilt. In späteren Zeiten wurde jedem dieser Nebenlappen ein besonderer Name beigelegt. Außerdem konstatierten sie auf der rechten Seite noch ein accessorisches Läppchen (Lobul. subcordialis der Zoologen), das seiner Form wegen den Namen „Rosenblättchen" erhielt.

Weiter wurde gelehrt, daß die Lunge gleich dem Gehirn, den Nieren und Hoden in zwei übereinander gelegene Häute eingehüllt sei, von denen die eine weiß, die andere rosenfarben sei. Wenn nun auch von einer Einteilung der Pleura in ein viscerales, kostales und diaphragmatisches Blatt nichts bekannt war, so muß doch zu Ehren der Talmudisten zugegeben werden, daß sie die Pleura überhaupt gekannt haben. Ja schon im 3. Jahrh. n. Chr. wußten jüdische Ärzte, daß die Atmung einem Verbrennungsprozeß analog sei, daß die einmal ausgeatmete Luft (Rauch) zur Einatmung 
keine Tauglichkeit mehr besitze und gleich dem Rauch die Luft verunreinige. ${ }^{*}$ )

Über das Herz finden sich nur wenige Bemerkungen im Talmud. Es hat zwei Kammern, eine größere rechte und eine kleinere linke, liegt links von der Medianlinie des Körpers und enthält im linken Ventrikel Luft. - Ob die Arterien Luft oder Blut enthalten, darüber bestand keine Einigkeit unter den Talmudisten.**)

Bei den Genitalien wiederholt sich wieder der alte Wechsel zwischen exakter Beschreibung und Phantasie, am meisten bezüglich des feineren Baus. Vom scrotum wulste man, daß es durch eine Scheidewand in 2 Hälften geteilt sei, ebenso von den Hoden das Eingehülltsein in deutlich differenzierte Hüllen, wozu noch ein fadenförmiges Nebengebilde komme nebst einem Nervenund Adergeflecht. Von einer Bereitung des Sperma in den Hoden wußten sie Nichts, vielmehr zogen sie daraus, daß sich bei Hodenverletzungen eine schleimige, fadenziehende Flüssigkeit entleere, den Schluß, daß die Hoden als spermaleitende Organe unter Oberleitung des Rückenmarks anzusehen seien. - Der Prostata geschieht im Talmud keine Erwähnung, dagegen stoßen wir auf die seltsame Ansicht, daß die Urethra ihrer ganzen Länge nach durch eine Scheidewand geteilt sei, wobei der eine Gang für den Urin, der andere für den Samen diene. (Später nahmen die arabischen Ärzte sogar 3 getrennte Gänge an, einen für den Harn, einen für den Samen und einen dritten für das Sekret der Prostata.)

Ziemlich gut bekannt waren die weiblichen Genitalien, wenigstens was das Äußere derselben betrifft. Es wurde beschrieben der mons veneris, die vulva, rima pudendi, vestibulum vaginae, orificium urethrae, hymen, ostium vaginae, vagina, septum vesicovaginale, septum vagino-rectale und schließlich der nicht zweihörnige, sondern als einfach gedachte uterus mit dem canalis uteri und dem cavum uteri. ${ }^{* *}$ )

Werfen wir noch einmal einen Rückblick auf die eben geschilderte talmudische Anatomie, so können wir ihr das Zeugnis nicht versagen, daß sie neben vielfacher Beibehaltung von althergebrachten Irrtümern doch manche Fortschritte aufzuweisen hat, welche unbedingt als Bereicherung der Kenntnisse vom menschlichen

*) Kazenelson a. a. O., S. $250-2551$.

**) Kazenelson a. a. O., S. 262.

***) Kazenelson a. a O., S. $275 \mathrm{ft}$. 
Körper betrachtet werden dürfen, so die Nierenanatomie, die Anatomie des Bauchfells und der Bauchspeicheldrüse. Gegenüber dem Stehenbleiben auf den galenischen und vorgalenischen Irrtümern sind diese Fortschritte freilich gering. Wären dieselben aber auch größer und zahlreicher gewesen, so hätte die wissenschaftliche Anatomie der folgenden Jahrhunderte doch keinen oder nur geringen Gewinn davon getragen, weil die talmudische Weisheit allen, die nicht mit der hebräischen Sprache vertraut waren, verborgen bleiben mußte.

\section{Mittelalter.}

Über die Anatomie während des Mittelalters äußert sich J.Page el*) mit folgenden charakteristischen Worten: „Keine Tatsache zeigt und erklärt den Verfall der Medizin im Mittelalter deutlicher, als die vollständige Ergebnislosigkeit auf dem Gebiete der Anatomie und Physiologie." Bis auf Mondino war ja nirgends von Untersuchungen an menschlichen Leichen die Rede; man begnügte sich, die Lehren des Galen und seiner Erklärer, der arabischen Ärzte, immer wieder durchzuarbeiten. Wurden je Untersuchungen an Leichen vorgenommen, so waren es die Kadaver von Tieren, namentlich von Schweinen. So kam es, daß das I6. Jahrhundert die Anatomie genau so vorfand, wie sie das 3. Jahrhundert verlassen hatte.

Von den anatomischen Arbeiten und Kenntnissen der wenigen griechischen Ärzte aus den letzten Jahrhunderten des röm ischen Kaiserreichs, welche die Geschichte als hervorragend bezeichnet hat, sind uns nur spärliche Nachrichten überliefert. Gar keine Nachrichten über anatomische Leistungen haben wir von Alexanderv. Aphrodisias (Ende des 2. Jahrh.), von Antyllos (3. Jahrh.), von Philagrios und Poseidonios (Ende des 4. Jahrh.), von den bedeutenden Ärzten Magnos, Theon, Jonikos und Zenon (alle dem 4. Jahrh. n. Chr. angehörend).

Nachdem durch Konstantin d. Gr. die christliche Religion zur Staatsreligion erhoben worden war, begann eine Zeit, in welcher auch die medizinischen Anschauungen von der Religion beeinflußt und die einzelnen Teile des menschlichen Körpers vom teleologischen Standpunkt aus betrachtet wurden.

*) Handbuch der Geschichte der Medizin. Band I, S. 70 I. 
Die Kirchenväter, welche über Medizinisches schrieben, gingen bei ihren Betrachtungen von der kirchlichen Dogmatik aus, nicht bloß in Fragen der Physiologie und Psychologie, sondern auch in der somatischen Anthropologie resp. Anatomie. Tertullian, welcher wahrscheinlich der sizilischen Ärzteschule angehörte, erklärte im Anschluß an Empedokles das Herz als das Zentralorgan der Seele, welche sowohlSitz derSinneswahrnehmungen, als auch der höheren Erkenntnis ist. - In seiner Schrift „,de opificio dei" bespricht der Kirchenvater Lactantius den menschlichen Körper mit seinen Knochen, Nerven, Adern und den anderen einzelnen Körperteilen vom teleologischen Standpunkt. Auch die inneren Organe werden besprochen, und schließlich gelangt er auch zu dem Kapitel von der Fortpflanzung und zu der alten, viel wiederholten Behauptung, daß aus der rechten Seite (rechtes Horn) des Uterus die männlichen, aus der linken die weiblichen Kinder hervorgehen. Den Samen aber läßt er entweder aus dem Mark oder aus dem ganzen Körper entstehen. - Weitere teleologische Betrachtungen über den Bau des menschlichen Körpers finden wir in der Abhandlung des Dionysius Alexandrinus

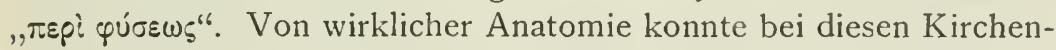
vätern keine Rede sein, denn sie waren ja nicht einmal Ärzte.

Von wirklichen Ärzten aus der byzantinischen Periode der Medizin kommt der berühmte Oreibasios aus Pergamon (geb. ca. $326 \mathrm{n}$. Chr.) in erster Linie in Betracht, allein auch er hat kein selbständiges anatomisches Werk verfaßt, sondern nur eine Bearbeitung der Galenschen Anatomie, die im Jahre I735 von J. Bapt. Rasarius in Leyden unter dem Titel „Oribasii anatomica ex libris Galeni cum recensione latina" herausgegeben wurde. Abweichungen von den Ansichten Galens finden sich in diesem Werke keine, wenn auch konstatiert ist, daß er anatomische Studien an Affen gemacht hat. Die Autorität des Galenos war eben so mächtig, daß seine Nachfolger zu dieser Zeit zufrieden waren, seine Angaben bestätigen zu können.

Ein griechisches Werk über Anatomie, das vielleicht ebenfalls dem Oreibasios zuzuschreiben ist, ist eine in 60 Kapitel eingeteilte Einleitung in die Anatomie, die I6I6 von dem Prof. med. Peter Lauremberg in Hamburg angeblich nach einem aus

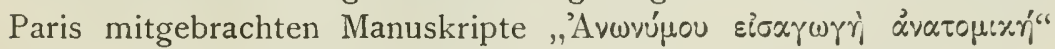
mit lateinischer Übersetzung herausgegeben wurde. Der anonyme 
Verfasser schließt sich in seinen anatomischen Angaben an Aristoteles an, weshalb einzelne Medico-Historiker, z. B. v. Töply*) als Verfasser den Aristoteles-Erklärer Porphyrios (3. Iahrh. n. Chr.) vermuten, nach Fuchs wahrscheinlich mit Unrecht.

Die Ausbeute für die Geschichte der Anatomie während der folgenden Jahrhunderte der byzantinischen Medizin ist eine sehr spärliche. So finden sich in den Schriften des Aëtios v. Amida (geb. Anfang des 6. Jahrh. n. Chr.) und des Alexandros v. Tralles (geb. ca. $525 \mathrm{n}$. Chr.) nur zerstreute anatomische Bemerkungen ohne selbständigen Charakter, obgleich beide Ärzte anerkanntermaßen zu den hervorragendsten ihrer Zeit gehörten. - Paulos Aeginetes und die griechischen Ärzte des 6.-8. Jahrhunderts haben uns keine anatomischen Werke hinterlassen, dagegen begegnen wir einem anatomischen Schriftsteller aus dieser Zeit in der Person des phrygischen Mönchs Meletios, der ein Buch über „den Bau des Menschen“ geschrieben hat, natürlich ganz im teleologischen Sinn. Von J. A. Cramer, Oxford 1836 ist eine

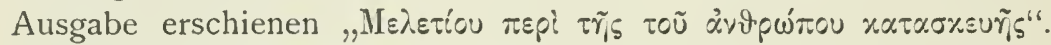
Er beschreibt zuerst den Schädel mit seinen einzelnen Teilen, namentlich den Sinnesorganen, dann die verschiedenen Atmungsorgane und den Brustlorb, den Hals, die Wirbel und das Rückenmark; dann folgen die Rippen, das Rippenfell, das Zwerchfell, die Lungen, das Herz, die Bauchorgane und zuletzt die Haut und die Haare. Nach v. Töply scheint sein Vorbild die Schrift des Gregorios v. Nyssa $(\dagger 395)$ über „die Erschaffung des Menschen" gewesen zu sein, worin dieser Bischof es für genügend erachtete, sich über die Einrichtung unseres Körpers am eigenen Leibe zu unterrichten. Wer aber weiter wissen wolle, könne ja die Schriften der alten Ärzte über Anatomie studieren. Seine Einteilung ist höchst einfach. Er unterscheidet I. lebenswichtige Organe: Gehirn, Herz, Leber; 2. Zutaten, um gut zu leben: die Sinnesorgane; 3. die für die Sicherung der Nachkommenschaft bestimmten; 4. die gemeinsamen Erhalter der übrigen Organe: Magen und Lunge.

Die übrigen Jahrhunderte der byzantinischen Medizin bis zu dem hoch angesehenen Joannes Aktuarios (I4. Jahrh.) blieben für die Anatomie vollständig bedeutungslos.

") v. Töply, Gesch. der Anat. des Mittelalters. S. 32-36. 
Von den bedeutenden a rabischen Ärzten, deren Blütczeit sich an die byzantinische Medizin anschloß, ist schon deshalb kein Fortschritt in der Anatomie zu erwarten, weil ihnen durch ihre Religion das Sezieren von Leichnamen verboten war; Bearbeitung und immer wieder Bearbeitung der griechischen Lehren, namentlich der Anatomie des Galenos, ist daher die Signatur dieses Teils der arabischen Medizin. Bekannt wurden die Araber mit der griechischen Medizin teils in Alexandria, teils auf dem Wege über Persien und Syrien.

Der gelehrte arabische Arzt Geber (Abu Abdallah Dschabir ben Hajjan es-Sufi $\uparrow 776$ ) hinterließ unter den zahlreichen Traktaten, welche er geschrieben hat, auch einen solchen über Anatomie. Rhazes (Abu Bekr Muhammed ben Zakarjja er Razi ca. 850-923) verfaßte ein umfangreiches medizinisches Werk ,al Hawi“, gewöhnlich „Continens" genannt, außerdem ein „liber medicinalis Almansoris", dessen erster Traktat „, de figura et forma membrorum" die erste auf uns gekommene arabische Anatomie, wenn auch in Galenschem Sinne, bildet. - Eine allgemeine A natomie enthält das erste Buch der von Averroës (Abul Welid Muhammed ben Ahmed Ibn Roschd II26-II98) verfaßten Schrift über die Hauptregeln der Medizin (Liber universalis de medicina). - Auch der weit über das Mittelalter hinaus berühmte Avicenna (Abu Ali el-Hosein ben Abdallah Ibn Sina (980-1037) schrieb im ersten Buch seines großen Kanon der Medizin über Anatomie und Physiologie, ein Abschnitt, der sich ganz besonders durch seine teleologische Auffassung auszeichnet und auf die scholastische Medizin des Mittelalters den größten Einfluß ausübte. - Von den arabischen Ärzten der nachfolgenden Jahrhunderte weiß die Geschichte der Anatomie nichts zu berichten.

Wir haben in Obigem den mächtigen Einfluß der griechischen Medizin auf die der Araber kennen gelernt, welche ja nicht müde wurden, immer wieder griechische Texte zu übersetzen und zu exerzieren. Die Geschichte der Medizin hat aber erwiesen, daß dieser griechische Einfluß sich noch viel weiter in den Orient erstreckt und in Indien von der Zeit der Diadochen auf die einheimische Medizin eingewirkt hat. Dem direkten Verkehr mit Griechenland folgte der indirekte durch Vermittlung der auf griechischer Wissenschaft fußenden Araber. Als ein Faktor endlich, der hier seit ältester Zeit in Rechnung zu ziehen ist, muß mit 
größter Wahrscheinlichkeit die Keilschriftmedizin betrachtet werden. Wenn wir also von den drei Werken Caraka, Susruta und Vaghbata als den ältesten Überlieferungen indischer wissenschaftlicher Medizin lesen, so werden wir immer wohl daran tun, in denselben nicht nur rein autochthone, sondern auch importierte Vorstellungen und Begriffe zu suchen.

Diese drei ältesten Werke der wissenschaftlichen indischen Medizin tragen die Namen dreier altberühmter Ärzte, des Caraka, des Vaghbata und des Susruta. Alle drei haben auch über Anatomie geschrieben und wahrscheinlich auch sich praktisch mit Anatomie befaßt. Wenigstens spricht dafür ein Kapitel des Susruta. Denn wenn auch das Religionsgesetz die Berührung mit Leichen verbot, so konnte eine Übertretung dieses Gesetzes leicht dadurch gesühnt werden, daß man ein Bad nahm oder eine Kuh berührte oder einen Blick in die Sonne warf.

Nach R. Roth*) handelt von den I I Hauptteilen des Caraka (wahrscheinlich Beginn der christlichen Zeitrechnung) der 3. vom Maße der drei Humores, der 4. in 7 Kapiteln von Anatomie und der 5. in 12 Kapiteln von Anatomie und Pathologie der Sinnesorgane. - In dem zweiten Werke, dem des Vaghbata (7.-8. Jahrh. n. Ch.) ist der 2. Hauptabschnitt der Anatomie und Embryologie gewidmet. - Das Werk des Susruta (Anfang des IO. Jahrh. n. Chr.) handelt in Io Kapiteln des 3. Hauptabschnitts ebenfalls von Anatomie und Embryologie.**) - Die übrigen mittelalterlichen Schriften der indischen Medizin (Harifa, Bhāvaprakasa, Mādhava etc.) handeln vorzugsweise über Therapie, namentlich Arzneimittellehre, ohne der Anatomie zu gedenken.

In welch ursprünglicher und doch so umständlicher Weise letztere getrieben wurde, wird von Häser (l. c.) folgendermaßen beschrieben: Die Leiche mußte von einem Menschen stammen, der nicht zu alt, nicht verbildet, nicht an Gift oder einer langwierigen Krankheit gestorben war. Fand sich eine solche, so wurde sie auf 7 Tage und 7 Nächte in einen Bach gelegt und dann mit Pflanzenrinden oder einer Art groben Basts geschabt, so daß die

*) R. Roth, Caraka in Zeitschrift d. deutschen morgenldsch. Gesellschaft 1872 , Band XXXV1, S. $441-452$.

**) Anatomische und physiologische Angaben finden sich auch in dem Gesetzbuche Yajnavalkyas (wahrscheinl. aus dem 2. christl. Jahrh.) und in dem Werke Amarakosha (8oo n. Chr.) mit Annerkungen über den menschlichen Leib. (Häser, Band I, S. I 8 ff.) 
inneren Teile sichtbar wurden, ohne daß es aber weiter als bis zu einer Okular-Inspektion kam. Statt einer Beschreibung der Körperteile beschränkte sich die altindische Anatomie auf Zählungen, Messungen und Einteilungen. Der menschliche Körper besteht*) aus 6 Hauptgliedern, aus 4 Extremitäten, aus Kopf und Rumpf. Einzelne Glieder sind Kopf, Bauch, Rücken, Nabel, Stirne, Kinn, Hals und Brust. Doppelte Glieder sind Augen, Ohren, Nasenhöhlen, Augenbrauen, Schläfen, Oberarme, Unterarme, Oberschenkel, Unterschenkel, Hoden, Seitenteile, Hinterbacken und Kniee. Dazu kommen noch 20 Finger und die Sinnesorgane.

Im besonderen werden von Susruta aufgezählt 7 Häute, 7 Segmente, 7 Elemente, 7 Sitze der einzelnen Organe, 70 Gefäße, 500 Muskeln (bei Frauen 490), 90 Sehnen, 300 Knochen (nach Caraka 306, nach anderen 340-360), 2 Io Gelenke (darunter 68 bewegliche), I 7 Punkte, deren Verletzung lebensgefährlich ist, 24 Nerven, 3 Körperflüssigkeiten, 3 Exkretionsflüssigkeiten, 9 Sinnesorgane.

„Alle Gefäße laufen im Nabel zusammen und führen teils Blut, teils Luft, Schleim und Galle. Auch die 24 Nerven entspringen vom $\mathrm{Nabel}$, IO gehen nach oben, Io nach unten, 4 nach den Seiten. Der Mensch hört, sieht, schmeckt und riecht mit 8 Nerven, spricht mit 2, schläft mit 2 etc."

Phantastisch und unwissenschaftlich ist auch die auf der Anatomie aufgebaute Physiologie, welche hier kurz berührt werden soll. Drei Humores sind im Körper, die Luft, der Schleim und die Galle; alle drei durchfließen den ganzen Körper. Die Luft befindet sich hauptsächlich zwischen Fuß und Nabel, die Galle zwischen Nabel und Herz, der Schleim zwischen Herz und Scheitel. Luft herrscht im Greisenalter, Galle im Mannesalter, Schleim in der Kindheit vor. Ebenso besteht eine Verschiedenheit je nach der Tageszeit! Schleim ist vorherrschend am Morgen, Galle am Mittag, Luft am Abend. Die Luft ist Trägerin und Vermittlerin der Bewegung, die Galle für die tierische Wärme, Schleim für die Tätigkeit der einzelnen Organe.

Luft, Galle und Schleim als Elementarstoffe erzeugen 7 andere Stoffe: Chylus, Blut, Fleisch, Fett, Knochen, Mark und Samen.

*) Iwan Bloch, Indische Medizin, im Handbuch der Geschichte der Medizin. Band I, S, I $39 \mathrm{ff}$. 
In der Milz und Leber wird der Chylus zu Blut, das Blut verwandelt sich in Fleisch, Fleisch in Fett, Fett in Knochen, Knochen in Mark und Mark in Samen je innerhalb eines Monats. - Sechs hohle Eingeweide dienen zu dem Zwecke, den Schleim, die unverdaute Nahrung, die Galle, die Luft, die Fäzes und den Urin in sich aufzunehmen. Das Weib hat drei weitere hohle Organe, nämlich eines für die Aufnahme des Fötus und zwei für die Milch. Von Drüsen und ihrer Tätigkeit wird nicht gesprochen, dagegen heißt es, das Blut sei schwerer als Chylus, bewege sich durch die verschiedenen Gefäße des Körpers, ja Hārita und Bhāvanis'ra sollen sogar schon Vorläufer von Harvey gewesen sein, indem sie die Zirkulation des Blutes vom Herzen durch Arterien und Venen gewußt haben.

Finden wir schon in dieser brahmanisch-indischen Anatomie genug des Absonderlichen und Phantastischen, das wir nur aus der orientalischen Phantasterei überhaupt, namentlich aber aus Anklängen an die unter planetarischen Einflüssen stehende Keilschriftmedizin erklären können, so steigert sich dieser Eindruck noch, wenn wir weiter gegen Osten, zu dem Volke der Chinesen gelangen und die seltsamen Ausgeburten ihrer „,wissenschaftlichen“ Anatomie in Augenschein nehmen. In J. Hyrtls Antiquitates anatomicae rariores (S. 95) findet sich ein Auszug aus einer Schrift des Andr. Cleyer (Francof. I682) über „Medicina Sinica“. Sie teilen, so heißt es daselbst, den Körper in Glieder und Eingeweide ein. Glieder zählen sie 6, 3 auf der linken Seite, nämlich das Herz, die Leber und die Nieren, ebensoviele rechts, nämlich die Lunge, die Milz und die Lebenspforte. Ähnlich ist die Einteilung der Eingeweide: 3 auf der rechten Seite, nämlich die großen Gedärme, der Magen und das vom Nabel zur Fußsohle verlaufende Organ; 3 auf der linken, nämlich die kleinen Gedärme, die Gallenblase und die Uretheren.

Zuerst entstehen die Nieren, dann das Herz und ganz zuletzt die Milz. Aus den Nieren entstehen die Zähne, die Knochen, die Ohren; aus dem Herz das Gesicht, die Oberarme, die Fußsohlen und die Hände; aus den Lungen die Lippen, die Nase, die Haut, die Nägel und die Haare. Die Lunge hat den obersten Platz im Körper.

Und nun folgt der Passus, der für die Anlehnung der altchinesischen Anatomie an die altchaldäische Medizin am deutlichsten 
spricht, nämlich die Bezugnahme auf die Gestirne. „Das Herz ist dem Mars befreundet, die Leber dem Jupiter, die Nieren dem Mercur, die Lunge der Venus, die Milz dem Saturn."

Nach dem alten Andr. Cleyer wollen die Chinesen die Blutzirkulation schon vor 4000 Jahren entdeckt haben. Dieser Anspruch würde aber zu der lächerlichsten Überhebung, wenn die alten Chinesen wirklich solche Ansichten über den Verlauf der Gefäße hätten, wie es Cleyer erfahren haben will. Da heißt es, in den Füßen sei ein Blutgefäß, das vom Innern der Nase komme und zur großen Zehe verlaufe; ein anderes, aus dem Innern des Leibes kommendes endige im 3. Finger, ein drittes in der kleinen Zehe. Insgesamt zählen sie 12 Arterien der Extremitäten, in jedem Arm verlaufen 3 Arterien, die mittlere zum Mittelfinger, die anderen zum Daumen und Kleinfinger. Ein ähnliches Verhältnis besteht in beiden Füßen. Den Eingeweiden aber schreiben sie 4 Blutgefäße zu. Der Verlauf dieser Blutgefäße soll durch die schematische Abbildung aus der Schrift J. Hyrtls veranschaulicht werden.

Noch abenteuerlicher sieht sich eine andere, der Hyrtlschen Schrift beigefügte Abbildung an, welche nach altchinesischer Anschauung den situs viscerum darstellen soll. Ohne auf das Detail (das kleine birnförmige Gehirn, die ohne Kehlkopf und Trachea figurierende Lunge, das bandartig gezeichnete Diaphragma, das Fehlen einer Verbindung zwischen Nieren und Blase etc.) einzugehen, möchte ich nur die Darstellung einer Ansicht hervorheben, welche auch sonst das ganze Altertum beherrscht hat, nämlich die Bereitung des Blutes in der Leber und in der Milz. Von beiden Organen aus, nämlich von der beutelförmigen Milz wie von der vielgelappten Leber sieht man je ein dickes Gefäß ausgehen und ihr Blut im Bogen in das napförmige Herz ergießen.

Noch deutlicher treten die Beziehungen der alt-chinesischen Anatomie $\mathrm{zu}$ der Keilschriftmedizin mit ihrer Lehre von dem Planeteneinfluß auf den Menschen in einer neuen Abhandlung von B. Scheube*) hervor. Wie erfahren da zunächst in Betreff des Geschichtlichen, daß es eine eigentliche Anatomie bei den Chinesen nie gegeben hat, weil dieselbe verboten war. Wer im Jenseits erscheinen will, muß nach der religiösen Anschauung der Chinesen alle Glieder beisammen haben. Nur zuweilen sollen

*) B. Scheube, Die Geschichte der Medizin bei den Chinesen. Im Handbuch der Geschichte der Medizin. Band I, S. 2 Iff. 
Ausnahmen gemacht worden sein. So ließ ein Gouverneur einer Provinz im 4. Jahrhundert 40 enthauptete Verbrecher durch Ärzte sezieren und die Organe zeichnen. Im Anfang des 19. Jahrhunderts nahm sogar der Kaiser Khang-hi bei den Jesuiten Unterricht in der Anatomie unter Benützung der anatomischen Bilder des Thomas Bartholinus, doch durften keine Menschen seziert werden. Im übrigen aber war die chinesische Anatomie rein spekulativ aufgebaut und zwar, wie mit großer Wahrscheinlichkeit angenommen werden kann, unter Anlehnung an die Spekulationen der Mesopotamier.

Da ist zunächst der erste Glaubenssatz: wie jedes Ding auf der Welt, sei auch der Mensch aus 5 Elementen (Holz, Feuer, Erde, Metall und Wasser) zusammengesetzt und bilde für sich einen Mikrokosmus gegenüber dem Makrokosmus. Hier 5 Planeten (dazu noch Sonne undMond), dort Zusammensetzung aus 5 Elementen, 5 Sinne und 5 Eingeweide. Im Körper zirkuliert neben dem Blute die Lebensluft, eine belebende ätherische Substanz = dem Äther der Natur, von größerer Bedeutung als das Blut. Als Mittel zur Zirkulation des Blutes und der Lebensluft durch den ganzen Körper dient ein reich verzweigtes $\mathrm{Kanalsystem.}$

An Knochen, die beim Weibe etwas dunkler sein sollen, als beim Manne, zählt die chinesische Anatomie 365 im ganzen Körper, eine Zahl, die um so merkwürdiger ist, da der Schädel, das Becken, der Vorderarm und Unterschenkel je nur als ein einziger Knochen zählen.*) Von Muskeln, Sehnen, Bändern, Knorpeln wird nichts berichtet. Auch das Nervensystem ist fast vollständig unbekannt. Das Gehirn, der Sitz aller Sinne mit ihren Äußerungen in den animalen Funktionen, nimmt nur einen kleinen Raum in der Schädelhöhle ein. Die Basis des Gehirns bildet ein Behälter, von welchem das Mark durch den Wirbelkanal geht, um sich im Körper zu verbreiten. - Ganz dunkel sind die Vorstellungen der Chinesen über den Kreislauf; die eigentliche Natur der Gefäße kennen sie nicht; sie denken sich eben die verschiedenen Organe unter einander durch Kommunikationskanäle verbunden, in denen Blut und Lebensluft zusammen mit den beiden Prinzipien, dem männlichen und dem weiblichen, zirkulieren. Solcher Kanäle, die durch Zweige im ganzen Körper verteilt sind, gibt es 12 große und zwar 6 für das männliche und

*) B. Scheube a. a. O., S. 26. 
6 für das weibliche Prinzip. Gcradezu komisch klingt es, wenn man erfährt, die Lebensluft mit dem Blut zusammen machen in 24 Stunden 50 Umläufe, während welcher Zeit zugleich 13500 Atemzüge erfolgen. Von dem Bau des Herzens, von den Herzklappen, von dem Gasumtausch in den Lungen und der Veränderung des Blutes in den Kapillaren hat die altchinesische Anatomie keine Ahnung.

Entsprechend der 5-Zahl der Planeten zählen sie nach Scheube 5 Haupteingeweide: Herz, Lunge, Niere, Leber und Milz. Dazu kommen als Gehilfen 5 weitere Organe: Dünndarm, Dickdarm, Harnleiter, Gallenblase, Magen. Die 5 Haupteingeweide sind Sitz des weiblichen, die 5 Nebeneingeweide Sitz des männlichen Prinzips. Jedes der 5 Haupteingeweide entspricht einem Elemente, einem Planeten, einer Jahreszeit, einer Himmelsgegend, einer Farbe, einem Geschmack. Jedes derselben hat ein anderes Organ zur Mutter, zum Sohne, zum Freunde, zum Feinde.*)

Das vornehmste Eingeweide ist das Herz. Seine Mutter ist die Leber, sein Sohn der Magen (oder die Milz), sein Freund die Leber, sein Feind die Niere. Sein Element ist das Feuer, sein Planet der Mars, seine Jahreszeit der Sommer, seine Tageszeit der Mittag, seine Himmelsgegend der Süden, seine Farbe rot, sein Geschmack bitter. Seine Gestalt ist die erschlossene Blüte der Wasserlilie, seine Lage unter der Lunge, sich stützend gegen den fünften Wirbel, seine Hülle der Herzbeutel, sein Inhalt ein feiner Saft, seine Öffnungen 7 Löcher und 3 Spalten, seine Funktion, den Chylus zu empfangen, denselben zu vervollkommnen und in Blut $\mathrm{zu}$ verwandeln. Sein Gehilfe ist der Dünndarm, derselbe macht I6 Krümmungen und hat 2 Löcher, nach oben zum Magen, nach unten zum Dickdarm.**)

Die Mutter der Lunge ist die Milz (oder der Magen), ihr Sohn die Niere, ihr Freund die Leber, ihr Feind das Herz, ihr Element Metall, ihr Planet die Venus, ihre Jahreszeit der Herbst, ihre Tageszeit der Abend, ihre Himmelsgegend der Westen, ihre Farbe weiß, ihr Geschmack scharf. Sie liegt angeheftet am dritten Wirbel, teilt sich in 8 Blätter, davon 2 je eines der beiden Ohren bilden, ist durchbohrt von so kleinen Löchern zum Entweichen der Luft, oben mit dem Schlund durch ein Gefäß mit 9 Gelenken

") B. Scheube a. a. O., S. 24.

"*) B. Scheube 1. c. 
verbunden, bildet einen Deckel für die Eingeweide, enthält viel Luft, wenig Blut und hat die Funktion, das Blut laufen zu lassen und den Schleim und die anderen Materien zu entfernen. Gehilfe der Lunge ist der Dickdarm mit 16 Krümmungen und 2 Löchern, je für den Dünndarm und den After. Er entfernt die groben und unreinen Materien.

Die Niere hat zur Mutter die Lunge, zum Sohn die Leber, zum Freund das Herz, zum Feind die Milz (oder den Magen). Ihr Element ist das Wasser, ihr Planet der Merkur, ihre Jahreszeit der Winter, ihre Tageszeit die Nacht, ihre Himmelsgegend der Norden, ihre Farbe schwarz, ihr Geschmack salzig, ihre Gestalt bohnenförmig, ihre Lage am I4. Wirbel und ihre Funktion die Bildung von Harn aus dem vom Herzen kommenden Blut. Thr Gehilfe ist der Harnleiter zum Ableiten des Harns in die Blase. Die rechte Niere, die Pforte des Lebens, verwandelt das Blut in Samen. (Der Hoden ist Samenbehälter, wie die Blase Harnbehälter.)

Die Milz hat zur Mutter das Herz, zum Sohn die Lunge, zum Freund die Niere, zum Feind die Leber. Ihr Element ist die Erde, ihr Planet Saturn, ihre Jahreszeit die letzten is Tage jeder Jahreszeit, ihre Himmelsgegend die Mitte, ihre Farbe gelb, ihr Geschmack süß. Sie hängt am 11. Wirbel.

Der Magen, welcher vielfach der Milz gleich gestellt wird, hat zwei Löcher, eins oben zu dem Nahrungs- und Luftgang, das andere unten zum Dünndarm. Er ist Sitz der Freude und hat die Funktion, Nahrung zu empfangen, zu zerreiben und für die Verdauung vorzubereiten.

Die Mutter der Leber ist die Niere, ihr Sohn das Herz, ihr Freund die Milz (oder der Magen), ihr Feind die Lunge. Ihr Element ist das Holz, ihr Planet Jupiter, ihre Jahreszeit der Frühling, ihre Tageszeit der Morgen, ihre Himmelsgegend Ost, ihre Farbe blau, ihr Geschmack sauer. Sie stützt sich gegen den 9. Wirbel und hat 7 Blätter, 3 linke und 4 rechte. Gehilfin der Leber ist die Gallenblase, die in der Form einem Weingefäße ähnlich ist.*)

Außer den 5 Hauptorganen und ihren Gehilfen unterscheidet die altchinesische Anatomie noch ein weiteres, rätselhaftes Organ, das den Namen San-tsino führt. Dasselbe besteht aus

") B. Scheube a. a. (I., S. 25. 
3 Teilen und ist für die Funktionen der 5 Haupteingeweide unentbehrlich. Der obere Teil dieses Organs liegt in der Herzgegend und hilft der Lunge und dem Herz; der mittlere Teil liegt in der Brustbeingegend, 2 Zoll über dem Nabel und hilft dem Magen, die Nahrung zu verdauen; der untere Teil liegt I Zoll über dem Nabel und hat 2 Löcher, durch welche die Nahrung passiert. Er ist für die Leber, wie für die Niere zum Filtrieren der Flüssigkeiten nötig und ein guter Gehilfe der rechten Niere (in welcher der Samen bereitet wird).

Wenn wir die abstrusen, vielfach rätselhaften Vorstellungen und Begriffe der alt-chinesischen Anatomie nochmals vor unserem geistigen Auge vorüberziehen lassen, so bemerken wir neben vielem autochthon erscheinenden doch dies und das, was uns sogar schon in den Lehrmeinungen der alten Völker des Westens wie ein seltsames exotisches Gewächs sich vorgestellt hat. Nach der Ansicht des Verfassers ist dem Medico-Historiker v. Oefele beizupflichten, wenn er das alte Mesopotamien für ein Zentrum ansieht, von welchem durch Jahrtausende hindurch kulturelle Einwirkungen und nicht zum wenigsten auch auf dem Gebiete der Medizin sich auf die Völker des Westens wie des Südens (Ägypten) und des Ostens erstreckt haben. „Einstweilen," sagt er*), sind ja manche scheinbar wertvolle Fundstücke zur alten Medizin für das Zusammenfügen eines Gesamtbildes noch recht unverwertbare Brocken, und gar vieles, was den Schlüssel für das Verständnis anderer Fundstücke ergeben könnte, liegt ungekannt und ungenützt in den Rumpelkammern europäischer Museen, welche sich täglich mehr mit unverdautem Inhalte ohne Platz zur Aufstellung anschoppen und dabei vor allem medizinische Belege vernachlässigen." Eine raschere Entzifferung der Keilinschrift-Tafeln aus der Bibliothek Assur-banipal's dürfte auch über den Zusammenhang der chinesischen mit der chaldäischen Anatomie Aufschluß geben.

Im mittelalterlichen Japan wird niemand eine selbständige wissenschaftliche Anatomie erwarten, der mit dem Gange der Kultur in diesem Lande vertraut ist und weiß, daß letztere zu Anfang des 5. Jahrhunderts über Korea aus China eingeführt worden ist. Es soll zwar schon im 2. Jahrhundert v. Chr. unter der Regierung der Kaiserin Kogen ein chinesischer Arzt mit 300 Zöglingen in Japan 
eingewandert sein, allein dessen Auftreten scheint keinen dauernden Einfluß ausgeübt $z u$ haben. Noch nebelhafter lautet ein anderer Bericht aus dem 8. Jahrhundert, wonach im Zeitalter der Götter von einem Kaiser Sanitätsoffiziere angewiesen worden seien, mit Medizinalpflanzen Versuche an Affen anzustellen und darauf deren Leiber zu sezieren, damit der Bau ihres Körpers bekannt würde.*) Es darf uns nicht wundern, aus Japan die Kunde von einem so frühen Erwachen eines anatomischen Studiums $z u$ vernehmen, denn solchen Sagen von wißbegierigen Herrschern aus nebelhaft zurückliegenden Heroenzeiten sind wir ja auch in anderen Ländern (z. B. Ägypten) begegnet. - Im übrigen standen die anatomischen Kenntnisse der Japaner vor Einrichtung des medizinischen Unterrichts nach europäischem Muster (2. Hälfte des L9. Jahrhunderts) auf derselben Stufe, wie die der Chinesen.

Noch gänzlich den Anschauungen der europäischen Völker entrückt ist die Medizin der Tibetaner. Einerseits an Indien, anderseits an China grenzend waren dieselben schon in frühesten Zeiten Einflüssen von beiden Seiten her ausgesetzt; infolgedessen hat sich das, was man tibetanische Anatomie heißen kann, $\mathrm{zu}$ einem absonderlichen Gemisch autochthoner Vorstellungen nebst indischer und chinesischer Afterweisheit entwickelt und dank der hermetischen Abgeschlossenheit des Landes diesen Charakter noch bis auf die neueste Zeit bewahrt. Als Hauptquelle dienen die Untersuchungen von Heinr. Laufer.**) Wir erfahren von ihm, daß um 740-756 Vairocana die 4 Tantra, deren erster Teil u. a. auch die Anatomie umfaßt, aus dem Sanskrit in die Tibetsprache übersetzt hat.

Wie in Indien und China ist auch hier die Anatomie mit der Physiologie verbunden und beschäftigt sich in erster Linie mit der Entstehung und dem Aufbau des menschlichen Körpers. Als Faktoren, die bei der Entstehung wirken, gilt der männliche Samen und das weibliche Menstrualblut nebst dem sogenannten Lebensprinzip, und zwar wird die Wirkung der einzelnen Faktoren so gedacht, daß aus dem Sperma die Knochen des Skelets und das Gehirn, aus dem Menstrualblut die Weichteile (Fleisch, Blut, die

") B. Scheube a. a. O., S. 39.

*) Beiträge zur Kenntnis d. tibetan. Medizin, I. Teil Berlin, Gebr. Unger Igoo. II. Teil Leipzig, O. Harrasowitz 1900. 
Organe der Brust- und Bauchhöhle, sowie die 6 Venen) entstehen. Ich übergehe die seltsamen embryologischen Vorstellungen und gehe sofort zu dem fertigen Körper über, als dessen Grundbestandteile Schleim, Galle und Wind genannt werden, die ja wieder an bestimmten Orten 5 Funktionen erfüllen (cf. Indien). Ferner werden dem Körper 7 Stützen zugeschrieben (Chylus, Blut, Fleisch, Fett, Knochen, Mark und Samen) und 5 Organe als lebenswichtig bezeichnet, nämlich Herz, Lunge, Leber, Milz und Nieren (oder der Gefäßapparat).

Wie unklar die Vorstellungen von letzterem sind, ist daraus ersichtlich, daß zu ihm neben Arterien und Venen auch Nerven gezählt werden. Von Adern und Nerven wird in einem und demselben Sinne gesprochen; man unterscheidet deren 4 Arten, nämlich Adern (Nerven) der Vorstellung, des Seins, der Verbindung und der Lebenskraft.

$\mathrm{Zu}$ den Adern der Vorstellung gehören 3 vom Nabel ausgehende Nerven, einer zum Gehirn, einer in das Hypochondrium und ein dritter zu den Genitalien. - Von den Adern (Nerven) des Seins erregt einer vom Gehirn aus, ein anderer sitzt als Werkzeug der Erinnerung im Herzen, ein dritter leitet vom Nabel aus das Körperwachstum, ein vierter hat seinen Aufenthalt im Penis. Dabei muß noch bemerkt werden, daß jeder dieser 4 Nerven 500 kleinere als Begleiter hat. - Der Nerven (Adern) der Verbindung gibt es zweierlei, nämlich weiße und schwarze. Hier ist die Verworrenheit der tibetanischen Anatomie ganz besonders sichtbar. 24 breite Verbindungsnerven sollen dem Wachstum der Sehnen und der Vermehrung des Blutes, 8 breite verborgene zur Verbindung der Krankheiten der Eingeweide und Gefäße, 16 sichtbare zur Verbindung der äußeren Glieder dienen. Aber damit nicht genug: Es gibt II 2 schädliche Venen und I89 gemischter Natur, davon I 20 für die äußeren, mittleren und inneren Teile mit 300 kleineren netzartigen Verzweigungen. Schließlich gibt es noch I9 Nerven (Venen), die in kräftiger Funktion vom Gehirn herabsteigen, um teils verborgen die Eingeweide, teils sichtbar die äußeren Teile zu versorgen. - Von Adern (Nerven) der Lebenskraft gehen die einen zum Kopf und Leib, die anderen stehen mit der Atmung in Verbindung. Die Hauptader, die sogenannte Schlagader (Aorta?) verbindet die Umlaufskanäle für Luft und Blut und dient zur Regelung des Wachstums.*)

*) v. Töply, im Handb. d. Gesch. d. Med., Bd. II, S. 172. 
Schon das Zahlenwesen in diesen Angaben erscheint ganz indisch, es erstreckt sich aber noch weiter. Die tibetanische Anatomie zählt 12 große und 250 kleine Gliedergelenke, 16 (!) Sehnen, I I 000 Kopfhaare, I I Millionen Haarporen am ganzen Körper, I3 Öffnungen und Durchgänge beim Manne, 16 beim Weibe, 9 Venen für die Beförderung des Chylus zur Leber, wo er zu Blut wird etc.

v. Töply spricht schließ3lich auch noch von anatomischen Zeichnungen und Tafeln, welche die Lama der Tibetaner haben sollen, doch sollen dieselben sehr ungenau sein. Alles in allem macht die Anatomie der Tibetaner durchaus den Eindruck der Dürftigkeit, wie er dem Charakter des Landes und seiner Bewohner entspricht.

Wir sind jetzt genötigt, unsere Blicke wieder westwärts nach Europa zu wenden und als Gegenstück zu der byzantinischen die frühmittelalterliche An a tomie unter der Herrschaft der christlichen Kirche in Betracht zu ziehen. Die Geschichte lehrt, daß die Herrschaft über das gesamte Denken der westeuropäischen Völker von den Klöstern ausging, aber nicht, ohne daß ein hartnäckiger Kampf mit den Meinungen der landansässigen Priester und Ärzte vorausgegangen wäre.

Die germanischen Ärzte z. B. lehrten, daß der menschliche Körper $2 \mathrm{I} 4$ Knochen, $30 \mathrm{Zähne}$ und $3 \mathrm{I}_{5}$ Adern enthalte. Das Gehirn wie auch die Leber bezeichneten sie als dreilappig; der Herzbeutel galt als ein Teil des Zwerchfells; den Beckengürtel des Weibes dachten sie sich als ein Beinschloß (Schloßbein), welches sich in der Gebärnot verschließen könne und durch Zaubermittel aufsperren lasse. Sie kannten wahrscheinlich bloß den tierischen Tragsack und bezeichneten beim menschlichen Weibe alles normale Genitale (uterus, vagina, vulva, perineum) zusammen einfach als "Mutter, Iñeff oder Iñader.“*)

Wenn wir nun weiter erfahren, daß sie den Zorn der Galle, die Lebenskraft dem Herzen, das Gedächtnis dem Gehirn, den Übermut der Lunge, das Lachen der Milz, die Wollust der Leber zuschrieben, so sind nach Häser**) hierin Anklänge an die altindische Medizin nicht zu verkennen.

") M. Höfler, in Handb. d. Gesch. d. Med., Bd. I, S. $462,472$.

*) Lehrbuch d. Gesch. d. Med., 3. Bearbtg., Bd. I, S. 60\%. 
Solche Ansichten fanden keine Gnade vor der Mönchs me dizin, die vom 6.-I2. Jahrhundert, gestützt namentlich auf die Lehren des Aristoteles, als anatomische Wahrheit nur das gelten lassen wollte, was der große, von ihnen begünstigte Grieche gelehrt hatte. Doch wäre nach Pagel*) ,Nichts törichter und verhängnisvoller, als über die Heilkunde des Mittelalters wegen des präjudizierten Mangels an praktischer Ausbeute zur Tagesordnung überzugehen. Daß manches brauchbare Körnchen, manche an sich treffliche Beobachtung auch bei den mittelalterlichen Autoren anzutreffen ist, ist von den Historikern nachgewiesen worden".

Als einer der ersten mönchischen Schriftsteller auf dem Gebiete der Medizin, Anatomie und Physiologie ist der Bischof Isidor v. Sevilla (6.-7. Jahrh.) zu erwähnen, der im I. Kapitel des II. Buches seiner 20 Bücher starken Enzyklopädie auch über anatomische und physiologische Fragen, wenn auch in ganz oberflächlicher Weise, sich ausspricht. - Ebenso oberflächlich sind die aus Aristoteles entlehnten Bemerkungen über Anatomie und Physiologie in dem Werke „Elementa philosophiae" des englischen Kirchenhistorikers Beda Venerabilis (674-735 n. Chr.). - Von demselben Standpunkt zu betrachten sind die 22 Bücher „Physica“ des gelehrten Hrabanus Maurus (780-856 n. Chr.), von denen das 6 . und 7 . Buch vom Menschen handelt.

Ein Gewinn für die Anatomie ist aus diesen compilatorischen Werken des frühen Mittelalters nicht zu verzeichnen. Ein wirklicher gedeihlicher Fortschritt stand erst dann zu erwarten, als in Salerno (in der Nähe des Benediktinerklosters Monte Cassino) eine Hochschule entstanden war, auf welcher dann in der Folge die Medizin die gedeihlichste Pflege gefunden hat, namentlich, nachdem sich Ärzte aus dem Laienstande in beträchtlicher Anzahl dort angesiedelt, ein Kollegium gebildet und später unabhängig von jeder priesterlichen Gemeinschaft den Grund zur ersten medizinischen Schule des Abendlandes gelegt hatten.**)

In die erste Periode der Salernitanischen Hochschule, die von den Resten der griechischen Medizin beeinflußt ist, fallen verschiedene nennenswerte Werke anatomischen und physiologischen Inhalts, in erster Linie diejenigen des Alphanus I (Mitte des II. Jahrh.), nämlich die Schrift ,de quatuor elementis

J. Pagel, im Handb. d. Gesch. d. Med., Bd. I, S. 625.

**) J. Pagel a. a. O., S. 638.

Hopf, Anatomie. 
corporis humani", die zweite ,de unione corporis et animae" und eine dritte kurze ,de quatuor humoribus, ex quibus constat corpus humanum"“*)

In der zweiten Periode Salernos (vom 12. Jahrh. an) steht in erster Reihe der berühmte Constantinus Africanus ( $\dagger$ I087), der als Kenner der orientalischen Sprachen die arabischen Schriftsteller und so indirekt die Werke der griechischen Ärzte in Salerno einführte. Unter seinen Schriften wird auch eine Anatomie in 2 Büchern mit je I7 und 37 Kapiteln angeführt, doch sind nach Pagel berechtigte Zweifel vorhanden, ob Constantinus wirklich der Verfasser ist. Dagegen steht unımstößlich fest, daß der ebenfalls der zweiten Periode angehörende Copho junior (1085-I100) die berühmte Anatome porci geschrieben hat, die merkwürdigerweise noch bis zum I6. Jahrhundert dem Galen als eines seiner „libri spurii“" zugeschrieben wurde. - Schließlich ist auch das bekannte salernitanische Lehrgedicht ,regimen sanitatis" (Ende des I I. oder Anfang des I2. Jahrh.) zu erwähnen, weil es in 4 Kapiteln des 3. Teils (v. 1612-1649) die Anatomie behandelt. - Von da bis zum Niedergange des von anderen Hochschulen überflügelten Salerno ist nichts Rühmenswertes mehr über die salernitanische Anatomie zu berichten, wenn man überhaupt von einer Bedeutung dieser Anatomie reden will. Wohl war letztere aus praktisch-chirurgischen Gründen ein wertgeschätzter Lehrgegenstand und die vorgeschriebene Demonstratio anatomica Veranlassung zu häufigen Zergliederungen, aber diese bezogen sich nicht auf menschliche Leichname, sondern auf Schweine, so daß diese Anatomia porci der Salernitaner mit vollem Rechte hinter die Galensche Anatomie zurückzustellen ist.**)

Aber während sie so an wissenschaftlicher Bedeutung zurückstand, kann ihr doch nicht das Zeugnis versagt werden, daß sie der griechischen Anatomie wenigstens in freier Entfaltung ebenbürtig war. Und dies will für die damalige Zeit viel heißen. Denn während in dem glücklichen Salerno die Wissenschaft eine Freistätte gefunden hatte und diesen Charakter bis in das I3. Jahrhundert hinein bewahrte, hatte die Scholastik, entstanden aus klerikaler Unduldsamkeit und genährt durch die spitzfindige Dialektik des arabisierten Aristotelismus, im übrigen Europa ihren 
lähmenden Einfluß auf die gesamte Wissenschaft ausgeübt. J. Pagel*) schildert in treffenden Worten, wie an die Stelle unbefangener klarer Sinnesarbeit und echter frischer Naturbeobachtung die drückende Tyrannei übersinnlicher, aprioristischer Spekulation, nach deduktivem Schema konstruierter Lehrsätze und starrer Dogmen getreten sei, für welche als Eideshelfer einzutreten sich der von den Arabern umgedeutete Aristoteles gefallen lassen mußte. Er auf philosophischem und Galen auf speziell medizinischem Gebiet galten in ihren, von den Arabern überkommenen Übersetzungen, die nun ihrerseits wieder in das Lateinische übertragen wurden, als die Autoritäten für die alles beherrschenden dialektischen Künste der Scholastik.**)

Um die der scholastischen Periode angehörenden Naturforscher aufzuführen, welche in den Bereich ihrer umfassenden Enzyklopädieen auch die Lehre vom Bau des Menschen hereinzogen, so ist an erste Stelle der berühmte Dominikaner Albert Magnus (II93-1280) zu stellen, in dessen naturwissenschaftlichen Werken übrigens die Anatomie des Menschen recht kurz wegkommt. - Der Engländer Bartholomaeus (gen. Anglicus) hat ,,de genuinis rerum coelestium, terrestrium et internarum proprietatibus et de variarum rerum accidentibus" zusammen I9 Bücher geschrieben (I258-I260), von denen das 5. Buch über Anatomie ganz in der oberflächlichen Weise des Isidor v. Sevilla gehalten ist. - Weiter schrieb der Niederländer Thomas Cantimpratensis ein compilatorisches Werk "de naturis rerum", ein dickes Buch, das später von dem Kanonikus Konrad v. Megenberg (I307-I374) in kleinerem Auszug und in deutscher Sprache umgearbeitet und so zur ersten, vielgelesenen deutschen Naturgeschichte geworden ist. Von dem anthropologischen Teile dieses Buches wird unten eingehend die Rede sein.

Endlich ist noch die umfangreiche Enzyklopädie des Franzosen Vincentius Bellovacensis ( $\dagger \mathrm{I} 264)$ zu erwähnen, die unter dem Namen "Speculum naturale" im Jahre 1250 fertig gestellt wurde. Vom 29. Buche "de formatione corporis humani" muß rühmend erwähnt werden, daß sich die darin enthaltene Anatomie neben allem gelehrten Zitieren griechischer, römischer und arabischer Autoren doch auch durch selbständige, vernünftige Urteile

-) J. Pagel a. a. O., S. 658.

"*) J. Pagel a. a. O., S. 666. 
auszeichnet.*) - Zwei weitere naturwissenschaftlich-theologische Schriftsteller dieser Periode, der englische Geistliche Alexander Neckam in seiner Schrift ,de rerum naturis“ und dessen Freund Alfred de Seresbel sind weniger bedeutend.

Um einen Begriff zu geben, in welcher Weise damals die Anatomie populär-wissenschaftlich, auf den Angaben griechischer, römischer und arabischer Autoren fußend, gelehrt wurde, will ich in Folgendem einen Auszug aus dem anthropologischen Teil von Konrads v. Megenberg „Buch der Natur" mitteilen.

Von dem Schädel sagt er***) : „Diu hirnschal hat dreu kämmerlein, daz ain ist vorn in dem haupt und in dem ist der sêl Kraft, die dâ haizt fantastica, — daz ander kämmerlein ist ze mittelst in dem haupt und in dem ist der sêl kraft, die dâ haizt intellectualis, - daz dritt kämmerlein ist ze hinderst in dem haupt und in dem ist der sêl kraft, die dâ haizt memorialis, daz ist gedächtniss." Von den Extremitätenknochen heißt es: "Galienus spricht, daz daz pain der êrsten glider ainz sei, diu geleichu stuck sint." „, die herten pain sint inwendig hol, weiz und gar werhaft. "***) Das Mark, ,ist ain überflüssichait dez pluots und ist in den painen, diu hol sint nach Galieni lêre." ,jedoch pringt daz mark den painen diu hilf, daz ez si fäuchtet und waicht oder zaech macht, dar umb, daz si niht zerbrechent."

Von den Muskeln ,sprechent etleich maister, daz sechs mäuslein in den menschen sein, zwai in den henden, zwai in den armen und zwai in den painen. den sechsen gesellent etleich noch vier stuck, die haizent si auch mäuslein; die vier stuck sint daz herz, daz hirn und diu zwai gezeuglein an den mannen und diu letzten dreu setzt Galienus, aber daz hirn haizt er nicht auch ain mäuslein. Nu sprechent diu andern maister, daz ez nicht zimleich sei, daz man diu edeln stuck dez leibs mäuslein haiz, wan ain mäuslein, alz wir ez hie nennen, ist ain geschirr der willicleichen wegung an den glidern und ist gesamnet auz flaisch und auz âdern und auz nàtürleichen panden und spricht Rasis, daz ir fünfhundert und achtundzwanzig sein nâch der lêr Galieni. $\mathrm{Nu}$ schreibt unser buoch neur von diu grôzen mäuslein. †) -

*) J. Pagel a. a. O., S. 666.

"*) Konr. v. Megenberg, ,Buch der Natur", herausgeg. v. F. Pfeiffer, Stuttgart K. Aue $186 \mathrm{I}, \mathrm{S}, 4 \mathrm{f}$.

***) K. v. Megenberg, S 23, 26.

†) K. v. Mígenberg a. d. O., S. 20. 
K. v. Megenberg sieht sich nach dieser Auseinandersetzung duch noch veranlaßt, von dem Fleisch besonders zu reden: „daz flaisch ist krank, waich und zart und wirt leicht zerbrochen." „dez flaisches vaizten ist pei dem nabel und pei den lenden." "Galienus spricht, daz daz flaisch dâr zuo nutz sei, daz ez diu Klunsen zwischen den painen und den âdern derfülle und daz ez diu gelider zesammen hab. Daz flaisch dâz hat mangerlai gestalt in mangerlai gelidern, wan daz flaisch in den lungen ist von rôter rôsenfarb und ist satrôt in dem herzen, in der leber ist ez purpurvar, in der milz ist ez swarz oder swarzlot.*)

Nun folgen die ,Bandadern": ,in den pantâdern ist niht pluotes sam in den runstâdern. die pantâdern sint von nâtur lang und niht dick. - si sint auch dâr zuo nütz, daz si di ziuleichen und die wegenden kräft tragent von dem hirn in allin andern glider und daz si den ganzen leib sterkent." "die rehten pantâdern, die Galienus ligamenta haizt, entspringent in den painen und dâr umb so empfindent si als wênich als diu pain, die si zesamen pindent." Also der alte Mangel an Unterscheidung von Bändern, Sehnen und Nerven.

Von den Adern heißt es: „hie ist ain krieg zwischen den ârzten und den maistern von der nâtur." "so schal man wizzen, daz dreierlai âdern sint in dem menschen. Die êrsten sint runstâdern, dâ daz pluot inne rint und fleuzt von dem herzen oder von der lebern in allin andrin glider, und daz sint roern neur von ainem rock und haizent ze latein vene. Diu andern âdern sint gaistâdern und haizent ze latein arterie, daz ist als vil gesprochen sam eng weg und in den oliezent diu nâtürleichen gaist und die lebleichen gaist, und sint von zwain röcken und sint auch klainer als die runstâdern. - Die dritten âdern sint pantâdern und haizent ze latein nervi; mit den pint diu nâtur diu herten pain in den glidern zesamen.**)

Das Hirn. "Galienus spricht, daz sich daz hirn tail in zwai stuck, daz ain stuck ist gegen der rechten seiten, daz ander stuck gegen der lenken und sprechent die maister von der nâtur, daz diu zwai stuck underscheiden sein mit ainem wändlein." „daz hirn hat minner pluotes wan kainerlei ander vänten, die in denn menschen sint, wan man sicht kain pluot in im." „und dâr umb

") K. v. Megenberg, S. 23.

**) K. v. Megenberg, S. 35 . 
daz ez niht pluotes hât, ist kain âder in im klain noch grôz, die ain pluottraegerin sei“" - „dez menschen hirn hât in im vil klainen painlein, als Plinius spricht." — ,und ist umbvangen mit zwain häutlein, dez ainz ist ze nächst pei der hirnschal und daz izt daz sterker und daz empfint versêrung; daz ander niht, dâr umb, daz daz sterker etleich âdern hât, die pluottragerinne sint, daz ist an der stat, dâ sich der hals veraint mit dem haupt.*)

Ich übergehe als zu weitläufig, was über die augen, die augenprâwen, die ôren, die nase, den mund, die zende, die zunge, die aichel (uvula) und den überval (epiglottis) gesagt wird und gehe über zu dem Hals. ,der hals ist auz kruspelichem flaisch gemact allermaist inwendig." - „der hals hât vil âdern, durch die vliezent die gaist und daz pluot von dem herzen und von der lebern in daz haupt und in die sideln aller sinnen und aller kreften der sêl.**) - Die Schlundröhre ,ligt hinten gegen dem halz. die roern haizt Aristoteles dez magen munt, dar umb, daz si rüert unz an dez zungenursprunch." - Die Luftröhre ,,ist ain grôzin âder." Der Kehlkopf, einfach „kel“ genannt, ,ist neur in dem menschen, in den sweinen und in den vogeln und in den tiern, die den geleich sint. diu kel hât oben ain pain ze mittelst durchhölert an der stat, dâ daz haupt veraint ist mit dem hals. diu kel ist voller kruspeln und knoden und hât geleich staffeln."

Die Brust, ist ain praitz pain voller roerlein in im selber ze mittelst in der prust, dem sint die ripp und die âdern zuo gesellt, und under demselben pain entspringent die vodersten âdern, dâ daz pluot inne lauft und die ze latein vene haizent. die selben âdern estent sich überal zuo den andern glidern, reht als die est an ainem weinreben." - Von den Achseln heißt es: „der mensch hât groezer achseln dann kain ander tier nach seiner groezen; die achseln sint gemacht von starken painen." - Daran schließen sich die Arme ,,auz starken painen und daz voder tail dez arms, daz veraint ist mit der hant, ist auz zwain painen, der ainz groezer ist wan daz ander, abu daz hinder tail, daz veraint ist mit der achseln, daz hat neur ain starkez kreftigez pain. In den armen sint vil âdern und roerlein." "die hend an dem menschen sint an der vorderen füeze stat gemach, also Aristoteles spricht."

") K. v. Megenberg, S. 6.

*) K. v. Megenberg, S. $17 \mathrm{f}$. 
Über den Rücken weiß er folgendes zu berichten: „der ruck hât sainen anvanch an dem hals und strecket sain leng auz an dic mistporten und der durn, der den rucken zesamen helt, ist auz vilen painen, diu sint alliu ze mitelst durchlöchert und denselben painen sint diu ripp ze paiden seiten zuogesellt." „und gêt ain langez mark durch diu pain oben in dem ruck von dem hals unz an daz end geleich ainem strick." ${ }^{(*)}$

Von den Brustorganen ist die Lunge, ,lind sam ain padeswamp, daz si den luft gevahen mag." Das Herz aber ,, ist auz hertem dickem flaisch." "daz herz hât zwai kämmerlein, daz ain gegen der rehten seiten und daz ander gegen der denken, und darinne ist edelz pluot und die edeln gaist, daran daz leben ligt." „daz herz ist gesezt in ain pälglein, daz ist wol als dicke sam aines menschen hant und daz haizt des herzens huot oder sein kasel und hât diu nâtur daz herz dâ mit verhüllet durch ain sicherhait, daz ez niht leicht icleichen leid.**)

Nun folgt der Bauch. „Plinius nimpt den pauch für den magen und für die andern seck, die under dem magen sint, darein daz ezzen gêt ie von aim in den andern. aber aigenleich ze nemen sô haizt der pauch die ganz samnung auz den secken allen mit der haut bedeckt, die oben herab gêt über den nâbel.“ - „Aristoteles spricht, daz die menschen geleich seien den hunden an dem oberen pauch und den sweinen an dem underen pauch. “****) Der Magen ,ist der êrst haven, dar inn daz ezzen gekocht wirt in dem menschen". „der mag hât inwendig vil häutelvasen reht sam klainen plättlein an ainem püechlein." „ain gedärm ân ander grôz gedärm gêt von dem magen ze tal, daz haizt daz vastend gedärm, darumb daz ez allezeit wan ist von den gerben dez ezzens." ,in dem vastenden gedärm sint fünf âdern gestecket, die haizent die pärmleichen âdern, dar umb daz si mit allen andern âdern mitleident. (Sympathikus.) dieselben âdern streichent sich unz an die lebern." $\dagger$ )

Die Leber ,ist sinbel reht als ains ochsen leber ist.“ „Clemens der maister spricht, daz diu leber dar umb in der rehten seiten lig, daz si hitz geb dem magen, auch dar umb, daz diu leber pluot gesenden mög allen andern glidern." - Von der Bauchspeichel-

") K. v. Megenberg, S. 24.

*") K. v. Megenberg a. a. O., S. 271.

***) K. v. Megenberg, S. 3 I.

) K. v Megenberg, S. 32 . 
drüse keine Spur. - Über die Milz äußert sich Meister Konrad kurz: „Aristoteles spricht, daz der mensch hab ain milz sam ain swein, lang und smal." - Bezüglich der Gallenblase und ihres Verhältnisses zur Leber herrscht vollständige Unklarheit. „Aristoteles spricht, daz etleich leut ir gallen haben gesetzt von der lebern und die sint sünftiger von nâtur wan die ir gallen habent pei der lebern." Dann heißt es: „Plinius spricht, daz etleich leut nit gallen haben (jedoch vinde man îr wênich) und daz si lang leben und lange stark sein."*)

Der Nieren ,,ietweder hât zwên häls oder zwuo âdern. der häls ainen streckt der nier auf in der seiten, dâ er inne ligt, unz an die grôzen âdern, diu da ist an dem auswendigen tail der lebern, und den andern hals streckt er ze tal unz an die plâsen." „Aristoteles spricht, daz des menschen niern geleich sein den niern ains rindes. " $\left.{ }^{* * *}\right)$

Die Blase ,ist gesament auz zwain röcken oder auz zwain häuten. der prunn ileuzt von den niern durch zwên häls oder durch zwuo âdern."****)

In solchen Anschauungen bewegten sich nicht nur Konrad v. Megenberg und sein Vorgänger Th. Cantimpratensis, sondern auch die anderen nichtgeistlichen Naturhistoriker auf dem Gebiete der Anatomie resp. somatischen Anthropologie. Sie wissen nichts Sicheres, weil sie Nichts selber gesehen und untersucht haben. Sie sind zufrieden, wenn sie sich auf einen anderen geistlichen Herrn berufen können, noch zufriedener aber, wenn Plinius oder gar Aristoteles ihren Rücken deckt. Irgend ein Fortschritt in der Anatomie war von diesen gelehrten Zusammenschreibern nicht zu erwarten.

Glücklicherweise erwuchsen der Scholastik gerade in den Universitäten, die von ihr begünstigt als Rivalinnen der freien Hochschule von Salerno entstanden waren, später ihre mächtigsten Feinde. Ganz allmählich entwickelte sich eine gewisse Neigung $z u$ eigener Beobachtung und selbständiger Prüfung der Überlieferungen, allerdings in Fragen der Medizin früher, als auf dem Gebiete der Anatomie, wo Galen und sein Herold Avicenna nur zu lange

*) K. v. Negenberg a. a. O., S. 28.

*) K. v. Megenberg, S. 35 .

*.*) K. v. Mlegenberg, S. 34 . 
das Feld behaupteten. Namentlich war letzteres auf den italienischen Universitäten der Fall, und die berümtesten derselben, Bo$\operatorname{logna}$ und $\mathrm{Padua}$, hatten den Ruf, nicht bloß die besuchtesten Rechtsschulen, sondern auch diejenigen medizinischen Hochschulen zu besitzen, auf welchen spitzfindige Dialektik ihre größten Triumphe feierte.

In gewissen Gegensatz dazu stellte sich die ebenfalls der scholastischen Periode angehörende Universität Montpellier, indem sich dieselbe*), anfangs wenigstens, in einer gewissen Unabhängigkeit von klerikalem Einfluß zu halten verstand und rein praktischen, auf die Beobachtung von Tatsachen gerichteten Bestrebungen Geltung verschaffte. Wie in Salerno wurde auch in Montpellier, hauptsächlich mit Rücksicht auf die Chirurgie, der Anatomie große Bedeutung zugemessen. Man hat Grund anzunehmen, daß die von Daremberg entdeckte "Anatomia Richardi" nicht der Hochschule von Salerno, sondern derjenigen Periode der Scholastik angehört, in welcher der Chirurg Henri de Mondeville († I 320), allerdings ganz im Sinne Avicennas, in Montpellier Schädelanatomie an einem knöchernen Modell und die Anatomie des übrigen Körpers an 13 Figurentafeln demonstrierte.

Von Bernh. v. Gordon, Gerardus de Solo, Johannes Jacobus, Valascus de Taranta etc., die ebenfalls der Schule von Montpellier angehören, wird keine besondere Förderung der Anatomie berichtet, dagegen weiß man von dem hoch über seinen Zeitgenossen stehenden Arnoldus de Villanova († I3I2), dem feurigen, schon zu der Prärenaissance zu zählenden Gegner der Scholastik, daß er die Anatomie sehr hoch geschätzt hat.

Freilich mußte auch seine Anatomie, wenn praktisch an der Leiche ausgeübt, immer noch eine Anatomia porci bleiben, weil das Sezieren menschlicher Leichname strenge verboten war. Um so höher ist das Verdienst des Bologneser Arztes Mondino de Liucci (1275-1326) anzuschlagen, der es zum erstenmal wieder seit der Zeit der Alexandriner gewagt hat, menschliche Leichname zu zergliedern und an diesen die Anatomie zu demonstrieren. Außerdem hat er für Studierende ein Kompendium der Anatomie geschrieben, worin er den Schüler in der Weise in die Wissenschaft einführen wollte, daß er ihn im Geiste an dem

") J. Pagel a. a. O., S. 687. 
schrittweisen Vorgehen im Präparieren teilnchmen ließ. Zwei Jahrhunderte lang hat dieses Buch in hohem Ansehen bei Chirurgen und Anatomen gestanden.

Aber bei aller Anerkennung seiner Verdienste kann doch nicht geleugnet werden, daß es, wie Pagel sich ausdrückt*), die alte Autoritäts-Anatomie war, die er lehrte, und daß sich die eigenen Beobachtungen und Verbesserungen auf einige unwesentliche Einzelheiten beschränkten. So war das Lebenswerk des Mondino nur ein schwacher Trieb, den die Anatomie ansetzte, der zudem dadurch bald wieder in seinem Wachstum bedroht war, daß der Papst Bonifacius VIII. durch eine Bulle die Anatomie am menschlichen Körper untersagte.

Wie es so häufig der Fall ist, behielt auch dieses Verbot nur eine Zeitlang seine Wirkung, um dann später erst recht übertreten zu werden. So berichtet die Geschichte, daß schon die beiden Nachfolger des Mondino, Nicol. Bertucci ( $\dagger$ I347) und Pietro di Argelata, wieder regelmäßig und systematisch Sektionen menschlicher Leichname vornahmen und im Jahre $\mathrm{I}_{404}$ in Wien die erste anatomische Zergliederung durch die Hand des Paduaner Magisters Galeatus de St. Sophia stattfinden konnte. Ein selbständiger, energischer Anatom des I 5. Jahrhunderts war ferner Jac. Sylvius; auch Alexander de Benedetti (1495), Matheus de Gradibus († I480), Magnus Hundt, Guentherus Andernacensis, Gabriel de Zerbis (1505) und Alexander Achillinus († I5I2) hatten als Anatomen gute Namen. Das Verlangen nach selbstständigen Forschungen am menschlichen Körper muß in dieser Zeit ein ganz gewaltiges gewesen sein, sonst hätte es nicht in das Verbrechen der Sektion Lebender ausarten können. J. Hyrtl**) wenigstens erzählt, im Jahre 1474 haben sich die Pariser Wundärzte von Ludwig XI. die Erlaubnis erbeten, gefangene Feinde lebend zu sezieren, um damit die beste Methode des Steinschnitts ausfindig zu machen, und von Jakob Berengar berichtet Falloptus, er habe zwei Syphilitiker lebend seziert und ihre Anatomie veröffentlicht. Und dies alles, um die Richtigkeit der Anatomie des Galen $\mathrm{zu}$ beweisen, eine Anatomie, die doch nur auf die Sektion von Hunden und Affen gegründet war!

*) J. Pagel a. a. O., S. 703.

**) Antiquitates anat. rariores, S. 231. 
Diese Wahrheit und damit die tausendjährigen Irrtümer der vorangegangenen Anatomen durch eigene sorgfältige Menschenzergliederungen nachgewiesen $\mathrm{zu}$ haben, ist die große, unsterbliche Ruhmestat des Anatomen Vesal (geb. 1514). Er ist es, der die Anatomie gelehrt hat, ihre Kinderschuhe auszuziehen. Hinter ihm schließt die Geschichte der tastenden Anfänge, der Irrtümer und Spekulationen. Mit ihm und seinem schönen Werke „, de corporis humani fabrica libr. septem (Basil. I 543)" beginnt eine neue Epoche, die Epoche der Nüchternheit, der Wahrheit und der eigentlichen wissenschaftlichen Anatomie. 



\section{Literatur-Verzeichnis.}

C. K. Barth, Über die Druiden der Kelten und die Priester der alten Deutschen. Erlangen J. J. Palm I 826.

I wan Bloch, Indische Medizin. Im Handb. d. Gesch. d. Medizin, begründet von Dr. Puschmann, Jena, Gustav Fischer, 1901, Bd. I, Liefg. I.

- Byzantinische Medizin. Im Handb. d. Gesch. d. Medizin, I901, Bd. I, Liefg. 3.

- Altrömische Medizin. Im Handb. d. Gesch. d. Medizin, Bd. I, Liefg. 3.

- Celsus. Im Handb. d. Gesch. d. Medizin, Bd. I, Liefg. 3.

- Griechische Ärzte des 3. und 4. Jahrlı. n. Chr. Im Handb. d. Gesch. d. Medizin, Bd. I, Liefg. 3 .

A. Boissier, Note sur un Monument Babylonien se rapportant à l'extipicine, Genève, Impression de la Société anonyme des Arts Graphiques, I899.

M. T. Cicero, De divinatione libri duo. Ed. Klotz, Lips. 1869.

- De natura Deorum. Ex recens. Ernesti. Lips. 1818.

G. Ebers, Die Körperteile, ihre Bedeutung und Namen im Altägyptischen. Abhandlung d. k. bayr. Akad. d. Wissensch., philosophisch-histor. Klasse, Bd. XXI, München 1901.

K. Eckermann, Lehrbuch der Religionsgeschichte und Mythologie der Völker des Altertums. Halle 1845 .

Sext. Pomp. Festi, De verborum significatione, quae supersunt. Emend. a Carolo Odofr. Müllero, Lips. 1839.

J. Jac. Frey, Disquisitio de more gentium, diis simulacra membrorum consecrandi, Alttorf 1786.

Rob. Fuchs, Geschichte der Heilkunde bei den Griechen. Im Handb. d. Gesch. d. Medizin, Jena, Gustav Fischer 1901, Bd. I, Liefg. 1-3.

Jac. Grimm, Deutsche Mythologie, 2. Ausgabe, Göttingen 1844 .

K. F. Herma nn, Lehrbuch der griechischen Antiquitäten, Heidelberg, J. C. B. Mohr, I 84 I.

Hesychii Alexandrini Lexicon, recens. Maurit. Schmid, Jenae 1860.

Dr. M. Höfler, Altgermanische Heilkunde. Im Handb. d. Gesch. d. Medizin, Bd. I, Liefg. 3 .

- Deutsches Krankheitsnamenbuch, München, Piloty u. Loehle, 1899.

- Zur Opferanatomie. Korrespondenzblatt für Anthropologie, Ethnologie und Urgeschichte, 1896.

J. Hyrtl, Antiquitates anatomicae rariores, Vindobon. I835.

Dr. Uilr. Jahn, Die deutschen Opfergebräuche b. Ackerbau u. Vielızuclıt. Breslau, W. Koebner, I 884 .

Dr. L. Kazenelson, Die normale und pathologische Anatomie des Talmud. In lioberts pharmakol.-histor. Studien, Bd. V, Leipzig I 896.

Konrad v. Megenberg. Das Buch der Natur. Herausgeg. von Franz Pfeiffer, Stuttgart, K. Aue, 186r. 
L. Lange, Römische Altertumer, Berlin, Weidmann i 876-79.

H. Marquardt, Römische Staatsverfassung; Leipzig, S. Hirzel I88 I-I885.

Dr. v. Oefele, Freiherr. Vorhippokratische Medizin Westasiens, Ägyptens und der mediterran. Vorarier. Hanub. d. Gesch. d. Medizin, Bd. I, Liefg. I, Igor.

- Keilschriftmedizin in Paralielen. Mit I Tafel. Leipzig, J. C. Hinrichs, I902.

- Keilschriftmedizin. Mit 3 Tafeln. Abhandlungen zur Geschichte der Medizin, Heft III. Breslau, J. U. Kern, 1902.

J. Pagel, Geschichte der Medizin im Mittelalter. Handb. d. Gesch. d. Medizin, Bd. I, Liefg. 4.

Dr. Pauli, Über die Benennung der Körperteile bei den Indogermanen. Progr. Stettin I867.

J. Preuß, Die Medizin der Juden. Handb. d. Gesch. d. Medizin, Bd. I, Liefg. I.

B. Scheube, Die Geschichte der Medizin bei den ostasiatischen Völkern. Handb. d. Gesch. d. Medizin, I9or, Bd. I, Liefg. I.

G. F. Schömann, Griechische Altertümer. Neu bearbeitet von J. H. Lipsius, Berlin, Weidmann, I897.

Ebh. Schrader, Keilinschriftl. Bibliothek, Berlin, Reuther, Bd. I-III, I889-I90 I

Schrutz, Die Medizin der Araber. Handb. d. Gesch. d. Medizin, Bd. I, Liefg. 4.

Dr. Jul. Schwab, Das altindische Tieropfer. Erlangen, A. Deichert, 1886.

Dr. L. Stieda, Anatomisch-archäologische Studien. Sonderabdruck aus BonnetMerkels anat. Heften, Bd. I5-16. Wiesbaden, J. F. Bergmann, Igo1.

v. Töply, Rob., Ritter ron. Geschichte der Anatonie. Handbuch d. Gesch. der Medizin, Bd. II, Liefg. 6.

M. Ter. Varronis de lingua latina libri, ed. And. Spengel, Berlin, Weidmann, 1885 .

J. G. WVilkinson, Manners and Customs of the ancient Egyptians. London, John Murray, $1837 \mathrm{ff}$.

Dr. H. Winkler, Himmels- und Weltbild der Babylonier. Mit 3 Abbildungen. Leipzig, J. C. Hinriclıs, 1901. 


Abhandlungen zur Geschichte der Medicin.

Herausgegeben von

Professor Dr. Hugo Magnus, Docent Dr. Max Neuburger und Sanitätsrat Dr. Karl Sudhoff.

\section{Eeft VIII.}

\section{Medieinisehes}

der altfranzösischen Dichtung.

Von

Oscar Kühn,

Dr. phil.

Breslau 1904

J. U. Kern's Verlag

(Max Müller). 


